IZA DP No. 4417

The Effect of the Timing and Spacing of Births on the Level of Labor Market Involvement of Married Women

Kenneth R. Troske

Alexandru Voicu

September 2009 


\title{
The Effect of the Timing and Spacing of Births on the Level of Labor Market Involvement of Married Women
}

\author{
Kenneth R. Troske \\ University of Kentucky \\ and IZA
}

\author{
Alexandru Voicu \\ City University of New York \\ and IZA
}

\section{Discussion Paper No. 4417 \\ September 2009}

\author{
IZA \\ P.O. Box 7240 \\ 53072 Bonn \\ Germany \\ Phone: +49-228-3894-0 \\ Fax: +49-228-3894-180 \\ E-mail: iza@iza.org
}

Any opinions expressed here are those of the author(s) and not those of IZA. Research published in this series may include views on policy, but the institute itself takes no institutional policy positions.

The Institute for the Study of Labor (IZA) in Bonn is a local and virtual international research center and a place of communication between science, politics and business. IZA is an independent nonprofit organization supported by Deutsche Post Foundation. The center is associated with the University of Bonn and offers a stimulating research environment through its international network, workshops and conferences, data service, project support, research visits and doctoral program. IZA engages in (i) original and internationally competitive research in all fields of labor economics, (ii) development of policy concepts, and (iii) dissemination of research results and concepts to the interested public.

IZA Discussion Papers often represent preliminary work and are circulated to encourage discussion. Citation of such a paper should account for its provisional character. A revised version may be available directly from the author. 
IZA Discussion Paper No. 4417

September 2009

\section{ABSTRACT}

\section{The Effect of the Timing and Spacing of Births on the Level of Labor Market Involvement of Married Women}

We use panel data from NLSY79 to analyze the effects of the timing and spacing of births on the labor supply of married women in a framework that accounts for the endogeneity of labor market and fertility decisions, the heterogeneity of the effects of children and their correlation with the fertility decisions, and the correlation of sequential labor market decisions. Our results show that timing and spacing of births are important determinants of the effect of children on women's labor supply. Delaying the first birth leads to higher levels of labor market involvement before the birth of the first child and reduces the negative effect of the first child on the level of labor market involvement. Having the second birth after a longer interval reduces the effect of the second child on participation but increases its effect on the probability of working full time, as more women, having returned to work, respond to the second birth by moving from full time to part time jobs. Individual heterogeneity plays an important role in the relationship between labor market and fertility decisions. Women who have fewer children have the first birth later in life and space subsequent births more closely together, work more before the birth of the first child, but face larger effects of children on their labor supply.

JEL Classification: C11, C15, J13, J22

Keywords: timing and spacing of births, female labor supply, endogenous fertility decisions, heterogeneous children effects, multinomial probit model, Gibbs sampler

Corresponding author:

Alexandru Voicu

College of Staten Island

The City University of New York

2800 Victory Boulevard

Staten Island, NY 10314

USA

E-mail: voicu@mail.csi.cuny.edu 


\section{Introduction}

The effect of children on women's labor supply - the underpinning element of the relationship between labor market and fertility decisions - has been a long-standing focus of economics research seeking to explain the increase in the labor force participation of women over the past few decades and the simultaneous decline in fertility rates in most OECD countries. It has also been the cornerstone of public policy regarding parental leave and benefits, ${ }^{1}$ whose efficient design depends on the accurate description of the magnitude and the determinants of the effect of children on women's level of labor market involvement. Estimating this effect, however, has proven challenging for several reasons. ${ }^{2}$ First, labor market and fertility decisions are endogenous as the number of children and the timing and spacing of births are controlled, at least in part, by women. ${ }^{3}$ Second, sequential labor market decisions are correlated and, therefore, maternity-related work interruptions or reductions in the level of labor market involvement affect labor supply in subsequent periods. Third, the effects of children on labor supply are heterogeneous and are correlated with the fertility decisions. Heterogeneous preferences for market work and for children influence pre-market and early career investments in human capital, which, in turn, affect the opportunity cost of children. Together, heterogeneous preferences and correlated, heterogeneous opportunity costs of children jointly determine women's fertility and labor market decisions. As recent literature on treatment effects $^{4}$ indicates, if the effects of children are heterogeneous and if individuals act on the basis of those differences, the average effect underestimates the effect of additional children for those who choose not to have them and overestimates it for those who had the children.

One of the key aspects of the relationship between labor market and fertility decisions is the timing and the spacing of births. On the one hand, with the declining variance of completed fertility in developed countries, timing and spacing of births become just as important as completed fertility in explaining trends in fertility. ${ }^{5}$ Moreover, the increase in labor force participation of women and the increase in fertility control through the improvement of contraceptive methods imply that economic factors are important determinants of timing and spacing decisions. On the other hand, the timing of the first birth and the spacing of subsequent births influence the effects of children on labor supply. Postponing the first birth, allows women to pursue higher levels of pre-market and early-career investments in types of human capital that raise their market productivity, which leads to higher wage offers. Theoretical household models of time allocation (Mincer, 1962, Becker, 1965, Willis, 1973, Michael, 1973, Leibowitz, 1974, Gronau, 1977, Angrist and Evans, 1998) suggest that

\footnotetext{
${ }^{1}$ Economic and social developments have lead to a rise in the private costs of children while increasingly making children a public good. Better job opportunities and higher wages for women raised the opportunity cost of children; the growth of transfer payments like social security or public health systems and taxation of future generations through reliance on public debt have raised the public benefits of children (Folbre, 1994). Moreover, some recent economic and developmental psychology literature have suggested that longer periods of maternal care improve child cognitive and behavioral outcomes (Waldfogel at al., 2002, Broogs-Gunn et al., 2002, Ruhm, 2004). The existence of positive externalities from raising children and from longer periods of maternal care as well as from mothers' investments in their own education and training creates the scope for public policies, such as parental leave benefits and subsidies for families with children, which are aimed at reducing the opportunity cost of children.

${ }^{2}$ Browning (1992) and Nakamura and Nakamura (1992) provide reviews of the history of this literature.

${ }^{3}$ Browning (1992), Rosenzweig and Wolpin (1980), Angrist and Evans (1998), Carrasco (2001);

${ }^{4}$ Heckman and Robb (1985), Bjorklund and Moffitt (1987), Imbens and Angrist (1994), Heckman and Vytlacil (1999, 2000, 2001), Carneiro, Heckman, and Vytlacil (2001), Moffitt (2005).

${ }^{5}$ Hotz et al. (1997) show that the postwar baby boom in the US was generated in great part by women shifting their childbearing to earlier ages, and the subsequent decline in fertility was largely the result of the women postponing childbearing. Gustafsson (2001) documents the role of delaying childbearing in declining fertility rates in European countries.
} 
higher wage offers are associated with higher levels of labor market involvement before the birth of the first child and with a smaller negative effect of the first child on the mothers' level of labor market involvement. The spacing of subsequent births influences the effects of children on women's labor supply through two channels. Having the second birth at a longer interval after the first birth implies that the first child is older at the time of the second birth. Market inputs become relatively more productive than own time in the production of child care for the first child, and women spend gradually more time in market work. As they return to work, they accumulate experience, their wages rise, and higher wages reduce the effect of subsequent children. However, as women spend more time working in the market, they will finance the increase in time spent in child care for the second child to a larger degree through a reduction in market time, which increases the effect of the second child on labor supply.

The issue of the timing of the first birth and the spacing of subsequent births has received a great deal of attention in economic studies of fertility (Newman, 1983, Montgomery and Trusell, 1986, Hotz et al., 1997, and Gustafsson, 2001 provide reviews of this literature). Many theoretical studies propose dynamic fertility models that identify potential determinants of timing decisions (e.g. Happel et al., 1984, Moffit, 1984, Heckman and Willis, 1975, Wolpin, 1984, Newman, 1988, Hotz and Miller, 1988, Cigno and Ermisch 1989, Walker, 1995) and a large empirical literature provides estimates of the effects of economic factors on timing and spacing of births (e.g. Heckman and Walker, 1990, Merrigan and St. Pierre, 1998, Tasiran, 1995, Gustafsson and Wetzels, 1997, 2000). Much less attention has been devoted, however, to the effect of timing and spacing of births on women's labor market outcomes, even though the effect of children on women's careers is the most important component of the opportunity cost of children, and variation in the opportunity cost of children over the life time is the basis for optimal timing and spacing decisions. Only a small number of studies (Miller and Xiao, 1999, Joshi, 1994) address this issue and none of them takes into account the problems inherent in studying the connection between fertility and labor market decisions.

The goal of this paper is to analyze the way in which timing and spacing of births influence the effect of children on the level of labor market involvement of married women. We use an econometric model that explicitly accounts for the endogeneity of labor market and fertility decisions, for the heterogeneity of the effect of children on labor supply, for the correlation between the effect of children and fertility decisions, and for the correlation of sequential labor market decisions. Sequential labor market decisions, represented by a four-state multi-period multinomial probit, and fertility decisions, represented by a dynamic probit model, are jointly modeled in a mixed-effects simultaneous equation framework. Correlated individual-specific random coefficients included in the labor market and fertility equations capture the variation in labor market and fertility behavior, the heterogeneity of the effects of children on the level of labor market involvement, as well as the correlation between the effects of children on labor supply and fertility behavior. We estimate the model using Markov chain Monte Carlo (MCMC) methods and panel data from 1979 National Longitudinal Survey of Youth (NLSY79). The 25-year (1979-2003) unbalanced panel we constructed ${ }^{6}$ follows women from their entry into the labor force and, for a large share of the sample, captures complete fertility histories. We use simulations based on the estimation results to measure the effects of two children on women's level of labor market involvement and to assess the way in which

\footnotetext{
${ }^{6}$ The panel is considerably longer than those previously used in the literature. For example Hyslop (1999) uses a 7-year panel of continuously married or women, with husbands continuously working, to estimate a two state model of labor force participation, Carrasco (2001) uses a 3-year panel of married or cohabitating women to estimate jointly two-state labor force participation decisions and fertility decisions.
} 
these effects vary with the timing and the spacing of the births.

Our analysis shows that the timing and spacing of births are important determinants of the effect of children on women's labor supply. Delaying the first birth leads to higher levels of labor market involvement before the birth of the first child and reduces the negative effect of the first child on the level of labor market involvement. The effect of the first child declines with the age of the child: both participation and the level of labor market involvement of women who participate increase with the time elapsed from the first birth. The spacing of the second birth reduces the negative effect of the second child on participation, but increases both the negative effect on the probability of working full time and the positive effect on the probability of working part time, as more women, having returned to work, respond to the second birth by moving from full time to part time jobs.

Fertility decisions (the number of children, the timing of the first birth, and the spacing of two births) are correlated with labor market decisions across education and race. White women and women with higher education have fewer children, have the first birth later in life, and have the second birth at a shorter time interval after the first birth; they work more before the birth of the first child and face larger effects of children on their labor supply. Individual heterogeneity also plays an important role in the relationship between labor market and fertility decisions. After controlling for personal characteristics, fertility and labor market decisions vary significantly across individuals, and individual differences are correlated. Women who have fewer children, have the first birth later in life and subsequent births spaced more closely together, work more before the birth of the first child, and face larger effects of children on their labor supply.

The remainder of the paper is structured as follows. In the next section, we discuss the theoretical background of our empirical approach. In section 3 we describe the construction of the panel data set used in the estimation and provide a preliminary, non-parametric analysis of the relationship between the number, the timing, and the spacing of births and labor market decisions. In section 4 we present the econometric model, the estimation procedure, and the design of the simulations. In section 5 we present the results of the empirical analysis. In section 6 we summarize the main results and discuss their implications.

\section{Theoretical Background}

Theoretical household models of time allocation (Mincer, 1962, Becker, 1965, Willis, 1973, Michael, 1973, Leibowitz, 1974, Gronau, 1977, Angrist and Evans, 1998) provide the ideal framework for studying the way in which the timing and spacing of births influence the effects of children on the labor supply of married women. In these models, families maximize inter-temporal utility functions defined over a set of commodities, which include the number and the quality of children (the utilitygenerating characteristic of a given child). The utility-generating commodities are produced at home with combinations of goods and services purchased on the market and the time inputs of household members. Utility is maximized subject to the wealth constraint, which equates life-time income with expenditure on utility-generating commodities evaluated at their respective opportunity costs. The solution to the optimization problem entails the demand functions for the utility-generating commodities and the optimal allocation of household members' time among leisure, market work, and home production. The demand for children is the underpinning element of economic models of fertility. On the supply side, the optimal allocation of time allows predictions about the effects of changes in wage offers, in non-labor income, in productivity of time spent in home production, 
and in the number of children on the supply of time to the market, on leisure, and on time spent in home production.

Theoretical dynamic models of fertility (Hotz et al., 1997, and Gustafsson, 2001) suggest that optimal timing of the first birth arises from the tension between the desire to have children earlier to enjoy them longer and the economic incentive to have them later when their opportunity cost $^{7}$ is smaller, while empirical studies (Gustafsson and Wetzels, 1997, 2000) suggest that the most important component of the opportunity cost of children is their effect on women's career plans. The timing of the first birth affects women's labor supply through its effect on wages. Other things equal (preferences, productivity of time spent in home production of utility generating commodities), longer periods with high level of labor market involvement before the birth of the first child lead to higher wages. Higher wages affect the time allocated to market work through three channels. First higher wages induce women to shift time from home production to market work (they substitute market goods and services for own time in the production of utility-generating commodities) until the marginal productivity at home is equal to the wage. Second, higher wages induce women to substitute goods-intensive commodities for time-intensive commodities, thus reducing leisure and increasing the time allocated to market work (the substitution effect). Third, higher wages induce women to consume more of each commodity, thus increasing leisure at the expense of market work (the income effect). Higher wages will be associated with higher level of labor market involvement before the first birth under two circumstances. First, if the substitution effect dominates the income effect, then time allocated to market work increases at the expense of both home production time and leisure. Second, if the income effect dominates the substitution effect, but the transfer of time from home production to market work exceeds the transfer of time from market work to leisure, the time allocated to market work and leisure will grow at the expense of home-production time.

When the first child is born, women who have been working start reallocating leisure and market time to the production of child-related, utility-generating commodities (number and quality). The transfer continues until the marginal product of time spent in the home production of child care is equal to the wage. If the market time is exhausted before the equality is reached, women will start transferring time spent in the home production of commodities unrelated to children. This transfer will continue until the marginal product of time spent in home production of child care is equal to the marginal product of time spent in the home production of commodities unrelated to children. Women who have not been working in the market will reallocate leisure and time spent in home production of the commodities unrelated to children to child care activities. Delaying the first birth leads to higher wages. Other things equal (productivity of home production of child care, preferences) higher wages imply that, following the birth of the child, the transfer of time from market work to home production of child care will be smaller. Since the transfer takes place until marginal product in home production of child care equals wage, decreasing marginal product and higher wage mean that less time will have to be transferred to equate the two. Hence, higher wages and, therefore, delaying the first birth reduce the effect of the first child on labor supply.

Also important is the relationship between the marginal product of own time and the marginal product of market inputs into the production of child quality. It is possible that, as more time is allocated to child care, its marginal product becomes smaller than the marginal product of market inputs. Beyond this point, increases in child quality can be achieved only by increasing the quantity of market inputs, which implies an increase in the time allocated to market work. As a result, if

\footnotetext{
${ }^{7}$ Opportunity cost of children includes direct costs, forgone wages during the time spent in home production of child care as well as forgone returns on human capital lost due to forgone human capital investment and depreciation during birth-related interruptions of market work.
} 
productivity of time in the home production of child quality is high relative to the productivity of market inputs, then, other things equal, the effect of the child on labor supply will be larger. For example, if market-supplied child care is of low quality, women will prefer producing child quality using own time as input, regardless of how high their wages are. Conversely, as children grow older, the marginal product of market inputs into child care increases relative to the productivity of own time. As a result, women return to work and substitute market inputs for own time in the production of child care.

When the second child is born, women start again reallocating leisure and market time and, potentially, time spent in home production of commodities unrelated to children and of child care for the first child, to the production of child care for the second child. The spacing of the two births influences the effect of the second child on women's labor supply through two channels. ${ }^{8}$ First, as women return to work after the first birth, they accumulate experience, which leads to higher wage offers. Higher wages, in turn, mean the effect of the second child will be smaller. Second, having the second birth at a longer interval after the first birth implies the first child is older at the time of the second birth. Market inputs are relatively more productive than own time in the production of child care for the first child, and therefore women spend more time in market work. As a result, the increase in time spent in child care for the second child will be financed to a larger degree through a reduction in market time, which implies the second child will have a larger effect on labor supply.

The main difficulty in estimating the way in which the timing and spacing of births influences the effects of children on labor supply arises from the fact that unobserved personal characteristics may jointly drive labor market and fertility decisions (the number of children, the timing of the first birth and the pace of subsequent births). Preferences for children (number and quality) and utility-generating commodities unrelated to children differ across individuals. Other things equal (wages, productivity in home production of child care and of commodities unrelated to children), women with stronger preferences for commodities unrelated to children will choose to have fewer children, will spend more time in market work, and enjoy less leisure time. Other things are not equal, however. Women with stronger preferences for commodities unrelated to children may find it optimal to choose relatively higher levels of pre-market and early-career investments in types of human capital that raise their market productivity. These investments translate into higher levels and longer periods of labor market involvement before the birth of the first child, which implies that women with stronger preferences for commodities unrelated to children may find it optimal to delay their first birth. Higher productivity in market work commands higher wages, and higher wages are associated with higher levels of labor market involvement before the first birth, larger opportunity costs of children, lower demand for children, and smaller effect of children on labor supply. On the other hand, higher levels of pre-market and early-career investments in types of human capital may raise not only the market productivity but also the productivity in home production of utilitygenerating commodities related to children. The increase in the productivity in home production of utility-generating commodities related to children leads to larger effects of children on labor supply.

The correlation between spacing of births and labor market decisions could arise through several channels. The existence of economies of scale in the home production of utility-generated commodities related to children implies births will be spaced more closely together. Fixed time or money

\footnotetext{
${ }^{8}$ Like the optimal timing of the first birth, optimal spacing of births arises from the tension between the desire to have children earlier to enjoy them longer and the economic incentive to have them later when their opportunity cost is smaller. The most important ingredient for generating non-trivial (zero or minimal spacing) is the variation over life time of the opportunity cost of children. Moffit (1984) and Hotz and Miller (1988) assume that home production of child services for very young children are intensive in women's time. Spacing births allows the shadow value of women's time to decline.
} 
costs of working, again, would imply women are less likely to combine market work and child care and therefore that births will be spaced more closely together. The existence of significant sunk costs of entering the labor market (search costs, information about the job match) also implies that women are more likely to space births more closely together. Whether the spacing of births is correlated with labor market decisions and with the other components of the fertility decisions (number of children, timing of the first birth) depends on the extent to which the factors that determine the optimal spacing of births are correlated with preferences, productivity in market work and in the home production of child care: whether scale economies are more likely to be present if women have higher productivity in the home production of child care, whether the fixed costs of working and the sunk costs of entering the labor market are higher for women with higher level of human capital.

\section{Data}

We study the way in which the timing and spacing of births influence the effect of children on the level of labor market involvement of married women using panel data from the 1979 National Longitudinal Survey of Youth (NLSY79). The NLSY79 contains a representative sample of individuals who were between 14 and 21 years old in 1979. Individuals were surveyed every year between 1979 and 1994, and every other year thereafter. For the purpose of our study, NLSY79 has two important features. First, it contains detailed information on respondents' labor supply history. Second, it contains information on the birth dates of respondents' children and on the beginning and end dates of respondents' marriages. Using this information, we constructed complete labor market, marital status, and fertility histories for each individual.

We use data from the nonmilitary sample of the 1979-2004 surveys. ${ }^{9}$ Since we focus on the labor supply of married women, we restrict the sample to women who are not married and are childless in 1979, get married after 1979, and remain married until 2004, only have children while married, and only have biological children in the household over the period of our data (this latter criteria eliminates women who adopt children or who marry men who have children who live with them). Imposing these strict selection criteria (specially the continuous marriage requirement) over a long period of time reduces the sample size, circumscribes the scope of our research to a narrower set of experiences and, potentially, leads to non-random selection of individuals with respect to unobserved traits that are relevant to their labor market and fertility behaviors. The focus on married women, however, is very common in the literature that studies the relationship between fertility and labor market decisions of women (Carrasco, 2001, Hyslop, 1999, Angrist and Evans, 1998, Heckman and Willis, 1977, etc). The motivation for this focus is twofold. First, married women, specially married women with children, have driven the dramatic change in the labor supply behavior among women that took place over the past few decades (Blau, 1998, Blau, Ferber, and Winkler, 1998, Leibowitz and Klerman, 1995). Second, underlying theoretical models of time allocation (like Mincer, 1962, Becker, 1965, Willis, 1973, Michael, 1973, Leibowitz, 1974, Gronau, 1977, Angrist and Evans, 1998) and dynamic models of fertility (like Happel et al., 1984, Moffit, 1984, Heckman and Willis, 1975, Wolpin, 1984, Newman, 1988, Hotz and Miller, 1988, Cigno and Ermisch 1989, Walker, 1995) are household models. Our sample is in a way more informative than those used in previous studies using panel data (e.g. Hyslop, 1999 and Carrasco, 2001) which contain women who are continuously

\footnotetext{
${ }^{9}$ We exclude women who live on a farm larger than 100 acres at any point in the period because it is difficult to identify hours worked for individuals living on a farm.
} 
married or cohabitating for the entire duration of the sample. Our panel is significantly longer and, since we begin following these individuals when they enter the labor market, we observe their level of labor market involvement both before and during marriage. ${ }^{10}$

In order to abstract from the trade-off between schooling and working, we only consider a woman at risk to work or to have a child once she has been out of school for at least 18 months continuously (once a women leaves school we consider her still at risk even if she returns to school). Finally, we require at least five years of data for each woman.

We represent the labor market decisions using four states - full time (FT), full time part year (FP), part time (PT), and nonwork (NW). To be considered working a woman must have both positive hours worked and positive income. Women who worked more than 1750 hours in a year are classified as full time. Women who work between zero and 1750 hours, but who work on average more than 35 hours a week, are considered full time part year. Women who work between zero and 1750 hours, but who work on average less than 35 hours a week, are considered part time (we imputed missing observations on the number of hours worked for several individuals; the imputation procedure is described in the data appendix). Women who work zero hours or who have zero income are considered not working.

Table 1 and figure 1 provide an overview of the variables used in the analysis. Panel A of table 1 presents summary statistics, by year, for the time-varying personal characteristics used in the analysis. Column 2, which presents the number of women considered at risk in a given year, shows the unbalanced nature of the data. In 1979 only 116 women are considered at risk, by 1997 all 645 women are considered at risk. Column 3 shows the proportion of women at risk that are married. Husband's income and income from other sources (columns 4 and 5 show averages per woman at risk) have been deflated using the CPI-U and are in 1979 dollars. Since after 1994 NLSY79 was conducted every other year, we imputed observations for the post-1994 missing years as well as several missing observations from the available years; our exact imputation procedure is described in the data appendix. Column 6 shows the yearly birth rates and columns 7 to 9 show the average number of children by age category, for women at risk. No women had any children prior to 1981. In the last years of the panel, birth rates are very low, which indicates that our data capture complete fertility histories for most women in the sample. In 2003, the average number of children was 1.8, and the average numbers of children for each age category were 0.05 for ages 0 to $1,0.14$ for ages 2 to 4 , and 1.61 for 5 years older. The empirical probability distribution of the labor market states of women at risk is showed in columns 10 to 13. The percentages of women working full time and

\footnotetext{
${ }^{10}$ We have carefully considered the possibility of using a sample that did not impose the marriage-related restrictions. We have decided not to pursue this avenue for several reasons. At the most basic level, a binary variable can capture the difference between single and married status, but it is inappropriate for describing marital histories of individuals who divorce or have multiple marriages - a nested categorical variable would be necessary. Second, marital status affects not only the level of labor market involvement, but also the effects of children on the level of labor market involvement. In the setting of our model this would mean adding interactions between the children variables and the variables describing marital status and, accordingly, expanding the layer of random effects that capture the role of time-invariant personal characteristics and individual level heterogeneity. Finally, removing marriage-related sample selection restrictions makes endogenous modeling of marital status more stringent. Technically, the Markov chain Monte Carlo techniques we employ in this paper provide an estimation framework flexible enough to model another binary variable, like marital status, endogenously. In practice, however, even if the binary variable provided an accurate representation of marital histories, we would be hard-pressed to find valid instruments. In addition, a significantly larger sample and a larger number of equations translate into significantly higher computational costs.

To test the robustness of our results to sample selection, however, we estimated our model with a sample that did not impose the marriage-related restrictions. While the average level of labor market involvement is lower in this larger sample, the qualitative results regarding the effect of children on the level of labor market involvement hold.
} 
working full time part year decline over time while the percentages of women working part time and not working rise.

Panel B presents summary statistics for the time-invariant personal characteristics and family background variables that are used as observed sources of heterogeneity: education, race, labor market status of respondent's mother, and parents' education. Thirty-six percent of the women in the sample have 12 years of education or less, 27 percent have between 13 and 15 years of education, while 37 percent have 16 years of education or more. Seventy percent of our sample is white, with the remainder evenly split between Hispanic and black. About $1 / 3$ of respondents' mothers worked full time and 1/3 did not work at all. For 75 percent of the sample neither parent has a college education, for 16 percent one parent has college education, and for 9 percent both parents have college education.

Figure 1 shows the distribution of the timing of the first birth and the distributions of the spacing of two and three births. We measure the timing of first birth from marriage. Empirical studies that document changes in fertility patterns use age of the first birth as a measure of timing. Our measure is consistent, however, with the setup of the dynamic models of fertility decisions (Hotz et al., 1997) in which the timing of the first birth is measured in terms of household "age." Panel A shows that the largest percentage of first births (23 percent) take place in the year following marriage. Fifty percent of the first births take place within two years of marriage, and 93 percent take place within 7 years of marriage. Panel B shows that most of the second births, 30 percent, take place two years after the first birth. Sixty-five percent of the second births take place within three years of the first birth, while 94 percent take place within six years of the first birth. Panel $\mathrm{C}$ shows that most of the third births, 23 percent, take place five years after the first birth; fifty five percent of the third births take place within five years of the first birth, while 91 percent take place within 9 years of the first birth.

The timing of the first birth and the spacing of the first two births are correlated with completed fertility. Panel A of figure 2, which compares the timing of the first birth across women with one, two, and three or more children, shows that women who have more children also have the first birth sooner after marriage. The probability of having the first birth in the year following marriage the most likely timing for the first birth regardless of the number of children - is 0.160 for women who have one child, 0.244 for women who have two children, and 0.284 for women who have three or more children. The probability of having the first birth within three years of marriage is 0.5 for women who have one child, 0.659 for women who have two children, and 0.781 for women who have three or more children. Panel B, which compares the spacing of the first two births across women with two and three or more children, shows that women who have more children space the first two births more closely together. The probability of having the second birth within three years of the first birth is 0.573 for women who have two children and 0.843 for women who have three or more children.

Completed fertility is correlated with the dynamics of the level of labor market involvement in the period surrounding the first birth. Column 1 of table 2, which shows the level of labor market involvement during the period between marriage and the first birth, indicates that women who have more children work less before the birth of the first child. Participation rates are very similar, but the level of labor market involvement of the participants is lower among women who have more children. The probability of working full time is 0.781 for women who have one child (81.1 percent of participants), 0.732 for women who have two children (75.9 of the participants), and 0.691 for women who have three or more children (71.8 of the participants). Columns 2 and 3 describe the effect of the first child on the level of labor market involvement. The birth of the first child reduces 
both participation, and the level of labor market involvement of those that continue to participate both participation and the probability of working full time decline, while the probabilities of working full time part year and part time increase. The reduction in the level of labor market involvement at the first birth is larger for women who have more children. The decline in participation following the first birth is 0.118 for women who have one child, 0.115 for women who have two children, and 0.177 for women who have three or more children. The decline in full time probability is 0.276 for women who have one child, compared with 0.345 for women who have two children and 0.441 for women who have three or more children.

Controlling for completed fertility, the timing and spacing of births are correlated with the dynamics of the level of labor market involvement during the periods surrounding births. Focusing on women who have two children between 1979 and 2003, in panel A of table 3 we assess the relationship between the timing of the first birth and the dynamics of the level of labor market involvement around the first birth. The table compares women who have the first birth within two years of marriage with women who have the first birth 3 to 7 years from marriage. The results suggest that the timing of the first birth is correlated with the dynamics of the level of labor market involvement in the periods surrounding the births. Women who have the first birth sooner have lower levels of labor market involvement before the birth of the first child. Their participation probability is 10 percentage points lower than that of women who have their first birth 3 to 7 years from marriage, and their probability of working full time is 13 percentage points lower. At the same time, they are more likely to work full time part year or part time before the birth of the first child. The first birth reduces participation and the probability of working part time and increases the probability of working full time part year and the probability of working part time. Women who have their first birth 3 to 7 years from marriage are relatively more likely to respond to the birth of the first child by reducing their level of labor market involvement, whereas women who have their first birth within two years of marriage are relatively more likely to stop working altogether.

In panel $\mathrm{B}$, we assess the relationship between the spacing of two births and the dynamics of the level of labor market involvement around the second birth. The table compares women who have the second birth within three years of the first birth with women who have the second birth 4 to 6 years from the first birth. The results show that women who have the second birth after a longer time interval work more before the birth of the second child. The birth of the second child reduces both participation and the level of labor market involvement of those who continue to work, but the effects to not vary much with the spacing of the two births.

These patterns may be generated in part by differences in observable personal characteristics and one goal of the subsequent analysis is to assess the extent to which that is the case. This caveat notwithstanding, the results of this simple non-parametric analysis suggest that delaying the first birth increases women's prenatal level of labor market involvement and reduces the effects of children on their labor supply, while having the second birth after a longer interval allows women to return to work before the second birth, but does not change the effect of the second child on the level of labor market involvement. At the same time they are consistent with a model in which heterogeneous preferences affect simultaneously labor market and fertility decisions: women with stronger preferences for utility generating commodities unrelated to children have fewer children, delay the first birth, and choose higher levels of early-career investments in human capital. 


\section{Econometric Framework}

The goal of the econometric model we propose is to analyze the way in which the timing and spacing of births influence the effect of children on women's labor supply in a framework that simultaneously addresses the three key issues in the estimation of the effects of children on labor supply: the endogeneity of labor market and fertility decisions, the heterogeneity of the effects of children on labor supply and their correlation with fertility decisions, and correlation of sequential labor market decisions.

\subsection{The Model}

We represent the labor market decisions using a model with four states - full time (FT), full time part year (FP), part time (PT), and nonwork (NW). This model provides a more accurate description of the level of labor market involvement than the two- or three-state models previously used in the literature. As we showed, a majority of women work full time before the birth of the first child. However, there is substantial variation in women's labor supply after birth with some women returning to full-time work, some switching to part-time and some choosing to remain out of the labor market for an extended period. In a two-state model (work, nonwork) in which labor market states are defined using hours worked in a given year, women who return to full-time work after short birth-related interruptions will be treated the same as women who switch to part-time work. Therefore, the two-state model does not capture the variation in the number of hours, which may represent a significant share of the effect of children. A three-state model (full-time, part-time, and nonwork) inaccurately classifies many of the years in which birth-related interruptions occur as part time when they are combinations of full-time work and inactivity (paid and unpaid leave). This will make it appear as if women are transiting to part-time work in the year of the birth of a child when, in fact, they are actually leaving the labor market. This in turn will make it appear as if part-time work is less persistent.

We model sequential labor market decisions using a multinomial probit model with autocorrelated error terms. Fertility decisions are modeled using a probit model with state-dependence and auto-correlated error terms. Labor market decisions and fertility decisions are driven by a sequential optimization process. At the beginning of each period an individual chooses the level of labor market involvement for the current period and simultaneously makes a fertility decision. The level of labor market involvement is selected from the set of four alternatives, by comparing the utility associated with each state. The value functions associate with each state are denoted by

$U_{i t}^{F T}, U_{i t}^{F P}, U_{i t}^{P T}$, and $U_{i t}^{N W}$, where the subscript $i$ indicates individuals, $i=1, \ldots, N$ the subscript $t$ indicates time periods, $t=1, \ldots, T_{i}$ and the superscripts denote the labor market state. Since the choice of a level of labor market involvement depends only on differences of value functions, we transform the model by considering only values relative to the nonwork state. The fertility decision is whether to conceive a child during the current period. Fertility choices are made by comparing the value functions corresponding to having and not having a child. We denote the difference between these value functions $U_{i t}^{F}$. The transformed value functions that drive the labor market and fertility decisions have the following specifications:

$$
\begin{aligned}
& U_{i t}^{1}=U_{i t}^{F T}-U_{i t}^{N W}=K_{i t} \alpha^{1}+X_{i t}^{L M} \beta^{1}+Z_{i t}^{1} \gamma+\left(K_{i t} * Z_{i t}^{1}\right) \delta+\sum_{m} K_{i t} \theta_{m l(i, m)}^{1}+u_{i t}^{1} \\
& U_{i t}^{2}=U_{i t}^{F P}-U_{i t}^{N W}=K_{i t} \alpha^{2}+X_{i t}^{L M} \beta^{2}+Z_{i t}^{2} \gamma+\left(K_{i t} * Z_{i t}^{2}\right) \delta+\sum_{m} K_{i t} \theta_{m l(i, m)}^{2}+u_{i t}^{2} \\
& U_{i t}^{3}=U_{i t}^{P T}-U_{i t}^{N W}=K_{i t} \alpha^{3}+X_{i t}^{L M} \beta^{3}+Z_{i t}^{3} \gamma+\left(K_{i t} * Z_{i t}^{3}\right) \delta+\sum_{m} K_{i t} \theta_{m l(i, m)}^{3}+u_{i t}^{3}
\end{aligned}
$$




$$
U_{i t}^{F}=K_{i t} \alpha^{F}+X_{i t}^{F} \beta^{F}+\sum_{m} K_{i t}^{F} \theta_{m l(i, m)}^{F}+u_{i t}^{F}
$$

We construct the fertility variable from data on children's birth dates and we do not consider pregnancies that end in miscarriage, stillbirth, or abortion. ${ }^{11}$ This specification is a departure from the previous literature which primarily used the occurrence of a birth to describe fertility decisions. Our specification rests on the premise that time-varying personal characteristics and variables describing a woman's relevant socioeconomic environment affect the fertility process through the conception decision, rather than through the birth of the child.

The vector $K_{i t}$ contains a constant term and variables describing the number of children in three age categories $(0-1,2-4,5$ and older), where age is measured at the last birthday. The variables describing the number of children and their age distribution are included in the participation equation in order to capture the effect of children on the level of labor market involvement. These variables which describe the entire history of fertility decisions - how many children have been born and how far in the past - are also included in the fertility equation, thus making current fertility decisions a function of past fertility decisions. The inclusion of the variables describing the number of children and their age distribution, together with the autocorrelated error term, helps us capture the timing and the spacing of births.

$X_{i t}^{L M}$ is a vector of personal characteristics relevant to labor market decisions that includes marital status, spouse's wage, other income, the region of residence (North East, North Central, South, and West), and whether the respondent resides in an urban or rural area. $X_{i t}^{F}$, is a vector of personal characteristics relevant to fertility decisions that includes other income, the region of residence, whether the respondent resides in an urban or rural area, and the number of siblings with children.

$Z_{i t}^{1}, Z_{i t}^{2}, Z_{i t}^{3}$ are expected hourly wages in each of the alternative labor market states. We include expected wages in the participation equations both by themselves, to capture the way in which they affect the level of labor market involvement, and in interaction with the variables describing the number and age distribution of children, $\left(K_{i t} * Z_{i t}^{1}\right),\left(K_{i t} * Z_{i t}^{2}\right),\left(K_{i t} * Z_{i t}^{3}\right)$, to describe the way in which the effect of children varies with the wage. We use the observed hourly wage for the current labor market state and impute the hourly wage for the alternative states. The imputation is based on a standard wage regression that includes second degree polynomials of years of education and experience, a full set of interactions between the terms of these polynomials and the labor market states, and the urban and region dummy variables. ${ }^{12}$

We do not include wages in the fertility equation. However, since wages affect the values of alternative levels of labor market involvement, and since we allow the value functions corresponding to labor market decisions to be correlated with the value function corresponding to the fertility decision, wages will affect fertility decisions in our framework.

We also do not include marital status or spouse's wage in the fertility equation because our data only includes women who have children while married. We do not include respondent's age in the specification of the labor market and fertility decisions. Since we account for the dependence of

\footnotetext{
${ }^{11}$ NLSY 79 contains information on the number of pregnancies ending in miscarriage, stillbirth, or abortion but not on the date those pregnancies begin. In addition, as one anonymous referee suggested, the likelihood of termination could be correlated with labor supply decisions.

${ }^{12}$ It is important to note that expected wages and the interaction terms between expected wages and the children variables vary over $i, t$, and labor market state, and their coefficients are constrained to be the same across states. Geweke, et al. (1997) point out that the inclusion of variables whose values differ across alternative choices and whose coefficient is constrained to be the same across states is important in the identification of multinomial probit models such as this, which would otherwise be difficult due to flat spots in the likelihood function.
} 
sequential labor market and fertility decisions by specifying AR(1) structures for the error terms of the four equations, the effect of age cannot be identified. However, it is unlikely our results will be affected by significant age effects since the age range in our sample is only seven years.

The mixed-effect structure, which combines fixed and random coefficients, allows us to study how the number of children, the timing and spacing of births, and the relationship between fertility and labor market behavior varies across time-invariant personal characteristics like education, race, and family background characteristics, and, controlling for these variables, to assess the role of individual-level heterogeneity. The $\alpha^{\prime} s, \beta^{\prime} s, \gamma$ and $\delta^{\prime} s$ in our model are vectors of global (fixed effect) parameters which are common across individuals in the sample. We allow five $(m=1, \ldots, 5)$ independent sources of heterogeneity to affect individuals' decisions: individuals' time invariant personal characteristics (education and race), family background variables related to tastes for work and family (the labor market status of respondent's mother and the education levels of respondent's parents), and individual-level heterogeneity. Each source of heterogeneity has $l_{m}$ levels. We have three levels for education (12 years or less, 13-15 years, 16 years or more), three for race (white, black, and Hispanic), two for respondent's mother's labor market status (full time and other) and three for parents' education (none of the parents, one, or both parents have college education); the number of levels for individual-level heterogeneity is equal to the number of individuals in the sample. Each individual in the data is assigned a level for each source of heterogeneity $l(i, m)$.

To level $l$ of heterogeneity source $m$ corresponds the vector of random coefficients $\theta_{m l}=$ $\left[\theta_{m l}^{1^{\prime}}\left|\theta_{m l}^{2^{\prime}}\right| \theta_{m l}^{3^{\prime}} \mid \theta_{m l}^{F^{\prime}}\right]$. The four components of $\theta_{m l}, \theta_{m l}^{1^{\prime}}, \theta_{m l}^{2^{\prime}}, \theta_{m l}^{3^{\prime}}, \theta_{m l}^{F^{\prime}}$, correspond to the four equations of the model. Each component includes four elements, one random effect and three random coefficients, corresponding to the four variables in the vector $K_{i t}$. We assume $\theta_{m l}$ are normally distributed, independent across the $l_{m}$ levels of heterogeneity of source $m, \theta_{m l} \sim \operatorname{MVN}\left(0, D_{m}\right)$, independent across sources of heterogeneity, and uncorrelated with the regressors $X_{i t}^{L M}, X_{i t}^{F}, Z_{i t}$ and the error terms $u_{i t}$.

The random coefficients corresponding to education, race, and family background variables capture the effects of these time-invariant personal characteristics on labor market and fertility decisions, while the individual-specific random coefficients describe the individual-level heterogeneity in labor market and fertility behavior. The random coefficients corresponding to the constant terms in the four equations capture the variation in propensities for market work and children. The random coefficients corresponding to the children variables in the participation equations describe the heterogeneity of the effects of children on the level of labor market involvement. The random coefficients corresponding to the children variables in the fertility equation capture individual variation in the timing and spacing of births. For example, a relatively small individual-specific coefficient for the variables describing the presence of young children and a relatively large individual-specific coefficient for the variable describing the presence of older children indicates the occurrence of births at larger intervals. Finally, the general correlation structure of the random coefficients captures the correlation between preferences for market work and children, effects of children on labor supply, and fertility behavior - the number, and the timing and spacing of births. ${ }^{13}$

We assume error terms are jointly normally distributed, $u_{i t}=\left[u_{i t}^{1}\left|u_{i t}^{2}\right| u_{i t}^{3} \mid u_{i t}^{F}\right]^{\prime} \sim N(0, \Sigma)$. Over time, error terms follow a $\operatorname{AR}(1)$ stationary process, $u_{i t}=R u_{i t-1}+\varepsilon_{i t}$, where $\varepsilon_{i t}=\left[\varepsilon_{i t}^{1}\left|\varepsilon_{i t}^{2}\right| \varepsilon_{i t}^{3} \mid \varepsilon_{i t}^{F}\right]^{\prime}$ is distributed $\operatorname{IIDN}(0, \Psi), \Psi=I_{4}$, and it is uncorrelated with the random coefficients $\theta_{s k}$ and variables $X_{i t}^{L M}, X_{i t}^{F}, Z_{i t}$, and $R$ is a $4 \times 4$ diagonal matrix whose elements are the $\operatorname{AR}(1)$ coefficients

\footnotetext{
${ }^{13}$ For each source of heterogeneity, random coefficients are assumed to be correlated within and between equations.
} 
corresponding to the four equations, $\rho_{1}, \rho_{2}, \rho_{3}$, and $\rho_{F} \cdot{ }^{14}$

Work experience, while not explicitly included in the specification of labor market decisions, enters our model in two ways. First, since we explicitly model dependence of sequential labor market decisions, the level of labor market involvement in the previous periods directly affects current decisions. Second, current labor market decisions depend on potential wages in each labor market state, which, in turn, depend on labor market experience - the realization of past labor market decisions.

We exploit several sources of identification. First, we assume that the vectors of random coefficients corresponding to each source of heterogeneity have a joint normal distribution. Second, children variables entering the participation equations are non-linear transformations of the lagged dependent variables in the fertility equation. This non-linearity is generated by the way in which we construct the number the children variables - number of children in certain age categories - as well as by measuring fertility as the date of conception (the decision to conceive a child in a given year could result in the birth of a child in the same calendar year or in the following calendar year, as well as in the birth of twins).

Finally, we include the number of siblings with children in the fertility equation but not in the labor market equations. This exclusion restriction helps identify the model. Our use of this variable rests on significant evidence from demographic literature that siblings' fertility behavior affects fertility decisions through social interaction occurring in the context of interpersonal networks. ${ }^{15} \mathrm{In}$ a panel data setting, identification comes from changes in the number of siblings with children. The temporal structure of the decision process we assume in this paper makes it unlikely that changes in the number of siblings with children are correlated with the error terms in the participation equations. While respondent's fertility variable captures the conception of a child during the current year, the number of siblings with children refers to the situation at the beginning of the same calendar year (children born to siblings during the past calendar year) and, therefore, reflects past fertility decisions made by the siblings. Even if contemporaneous shocks to labor supply are correlated across siblings, the number of siblings with children is predetermined. Evidence that changes in the number of siblings with children do impact a women's fertility decision is provided in Appendix table 1. In this table we present the estimation results of three OLS regressions where the number of children born between 1979 and 2003 is the dependent variable and the change in the number of siblings with children during the same period along with the number of siblings, respondent's education and race, respondent's parents' education are independent variables. The coefficient on the change in the number of siblings with children is significant in all specifications. In the specification that includes all controls, the coefficient for the change in the number of siblings with children is $0.1 .^{16}$

\footnotetext{
${ }^{14}$ The dynamic specification of both participation and fertility decisions requires assumptions regarding initial conditions. Specifically, we need to account for the distribution of the error terms and for the distributions of the children variables in the initial period. We assume that error terms follow stationary AR(1) processes, and we treat pre-sample error terms as parameters of the model. The selection of the sample ensures the number of children in the initial period is identical across individuals - we choose the first year out of school as the first period in the sample and we include only women who marry and have children only after entering our sample.

${ }^{15}$ Montgomery and Casterline (1996) provide a theoretical framework in which siblings' fertility affect fertility decisions through social interaction. Numerous papers provide empirical evidence that siblings' behavior influences a wide range of indices of fertility behavior: Rowe et al. (1989), Rodgers and Rowe (1988), Haurin and Mott (1990), Axinn, Clarkberg, and Thornton (1994).

${ }^{16}$ By comparison, Rosenzweig and Wolpin (1980), who use twins at the first birth as instrument for fertility, find that among women who have the first birth between 15 and 24, completed fertility, as measured 20 years later, was 0.15 greater for those women who had twins than for those women without twins. Angrist and Evans (1998) who
} 


\subsection{Estimation}

To estimate the model, we employ Markov chain Monte Carlo techniques (MCMC). MCMC methods avoid one of the major difficulties inherent in the alternative maximum likelihood or simulated maximum likelihood estimation methods - the evaluation at each step of the maximization process of multiple integrals, whose dimensions increase very quickly with the number of equations to be estimated. The estimation algorithm we propose in this paper builds on several sources in the literature: Geweke et al. (1997) who propose a Gibbs sampler algorithm for estimating a panel multinomial probit model where errors follow an AR(1) process, McCulloch and Rossi (1994) who estimate a multi-period multinomial probit model with random effects, and Gilks et al. (1993) who propose an algorithm for the estimation of a single-equation, panel-data model with random coefficients.

The posterior kernel for our model is given by the product of a multivariate normal kernel, the kernel of the unconditional distribution of the pre-sample error terms, the prior distributions of the parameters, and an indicator function controlling the ordering and the signs of the latent variables. For the parameters of interest we choose proper but noninformative prior distributions. A sevenstep Gibbs sampling algorithm is employed to construct draws from the posterior distribution of the parameters. Convergence is assessed using the method proposed by Brooks and Gelman (1998).

The goal of the empirical analysis is to study the way in which the timing and the spacing of births influence the effects of children on women's level of labor market involvement. Although the coefficients estimates, which are presented in appendix table 2, provide interesting insight into the effect of children on women's labor supply, they are difficult to interpret directly because of the non-linearity of the model. Therefore, we use simulations based on the estimation results.

\subsection{Simulation Design}

We measure the effects of two children on the probability distribution of the four labor market states and we assess the way in which the timing of the first birth and the spacing of two births affect the dynamics of the level of labor market involvement. We confine our analysis to a period of 20 years following entry into the labor market, and we focus on fertility histories with no birth, one birth, and two births. For all fertility histories marriage takes place in the second year. The timing of the first birth varies between year 3, the year following marriage, and year 20. For each possible timing of the first birth, the second birth can take place any period between the first birth and year 20. The total number of fertility histories constructed in this way is 172 .

We construct five individual profiles: white woman with 12 years of education, white woman with 14 years of education, white woman with 16 years of education, black woman with 12 years of education, and Hispanic woman with 12 years of education. For all the profiles, personal characteristics are set at the values with the highest frequencies in our sample. We assume that none of the respondent's parents has college education and that respondent's mother did not work full time. We set other family income at zero, the region of residence to North-East, and the type of residence to urban. We set spouse's wage at 15530, the median level. For each individual profile, we set the random coefficients corresponding to the individual heterogeneity to zero, the average value. For every period along each possible labor market history, we compute the wages corresponding to the three working labor market states using the coefficient estimates from the wage equation,

use the gender of the first two children as instrument for the birth of the third child find that among parents with 2 or more children, the proportion that have the 3 child is 0.06 greater if the first two children were of the same sex than if they were of opposite sex. 
the characteristics associated with the relevant individual profile, and the labor market experience accumulated until that point in time.

Individual-level variation in labor market and fertility behavior is captured by the set of 16 individual-specific random coefficients. We use principal component analysis to identify the most significant ways in which the random coefficients vary across individuals, and we use the first component to describe the individual variation in labor market and fertility decisions. The first principal component has an eigenvalue of 8.54 and explains 54 percent of the total variance, a far larger share than the other principal components. The components' weights suggest that women with large values of the first principal component are likely to have more children, are more likely to have births at larger intervals, have lower levels of labor market involvement, and face smaller effects of children on their labor supply. We rank women according to the values of the first principal component. We select individuals in the bottom decile, median decile (45 percentile to 55 percentile), and top decile of the first PC. To incorporate individual heterogeneity, we attach the random coefficients corresponding to these 195 individuals to the benchmark individual profile, white woman with 12 years of education, which gives us 195 additional individual profiles.

For all individual profiles we compute the joint probability distribution of all possible labor market and fertility histories, $f\left(s_{1}, s_{2}, \ldots, s_{20}, h_{b_{1}, b_{2}}^{j}\right) . s_{t}$ denotes the labor market state in period $t, t=1, \ldots, 20 ; h_{b_{1}, b_{2}}^{j}$ denotes the fertility history corresponding to $j$ births, $j=0,1,2$, with first birth taking place in year $b_{1}$ and second birth taking place in year $b_{2}$, where $b_{1}$ and $b_{2}$ take value 0 if the corresponding birth does not take place. We then compute the probability of each fertility history, $f\left(h_{b_{1}, b_{2}}^{j}\right)$, along with the probability of all possible labor market histories conditional on the specific fertility history, $f\left(s_{1}, s_{2}, \ldots, s_{20} \mid h_{b_{1}, b_{2}}^{j}\right)$. Finally, we compute the probability distribution of the labor market states in every time period conditional on a given fertility history, $f\left(s_{t} \mid h_{b_{1}, b_{2}}^{j}\right)$.

We measure the effect of the first birth on the level of labor market involvement by comparing the probability distributions of the labor market states, $f\left(s_{t} \mid h_{b_{1}, b_{2}}^{j}\right)$, for the fertility histories with one birth with the fertility history with zero births, in the years following the birth:

$$
T E_{b_{1}}^{1}(t)=f\left(s_{t} \mid h_{b_{1}, 0}^{1}\right)-f\left(s_{t} \mid h_{0,0}^{0}\right), t \geq b_{1}
$$

The effect of the second birth is computed by comparing the probability distributions for the fertility histories with two births with the corresponding fertility history with one birth, in the years following the second birth:

$$
T E_{b_{1}, b_{2}}^{2}(t)=f\left(s_{t} \mid h_{b_{1}, b_{2}}^{2}\right)-f\left(s_{t} \mid h_{b_{1}, 0}^{1}\right), t \geq b_{2}
$$

We assess the role of the timing of the first birth by comparing the effect of the first child, $T E_{b_{1}}^{1}(t)$, for different timing of the first birth, $b_{1}=3, \ldots 20$. To assess the role of the spacing of the two births, we compare the effect of the second child, $T E_{b_{1}, b_{2}}^{2}(t)$, for different timing of the second birth, $b_{2}=b_{1}+1, \ldots 20$., assuming that the first birth takes place in year $3, b_{1}=3$, the year following marriage, which is the timing of the first birth with the highest frequency in the data. We assess the role of personal characteristics by comparing results across levels of education and races, and the role of individual-level heterogeneity by comparing results across the 195 profiles constructed with the individual-specific random coefficients. 


\section{Results}

We begin by focusing on white women with 12 years of education, the profile we choose as baseline. For these women, we first present the predictions of our model with respect to the distributions of the number of children, of the timing of the first birth, and of the spacing of two births. Second, we construct the effects of two children on their level of labor market involvement. Third, we study three aspects of the connection between the timing and spacing of births and women's level of labor market involvement: the relationship between the timing of the first birth and the level of labor market involvement before the birth of the first child, the relationship between the timing of the first birth and the effect of the first child on the level of labor market involvement, and the relationship between the spacing of two births and the effect of the second child on the level of labor market involvement. Next, using white women with 12 years of education as reference, we study the way in which timing and spacing of births and the connection between the timing and spacing and births and the level of labor market involvement vary across levels of education, across races, and, controlling for personal characteristics, across individuals.

\subsection{White women with 12 years of education}

\subsubsection{The number of children, the timing of the first birth and the spacing of two births}

Figure 3 shows the predictions of our model with respect to the distributions of the number of children, of the timing of the first birth, and of the spacing of two births. Panel A shows that the probability of having no children is 0.169 , the probability of having one child is 0.446 , the probability of having two children is 0.250 , and the probability of having three children or more is 0.134. Panel B shows that the probability of having the first birth is the highest in the year following marriage, 0.091, and declines thereafter. Panel C shows that the most likely spacing of the two births is a two-year interval. The probability that the second birth takes place two years after the first birth is 0.324 , the probabilities for having the second birth three, four, or five years after the first birth are roughly equal, 0.14 , while probabilities of intervals longer that 5 years are smaller than 0.03 .

\subsubsection{The Level of Labor Market Involvement before the First Birth}

Figure 4 shows the relationship between the timing of the first birth and the level of labor market involvement before the first birth, $f\left(s_{b_{1}-1} \mid h_{0,0}^{0}\right)$. The four panels display the participation probability and the probabilities for the three working labor market states in the year before the first birth, by the timing of the first birth measured in years from marriage. Most women work before the birth of the first child, and most of the participants work full time. For women who have the first birth in the year following marriage (the timing with the highest frequency in this sample), participation probability is 0.913 . The probability of working full time is 0.568 (62.1 percent of those who participate), the probability of working full time part year is 0.205 (22.4 percent of those who participate), and the probability of working part time is 0.139 (15.3 percent of those that participate). Delaying the first birth leads to higher probability of participation and to higher probabilities of working full time, full time part year, and part time before the birth of the child. For women who have the first birth seven years after marriage (in this sample, 93 percent of the first births take place within seven years of marriage) participation probability in the year before 
birth is 0.970 , the probability of working full time is 0.580 (60.3 percent of those who participate), the probability of working full time part year is 0.216 (22.3 percent of those that participate), and the probability of working part time is 0.168 (17.4 percent of those that participate).

\subsubsection{The effect of the First Child on the Level of Labor Market Involvement}

Panel A of figure 5 shows the effect of the first child on the level of labor market involvement, $T E_{b_{1}}^{1}(t), t \geq b_{1}$, for the fertility history in which the first birth takes place in year $3, b_{1}=3$, the year following marriage and the timing of the first birth with the highest frequency in our sample. The birth of the first child reduces both participation and the level of labor market involvement of those who continue to work. The effect is strongest in the year of birth: participation probability falls by 0.282 , the probability of working full time falls by 0.266 , the probability of working full time part year falls by 0.105 percent, while the probability of working part time increases by 0.089 percentage points. Among participants, the share working full time declines by 16 percentage points, the share working full time part year declines by 6.6 percentage points, and the share working part time increases by 22.6 percentage points. The effect of the first child diminishes as the child grows older, but remains significant long after birth. Five years after birth, when the child moves into the age category 5 years or older, the probability of participation is 9.2 percentage points lower, the probability of working full time is 12.1 percentage points lower, the probability of working full time part year is 6.8 percentage points lower, while the probability of working part time is 9.7 percentage points higher.

Panel B of figure 5 shows the way in which the effect of the first child in the year of birth, $T E_{b_{1}}^{1}\left(b_{1}\right)$, varies with the timing of the first birth, $b_{1}=3, \ldots 20$. Delaying the first birth reduces the negative effects on participation, on the probability of working full time, and on the probability of working full time part year, and increases the positive effect on the probability of working part time. For women who have the first birth seven years after marriage, participation probability in the year of birth declines by 0.168 , an effect which is 11.3 percentage points smaller than if they had the first birth in the year following marriage; the effect on the probability of working full time is $-0.213,5.3$ percentage points smaller, the effect on the probability of working full time part year is $-0.076,2.9$ percentage points smaller, while the effect on the probability of working part time is $0.120,3.1$ percentage points higher.

Figure 6 compares the dynamics of the effect of the first child on the probability of participation and on the probabilities of the three working states in the period following the first birth, $T E_{b_{1}}^{1}(t), t \geq b_{1}$, for three alternative timings of the first birth: year $3, b_{1}=3$, the year following marriage, and the most frequent timing, year $6, b_{1}=6$, four years after marriage, and year 9 , $b_{1}=9$, seven years after marriage. The dynamics of the effects of the first child are similar for different timing of the first birth. The differences due to timing - the distances between the profiles - are stronger while the child is young. As the child grows older, the effects decline and so do the differentials due to the timing of the birth.

\subsubsection{The Effect of the Second Child on the Level of Labor Market Involvement}

As we showed in panel A of figure 5, the effect of the first child on the level of labor market involvement declines with the age of the child: both participation and the level of labor market involvement of those who participate increase. This implies that the level of labor market involvement before the second birth increases with the spacing of the two births. Figure 7 shows the effects of two children on the level of labor market involvement, $T E_{b_{1}}^{1}(t), t \geq b_{1}$ and $T E_{b_{2}}^{2}(t), t \geq b_{2}$, for 
the fertility history in which the births take place in years 3 and $5, b_{1}=3, b_{2}=5$. This fertility history has the highest frequency in the data: most first births (23 percent) take place in the year following marriage, while most second births (30 percent) take place two years after the first birth. The second child reduces the level of labor market involvement the same way as the first child: participation and the probabilities of working full time and full time part year decline, while the probability of working part time increases. In the year of the second birth, participation declines by 0.288 , the probability of working full time declines by 0.200 , the probability of working full time part year declines by 0.103 , while the probability of working part time increases by 0.014 . The effect of the second child declines with the age of the child. Eight years after marriage, when the second child moves into age category 5 years and older, the second child reduces participation by 0.143 , the probability of working full time by 0.155 , the probability of working full time part year by 0.079 , and increases the probability of working part time by 0.091 .

To analyze the relationship between the spacing of the two births and the effect of the second child on the level of labor market involvement we focus on fertility histories in which the first birth takes place in year $3, b_{1}=3$, the year following marriage. Figure 8 shows how the effect of the second child in the year of birth, $T E_{b_{2}}^{2}\left(b_{2}\right)$, varies with the spacing of the two births, $b_{2}=4, \ldots 20$. The effect of the second child on participation declines with the length of the interval between the two births. For women who have the second birth six years after the first birth (95 percent of the second births take place within seven years of the first birth, participation probability declines by 0.256 in the year of birth, an effect which is 3.2 percentage points smaller than for women who have the second birth two years after the first birth. The effect of the second child on the probability of working full time is smaller if the second child is born within four years of the first birth. In year five, when the first child moves to age category 5 and older, the effect of the second child on the probability of working full time increases. ${ }^{17}$ The effect on the probability of working full time part year varies little with the spacing of the two births. The effect of the second child on the probability of working part time is $0.089,7.5$ percentage points higher.

Figure 9 compares the dynamics of the effect of the second child on the probability of participation and on the probabilities of the three working states in the period following the second birth, $T E_{b_{2}}^{2}(t), t \geq b_{2}$, for three alternative spacing of the two births: the second birth takes place two years, four years, and six years after the first birth, $b_{2}=5,7,9$. The dynamics of the effects of the second child are similar for different spacing of the second birth. The differences due to spacing the distances between the profiles - are stronger while the second child is young, but they become very small once the second child reaches age 5 .

This first set of results suggests that the timing and the spacing of births are important determinants of the effect of children on women's labor supply. Postponing the first birth leads to higher levels of labor market involvement before the birth of the first child and reduces the effect of the first child on the level of labor market involvement. The spacing of the second birth leads to higher levels of labor market involvement before the second birth and reduces the negative effect of the second child on participation, but increases both the negative effect on the probability of working full time and the positive effect on the probability of working part time.

Our results are consistent with the predictions of household models of time allocation (Mincer, 1962, Becker, 1965, Willis, 1973, Michael, 1973, Leibowitz, 1974, Gronau, 1977, Angrist and Evans,

\footnotetext{
${ }^{17}$ The discrete changes in the direct effect of children are generated by the definition of the variables that describe the age of the children. In reality, the age of the child and the direct effect change continuously. An interpolation of our results would probably capture more accurately the dynamics of the direct and indirect effects and would mitigate the patterns that occur at discontinuity points.
} 
1998). Market work is associated with investments in human capital which raise productivity and, therefore, wage offers. Higher wages lead to higher levels of labor market involvement before the first birth, unless the income effect (higher wages induce women to consume more of each commodity, thus increasing leisure at the expense of market work) outweighs both the substitution in consumption of goods-intensive commodities for time-intensive commodities and the substitution in home production of market inputs for own time. Higher wages also imply that, following the birth of the child, the transfer of time from market work to home production of child care and, therefore, the effect of the first child on labor supply will be smaller. While the first child is young, the productivity of mother's time input into the production of child care is high relative to the productivity of market inputs, few women work full time, and the increase in time spent in child care for the second child is reflected in larger effects on participation. The productivity of market inputs in the production of child care for the first child increases relative to the productivity of mother's time with the age of the child, making it optimal for women to return to work gradually. As this happens, the increase in time spent in child care for the second child is financed increasingly by reductions in the market time, which implies a larger negative effect on the probability of working full time, a larger positive effect on the probability of working part time, and a smaller negative effect on the probability of participation.

\subsection{Education, Race and Individual Heterogeneity}

The results presented so far were obtained controlling for observed personal characteristics like education and race and for individual-level heterogeneity. By all accounts, however, both observed and unobserved personal characteristics play important roles in shaping the connection between labor market and fertility decisions of women. Women with higher education have higher wages, and, as household models of time allocation show, higher wages affect demand for children, labor supply before the birth of the first child, and labor supply responsiveness to children. In addition, dynamic models of fertility (Happel et al.,1984, Cigno and Ermisch,1989, and Cigno,1991) suggest that education is connected to the timing and spacing of births through two channels: the level of prenatal human capital and the shape of the life-cycle human capital profile, both of which are correlated with formal education. The relationship between labor market and fertility decisions of women also vary significantly across races. Many studies have found larger effects of children for white women than for black women (Bell, 1974, Lehrer, 1992, Shapiro and Mott, 1994, Troske and Voicu, 2009a), while Hotz et al. (1997) show that, over time, white women have shifted childbearing to later ages to a larger extent than non-white women. Finally, the role of unobserved characteristics has been a longstanding concern of fertility studies, many of which accounted for individual-level heterogeneity (Moffitt 1984; Newman and McCulloch 1984; Heckman et al. 1985; Hotz and Miller 1988, Heckman and Walker, 1990, Merrigan and St. Pierre, 1998). Unobserved characteristics have been found to be important determinants of fertility dynamics in countries with heterogeneous populations (Merrigan and St. Pierre, 1998). In addition, individual-level heterogeneity is central to estimating the effects of children on women's labor supply as preferences for children and utilitygenerating commodities unrelated to children jointly drive labor market and fertility decisions.

Our goal in this section is to study educational and racial differentials as well as individuallevel heterogeneity in completed fertility, in the timing and spacing of births, in the effects of children on labor supply, and, finally, in the way in which timing and spacing of births influence the effects of children on labor supply. To measure the variation in the effect of children across levels of education, we focus on three key measures of the dynamics of the level of labor market 
involvement: the probability distribution of the four labor market states in the year before the birth of the first child, $f\left(s_{b_{1}-1} \mid h_{0,0}^{0}\right)$, the effect of the first child on the distribution of the labor market states in the year of the first birth, $T E_{b_{1}}^{1}\left(b_{1}\right)=f\left(s_{b_{1}} \mid h_{b_{1}, 0}^{1}\right)-f\left(s_{b_{1}} \mid h_{0,0}^{0}\right)$, and the effect of the second child on the distribution of the labor market states in the year of the second birth, $T E_{b_{1}, b_{2}}^{2}\left(b_{2}\right)=f\left(s_{b_{2}} \mid h_{b_{1}, b_{2}}^{2}\right)-f\left(s_{b_{2}} \mid h_{b_{1}, 0}^{1}\right)$. We first compute these measures for the fertility histories with the most common timing and spacing of the two births - the first birth takes place in year 3 , $b_{1}=3$, the year following marriage, and the second birth takes place in year $5, b_{2}=5$, two years after the first birth. Second, to compare the way in which the timing and the spacing of births affect the dynamics of the level of labor market involvement across personal characteristics, we show how $f\left(s_{b_{1}-1} \mid h_{0,0}^{0}\right)$ and $T E_{b_{1}}^{1}\left(b_{1}\right)$ change if the first birth takes place seven years after marriage, $b_{1}=9$, instead of the year following marriage and how $T E_{b_{1}, b_{2}}^{2}\left(b_{2}\right)$ changes if the second birth takes place six years after the first birth, $b_{2}=5$, instead of two years after the first birth.

Before turning to the presentation of the results, it is worth recalling that education, race, and individual-level heterogeneity enter our econometric model in slightly different ways. For all three sources of heterogeneity, we use random coefficients to capture the variation of the labor supply, of the demand for children, and of the effects of children on labor supply across levels of education. Education, however, affects women's labor market and fertility decisions through an additional channel: expected wages, which are a function of education, are included in the participation equations both by themselves and in interaction with the variables describing the number and age distribution of children.

\subsubsection{Education}

Women with higher education have fewer children, have the first birth later in life, and have the second birth at a shorter time interval after the first birth. Panel A of figure 10, which compares the distribution of the number of children across levels of education, shows that the probability of having zero children increases with the level of education ( 0.169 for women with 12 years of education, 0.205 for women with 14 years of education, and 0.217 for women with 16 years of education) whereas the probability of having three children or more declines with the level of education $(0.134$ for women with 12 years of education, 0.112 for women with 14 years of education, and 0.107 for women with 16 years of education).

Panel B, which compares the profiles of first birth probabilities across levels of education, ${ }^{18}$ indicates that women with higher levels of education are likely to have the first birth later in life. The probability of having the first child in the year following marriage is 5 percent lower for women with 14 years of education and 6.6 percent lower for women with 16 years of education, compared with women with 12 years of education. Women with 14 and 16 years of education have relatively lower probabilities of having the first child up to 7 years after marriage, and relatively larger probabilities of having the first child 8 years or longer after marriage.

Results in panel $\mathrm{C}$ show that women with higher education have the second birth after a shorter time interval. The probability of having the second birth within two years of the first birth is larger for women with higher education. The probability of having the second birth one year after the first birth is 6.2 percent larger for women with 14 years of education and 7.1 percent higher for women with 16 years of education, compared to women with 12 years of education, the probability

\footnotetext{
${ }^{18}$ The profile corresponding to women with 12 years of education has been normalized and, therefore, the profiles for women with 14 and 16 years of education show their probabilities of having the first birth in a given year relative to the corresponding probability for women with 12 years of education.
} 
of having the first birth two years after the first one is 10.6 and 13.1 percent higher for women with 14 and 16 years of education compared with women with 12 years of education. At the same time the probabilities of having the second birth at longer intervals are larger for women with lower education. The probability of having the second birth between 3 and 5 years form the first birth is roughly 10 percent lower for women with 14 and 16 years of education compared with those with 12 years of education. The probability of having the second birth at longer intervals is lower for more educated women, but differences across education levels are smaller.

Panel A of table 4 shows the results for the level of labor market involvement before the birth of the first child, $f\left(s_{b_{1}-1} \mid h_{0,0}^{0}\right)$. Results in columns 1-3 indicate that women with higher education work more before the birth of the first child. Participation rate and the probability of working full time increase with education: participation rate is 0.913 for women with 12 years of education, 0.966 for women with 14 years of education, and 0.977 for women with 16 years of education, and the probability of working full time is 0.568 for women with 12 years of education, 0.715 for women with 14 years of education, and 0.744 for women with 16 years of education. At the same time the probability of working full time part year and the probability of working part time decrease with the level of education. Columns 4-9 show that delaying the first birth increases participation for all levels of education, but the change is larger for women with lower education. It also raises the probability of working full time for women with 12 years of education, but leads to small reductions in the probability of working full time for women with higher education, whose increase in participation is mainly fueled by increases in the probability of working part time.

Panel B shows the results for the effect of the first child on the level of labor market involvement, $T E_{b_{1}}^{1}\left(b_{1}\right)$. Results in columns 1-3 show that the birth of the first child reduces both participation and the level of labor market involvement of those that continue to participate. The effect of the first child on participation is smaller for women with higher education $(-0.283$ for women with 12 years of education compared with -0.255 for women with 14 years of education and -0.247 for women with 16 years of education), whereas the effect on the probability of working full time increases with education $(-0.266$ for women with 12 years of education compared with -0.305 for women with 14 years of education and -0.328 for women with 16 years of education). Both the negative effect of the first child on the probability of working full time part year and its positive effect on the probability of working part time are stronger for more educated women. The discrepancy between the effect of education on participation and the effect on the probability of working full time is explained by the fact that, following the birth of the first child, women with higher education are more likely to start working part time rather than to stop working.

Columns 4-9 show that delaying the first birth reduces the effect of the first child on the level of labor market involvement. The negative effects of the first child on participation and on the probabilities of working full time and full time part year decrease, while the positive effect on the probability of working part time increases. The reduction in the effect of the first child with the timing of the birth is larger for women with higher education. Having the first birth in year 9 reduces the effect of the first child on participation by 0.106 for women with 12 years of education, by 0.122 for women with 14 years of education, and by 0.128 for women with 16 years of education, and the effect of the first child on the probability of working full time by 0.059 for women with 12 years of education, by 0.080 for women with 14 years of education, and by 0.081 for women with 16 years of education.

Panel $\mathrm{C}$ shows the results for the effect of the second child on the level of labor market involvement, $T E_{b_{1}, b_{2}}^{2}\left(b_{2}\right)$. The negative effects of the second child on both participation and the probability of working full time increase with education, and so does the positive effect on the 
probability of working part time (columns 1-3). For women with all levels of education, having the second birth after a longer time interval reduces the negative effects of the second child on participation and on the probability of working full time part year, increases the negative effect on the probability of working full time and the positive effect of working part time. The reduction in the effect of the second child on the level of labor market involvement is larger for women with higher education who experience larger drops of the negative effect on participation and smaller increases in the negative effect on the probability of working full time.

Our finding that women's labor supply responsiveness to children increases with education is consistent with the results of Gronau (1973), Hill and Stafford (1980), Leibowitz (1974), Mincer and Polacheck $(1974,1978)$. The fact that women with higher education have higher levels of labor market involvement before the first birth suggests they not only have higher levels of pre-natal human capital stock, but also higher human capital investments and, therefore, steeper life-cycle human capital profiles. The predictions of theoretical models with respect to both channels are mixed. First, Happel et al. (1984) predict that women with higher pre-natal human capital have the first birth later in life to minimize losses due to human capital depreciation, while Cigno and Ermisch (1989) and Cigno (1991), who assume zero depreciation rate, predict that women with higher pre-natal human capital to will have the first birth sooner. Second, a steeper human capital profile implies that postponing the first birth leads to larger reductions in the human capital loss portion of the opportunity cost of the child, but increases the forgone wage portion. Our findings, which are consistent with the previous empirical findings (Cigno and Ermisch, 1989, and Happel et al., 1984, Gustafsson and Wetzels, 2000), suggest that women with higher levels of prenatal human capital and steeper human capital profiles are more likely to postpone the first birth. Moreover, the fact that for women with higher education the timing of births has stronger influence on the effects of children on labor supply is consistent with evidence from empirical studies of fertility patterns which indicates that, over time, women with higher education postponed fertility more than women with lower education (Gustafsson and Wetzels, 2000).

The results with respect to the spacing of the two births appear incongruous: women with higher education have more to gain from having the second birth after a longer interval, yet they are likely to space the two births more closely together. Several factors could generate this tension. It is possible that women with higher education have larger fixed time or money costs of working, which makes them less likely to combine market work and child care, or face higher sunk costs of entering the labor market (search costs, information about the job match), which makes them less likely to enter and exit the market repeatedly. In addition, if women with higher education have higher productivity in the home production of child care (as results of Troske and Voicu, 2009b, suggest) and if scale economies are more likely to be present if women have higher productivity in the home production of child care, women with higher education will have stronger incentive to have the two births at a shorter time interval. Finally, steeper human capital profiles make it optimal for women with higher education to postpone the first birth more. If life-cycle human capital profiles are concave, as Gustafsson (2001) suggests, the gain from spacing the two births would be smaller for women who postpone the first birth more. That is because they face smaller rates of decline for losses due to both forgone human capital investments and forgone wages during maternity related interruptions. 


\subsubsection{Race}

Figure 11 compares the distributions for the number of children, the timing of the first birth, and the spacing of two births across races. Panel A shows that the probability distribution of the number of children is very similar for white and black women, while Hispanic women are likely to have more children. They have a lower probability of having no children $(0.10$, compared with 0.163 for black women and 0.169 for white women) and higher probability of having three children or more (0.184 compared with 0.134 for black women and 0.136 for white women). Panel B shows that timing of the first birth is also very similar for white and black women. Hispanic women, on the other hand, are more likely to have the first birth sooner after marriage. Panel $\mathrm{C}$ indicates that white women are more likely to have the second birth in a time interval of two to five years after the first birth. The probabilities are less concentrated for black and Hispanic women, who are relatively more likely to have the second birth in the year following the first birth or at an interval longer than 5 years.

Table 5 compares the effects of timing and spacing of births on the dynamics of the level of labor market involvement across races. Results in columns 1-3 show that white women have higher levels of labor market involvement before the birth of the first child than black and Hispanic women (panel A), but both the first and the second child have stronger negative effects on their labor supply (panels B and C). As it was the case with education, differentials across races are stronger with respect to the probability of working full time than with respect to participation. Results in columns 4-9 show that delaying the first birth increases the level of labor market involvement before the first birth for all races (panel A). The increase is stronger for black and Hispanic women compared with white women. Delaying the first birth also reduces the negative effects of the first child on participation and on the probabilities of working full time and full time part year, and increases the positive effect on the probability of working part time (panel B). The reduction in the effect of the first child with the timing of the birth is larger for white women compared with black and Hispanic women.

Having the second birth after a longer time interval reduces the negative effects of the second child on the level of labor market involvement for all races (panel C). This reduction, however, is larger for black and Hispanic women compared with white women. For white women, having the second birth after a longer interval reduces the effect of the second child on participation and increases the effect on the probability of working full time, whereas black and Hispanic women not only experience larger reductions in the effect of the second child on participation, but also reductions in the effect of the second child on the probability of working full time.

The differences in labor supply responsiveness to children across races are similar to previous results (Bell, 1974, Lehrer, 1992, Shapiro and Mott, 1994). These differences could be due to minority women having better access to informal child care. The similarity between the ways in which education and race affect the relationship between fertility and labor supply suggests, however, that differences across race and ethnicity could be in part generated by human capital differences: minorities are more likely to live in central city and racial and economic segregation in the housing market may affect quality of schooling leading to less human capital even for the same level of schooling (Aaronson, 1998, and Altonji and Blank, 1999). The patterns of timing and spacing of births are consistent with the race differentials in the way in which timing and spacing influence the effects of children on labor supply: white women, who gain most from postponing the first birth but gain least from spacing the two births, have the first birth later in life and the second birth after a shorter interval. The result with respect to the effect of the timing of the first birth on the effect of the first child is consistent with the finding of Hotz et al. (1997) that over time white 
women have shifted childbearing to later ages to a larger extent than non-white women.

\subsubsection{Individual Heterogeneity}

Figure 12 compares the distributions for the number of children, the timing of the first birth, and the spacing of two births across individuals. The probabilities we show are averages for individuals in the bottom, median, and top deciles of the first principal component. After controlling for observable characteristics, fertility behavior displays a remarkable level of individual heterogeneity. Women in the top decile of the first PC are likely to have more children, have the first birth sooner in life, and the second birth after a longer time interval.

Table 6 compares the effects of timing and spacing of births on the dynamics of the level of labor market involvement across individuals. Columns 1-3 show women in the bottom decile of the first principal component have higher levels of labor market involvement before the birth of the first child (panel A), but face stronger negative effects of the first and the second child on their labor supply (panels B and C). The range of variation in the effect of children on labor supply is substantial. The effect of the first child on participation varies from - 0.519 for women in the bottom decile to 0.063 for women in the top decile, while the effect of the first child on the probability of working full time varies from -0.393 for women in the bottom decile to 0.049 for women in the top decile.

Delaying the first birth increases the level of labor market involvement before the first birth across the range of the first PC, but the increase in the level of labor market involvement is stronger for women with higher values of the first PC, who have relatively lower levels of labor market involvement (panel A). There are also significant differentials in the way in which timing of the first birth influences the effect of the first child on labor supply (panel B). For women in the bottom decile of the first PC, who have fewer children, are more likely to postpone the first birth, and face larger effects of the first child, delaying the first birth leads to larger reductions in the effects of the first child on the level of labor market involvement: the negative effects on participation and full time decrease by 0.080 and 0.018 , while the positive effect on the probability of working part time increases by 0.057 . The effect of postponing the first birth declines with the value of the first $\mathrm{PC}$, so that for women in the top decile, postponing the first birth increases the effect of the first child on labor supply, albeit by a very small margin.

For women in the bottom decile of the first PC, who space the births more closely and face larger effects of the second child, having the second birth after a longer interval increases the effect of the second child on the level of labor market involvement: the negative effects on participation and full time increase by roughly -0.117 , the negative effect on the probability of working full time part year by 0.033 , while reducing the negative effect on the probability of working part time by 0.033. The adverse effect of birth spacing declines with the value of the first PC so that for women in the top decile spacing of the second birth has very small effects.

Again the patterns of fertility dynamics are consistent with the individual-level differentials in the way in which timing and spacing influence the effects of children on labor supply: women who gain most from postponing the first birth but gain least from spacing the two births, have the first birth later in life and the second birth after a shorter interval.

The large degree of individual-level variation in completed fertility, timing of the first birth, and spacing of two births suggests unobserved characteristics are an important determinant of fertility dynamics. The correlation between these aspects of fertility indicates the presence of parity-specific heterogeneity (similar to results of Heckman and Walker, 1990, and Merrigan and St. Pierre, 1998) 
and that unobserved factors affecting the timing and spacing of births are correlated (similar to findings of Merrigan and St. Pierre, 1998, for Canada). The sign of the correlation is particularly interesting. Heckman and Walker (1990) expect serially correlated fecundity differences will affect all fertility transitions. This means individuals who have more children have the first birth sooner in life and the subsequent births at shorter intervals. They found this to be true for Hutterites but empirically irrelevant in Sweden. Merrigan and St. Pierre (1998), on the other hand, find that individual differences that affected second and third fertility transition are positively correlated but negatively (albeit weakly) correlated with those affecting the first transition. Our results - the fact that women who postpone the first birth have the second birth after a shorter interval - are consistent with their negative correlation between factors affecting the first and the second fertility transitions. The substantive implication of this finding is that individual differences in fecundity are not the main unobserved factor affecting fertility.

\section{Summary and Discussion}

We analyze the way in which the timing and spacing of births influences the effect of children on the level of labor market involvement of married women. The econometric framework we propose explicitly accounts for the endogeneity of labor market and fertility decisions, for the heterogeneity of the effect of children on labor supply, for the correlation between the effect of children and subsequent fertility decisions, and for the correlation of sequential labor market decisions. We use a model with four labor market states which provides an accurate description of the level of labor market involvement. We estimate our model using a 25-year panel, which follows women from their entry into the labor force and captures almost complete fertility histories.

Our results indicate that the timing and spacing of births are important determinants of the effect of children on women's labor supply. Delaying the first birth leads to higher levels of labor market involvement before the birth of the first child and reduces the negative effect of the first child on the level of labor market involvement. Both participation and the level of labor market involvement of women who participate increase with the time elapsed from the first birth. The effect of the second child on the level of labor market involvement declines with the spacing of the two births. The negative effect on participation decreases, while both the negative effect on the probability of working full time and the positive effect on the probability of working part time increase in absolute value with the spacing of the two births. This result indicates that as the time interval between the two births increases, more women, having returned to work, respond to the second birth by moving from full time to part time jobs.

Fertility decisions (the number of children, the timing of the first birth, and the spacing of two births) are correlated with labor market decisions across education and race. Women with higher education have fewer children, have the first birth later in life, and have the second birth at a shorter time interval after the first birth. They work more before the birth of the first child and face larger effects of children on their labor supply. Delaying the first birth has a stronger positive effect on the pre-birth level of labor market involvement of women with lower education, whose prenatal levels of labor market involvement are otherwise relatively lower. One the other hand, the reduction in the effect of the first child with the timing of the first birth and the reduction in the effect of the second child with the spacing of the two births are larger for women with higher education, who face larger effects of children on their labor supply.

Compared with black and Hispanic women, white women have fewer children, have the first birth later in life, and have the second birth at a shorter time interval after the first birth; they work more 
before the birth of the first child and face larger effects of children on their labor supply. Delaying the first birth has a stronger positive effect on the pre-birth level of labor market involvement of black and Hispanic women compared with white women. The reduction in the effect of the first child with the timing of the birth is larger for white women compared with black and Hispanic women. The reduction in the effect of the second child on participation with the spacing of the two births is larger for black and Hispanic women compared with white women.

Individual heterogeneity also plays an important role in the relationship between labor market and fertility decisions. After controlling for personal characteristics, fertility and labor market decisions vary significantly across individuals and individual differences are correlated. Women who have fewer children, have the first birth later in life, and subsequent births spaced more closely together, work more before the birth of the first child, and face larger effects of children on their labor supply. Delaying the first birth has a smaller positive effect on their pre-birth level of labor market involvement, but leads to larger reduction in the negative effect of the first child on their labor supply. Having the second birth after a longer time interval increases the effect of the second child on the level of labor market involvement.

The relationship between the timing and spacing of births and the effects of children on labor supply is important from a theoretical perspective. In dynamic models of fertility, optimal timing and spacing of births arise from the tension between the desire to have children earlier to enjoy them longer and the economic incentive to have them later when their opportunity cost is smaller. The most important component of the opportunity cost of children is their effect on women's career plans. Birth-related work interruptions are associated with forgone wages and investments in human capital and, possibly, with human capital depreciation. Postponing births allows consumption smoothing, which is important if borrowing against future income is not possible, and reduces the time horizon over which losses due to forgone human capital investments and human capital depreciation are incurred. Our results suggest that, in addition, postponing the first birth and spacing subsequent births reduces the effect of children on labor supply, which further lowers losses due to forgone wages, forgone the human capital investments, and human capital depreciation.

The postponement of childbearing to later ages has been linked to the decline in completed fertility in developed in countries, in many cases way below the replacement levels. Our results show that delaying the first birth does reduce an important component of the opportunity cost of children - their effect on mother's labor supply. This highlights an important inherent difficulty in designing effective public policy aimed at increasing fertility. In order to have an impact on fertility the policy has to change the behavior of women who do not plan on having children or who plan on having very few children. That is, the policies will have to impact the behavior of infra-marginal women. To be effective in raising the fertility of women with stronger preferences for market work, benefits would have to be correlated with individual opportunity costs. An example of policy that satisfies this requirement is paid maternity leave with the payments being an increasing function of wage and previous work experience, which offers benefits that are commensurate with individual opportunity costs of children. This policy will would lead to higher fertility by lowering the cost of children among women who have strong labor market attachments. On the other hand, it strengthens the incentive to postpone childbearing and could potentially lead to lower completed fertility.

\section{Acknowledgement}

The estimation has been carried out on the Athena computer cluster of the CUNY High Performance Computing Facility at the College of Staten Island and we would like to thank Michael 
Kress and the staff of HPC for their support. 


\section{References}

Aaronson, D. (1998), "Using Sibling Data to Estimate the IMpact of Neighborhoods on Children's Educational Outcomes," Journal of Human Resources, 33, 915-946.

Altonji, J. G. and Blank, R. M., (1999) "Race and Gender in the Labor Market," in Handbook of Labor Economics, eds. O. Ashenfelter and D. Card, North-Holland, Amsterdam, 3143-3259.

Angrist, J. D., and Evans, W. N. (1998), "Children and Their Parents' Labor Supply: Evidence from Exogenous Variation is Family Size," The American Economic Review, 80, 450-477.

Axinn, W. G., Clarkberg, M. E. and Thornton, A. (1994), "Family Influences on Family Size Preferences," Demography, 31, 65-79.

Becker, G. (1965), "A Theory of the Allocation of Time," Economic Journal 75, 493-517.

Bell, D., (1974), "Why Participation Rates of Black and White Wives Differ, " Journal of Human Resources, 9, 465-479.

Björklund, A. and Moffitt, R. (1987), "The Estimation of Wage and Welfare Gains in Self-Selection Models." Review of Economics and Statistics 69, 42-49.

Blau, F. D. (1998), "Trends in the Well-Being of American Women (1970-1995)," Journal of Economic Literature, 36, 112-165.

Blau, F. D., Ferber, M. A., and Winkler, A. E. (1998), "The Economics of Women, Men, and Work," Prentice Hall, Englewood Cliffs, New Jersey.

Brooks, S. P., and Gelman, A. (1998), "General Methods for Monitoring Convergence of Iterative Simulations," Journal of Computational and Graphical Statistics, 7, 434-455.

Brooks-Gunn, J., Han, Wen-Jui, and Waldfogel, J. (2002), "Maternal Employment and Child Cognitive Outcomes in the First Three Years of Life: the NICHD Study of Early Child Care," Child Development, vol. 73(4), 1052-1072.

Browning, M. (1992), "Children and Household Economic Behavior," Journal of Economic Literature, 30, 1434-1475.

Carneiro, P., Heckman, J., and Vytlacil, E. (2001), "Estimating the Rate of Return to Schooling when It Varies among Individuals," Economic Journal Lecture, Royal Economic Society.

Carrasco, R. (2001), "Binary Choice with Binary Endogenous Regressors in Panel Data: Estimating the Effect of Fertility on Female Labor Force Participation," Journal of Business and Economic Statistics, 19, 385-394.

Cigno, A. (1991), Economics of the Family. Clarendon Press, Oxford.

Cigno, A. and Ermisch, J. (1989), "A Microeconomic Analysis of the Timing of Births," European Economic Review 33, 737-760.

Folbre, N. (1994), "Children as Public Goods," American Economic Review, 84, 86-90. 
Geweke, J., Keane, M. P., and Runkle, D. E. (1997), "Statistical Inference in the Multinomial Multiperiod Probit Model," Journal of Econometrics, 80, 125-165.

Gilks, W. R., Wang, C. C., Yvonnet B., and Coursaget, P. (1993), "Random-Effects Models for Longitudinal Data Using Gibbs Sampling," Biometrica, 49, 441-453.

Gronau, R. (1973), "The Effect of Children on the Housewife's Value of Time," Journal of Political Economy, 81, No. 2, Part 2: New Economic Approaches to Fertility, S168-S199.

Gronau, R. (1977), "Leisure, Home Production, and Work - the Theory of the Allocation of Time Revisited," Journal of Political Economy, 85, 1099-1123.

Gustafsson, S. (2001), "Optimal Age at Motherhood. Theoretical and Empirical Considerations on Postponement of Maternity in Europe," Journal of Population Economics 14, 225-247.

Gustafsson, S. and Wetzels, C. (1997), "Paid Careers and the Timing and Spacing of Births in Germany, Great Britain and Sweden'" in Time Allocations and Gender. The relationship Beteween Paid Labour and Household Work, eds Tijdens K, Doorne-Huiskes A, van, Willemsen T., Tilburg University Press, Tilburg.

Gustafsson, S. and Wetzels, C. (2000), "Optimal Age at Giving Birth: Germany, Great Britain, the Netherlands and Sweden," in Gender and the Labour Market. Econometric Evidence on Obstacles in Achieving Gender Equality, eds Gustafsson S., Meulders, D., MacMillan, London.

Happel, S., Hill, J., and Low, S. (1984), "An Economic Analysis of the Timing of Childbirth", Population Studies 38: 299-311.

Haurin, R. J, and Mott, F. L. (1990), "Adolescent Sexual Activity in the Family Context: The Impact of Older Siblings," Demography, 27, 537-557.

Heckman, J. J. (1980), "Sample Selection Bias as a Specification Error: An Application to Estimation of Female Labor Supply Functions," in Female Labor Supply, ed. J. Smith, Princeton University Press, Princeton, NJ, 206-248.

Heckman J. J., Hotz, J., and Walker, J. (1985), "New evidence on the timing and spacing of births," American Economic Review 75, 179-184.

Heckman, J. and Robb, R. (1985), "Alternative Methods for Evaluating the Impact of Interventions," in Longitudinal Analysis of Labor Market Data, eds J. Heckman and B. Singer. Cambridge University Press.

Heckman J. J., Walker, J. (1990), "The relationship between wages and income and the timing and spacing of births: evidence from Swedish longitudinal data," Econometrica 52,1411-1441.

Heckman, J. and R. Willis (1975), "Estimation of a Dtochastic Model of Reproduction: An Econometric Approach", in: N. Terleckyj, ed., Household production and consumption (Columbia University Press, New York).

Heckman, J. J., and Willis, R. J. (1977), "A Beta-logistic Model for the Analysis of Sequential Labor Force Participation by Married Women," The Journal of Political Economy, 85, 27-58. 
Heckman, J. and Vytlacil, E. (1999), "Local Instrumental Variables and Latent Variable Models for Identifying and Bounding Treatment Effects," Proceedings of the National Academy of Sciences 96 (April). 4730-4734.

Heckman, J. and Vytlacil, E. (2000), "Causal Parameters, Structural Equations, Treatment Effects and Randomized Evaluations of Social Programs." Mimeo. UC and Stanford.

Heckman, J. and Vytlacil, E. (2001), "Policy-Relevant Treatment Effects." American Economic Review 91 (May), 107-111.

Hill, C. R. and Stafford, F. P. (1980)" Parental Care of Children: Time Diary Estimates of Quantity, Predictability, and Variety," Journal of Human Resources, 15, 219-239.

Hogan, D. and Kitagawa, E. (1985), "The Impact of Social Status, Family Structure, and Neighborhood no the Fertility of Black Adolescents, " American Journal of Sociology, 90, 825-855.

Hotz, V. J., Klerman, J. A., and Willis R. J. (1997) "The Economics of Fertility in Developed Countries," in Rosenzweig, M. and Stark, O. eds., Handbook of Population and Family Economics, Elsevier, Amsterdam, 275-347.

Hotz, V.J. and Miller, R. (1988), "An Empirical Analysis of Life Cycle Fertility and Female Labor Supply," Econometrica 56, 91-118.

Hyslop, D., (1999), "State Dependence, Serial Correlation and Heterogeneity in Intertemporal Labor Force Participation of Married Women," Econometrica, 67, 1255-1294.

Imbens, G. and Angrist, J. (1994), "Identification and Estimation of Local Average Treatment Effects." Econometrica 62, 467-76.

Joshi, H. (1990) The Cash Alternatives to Childbearing: An Approach to Estimation Using British Data, Population Studies 44, 41:60.

Klerman, J. A. and Leibowitz, A. (1994), "The Work-Employment Distinction among New Mothers," Journal of Human Resources, 29, 277-303.

Lehrer, E. L. (1992), "The Impact of Children on Married Women's Labor Supply: Black-White Differentials Revisited, "Journal of Human Resources, 27, 422-444.

Leibowitz, A. (1974), "Education and the Allocation of Women's Time." in Education, Income, and Human Behavior, ed. F. Thomas Juster McGraw Hill, New York, 171-197.

Leibowitz, A., Klerman, J. A., and Waite, L. (1992), "Employment of New Mothers and Child Care Choice: Differences by Children's Age," Journal of Human Resources, 27, 112-123.

McCulloch, R., and Rossi, P. (1994), "An Exact Analysis of the Multinomial Probit Model," Jornal of Econometrics, 64, 207-240.

Merrigan, P. and St. Pierre, Y. (1998) "An econometric and Neoclassical Analysis of the Timing and Spacing of Births in Canada from 1950 to 1990" Journal of Population Economics, 11, $29-51$ 
Michael, R. (1973), "Education and the Derived Demand for Children." Journal of Political Economy, 81, No. 2, Part 2: New Economic Approaches to Fertility, S128-S164.

Miller, C. and Xiao, J. J. (1999) "Effects of Birth Spacing and Timing on Mothers' LFP" Atlantic Economic Journal, 27, 410-421.

Mincer, J. (1962), "Labor Force Participation of Married Women," in Aspects of Labor Economics, ed. H.G. Lewis, Princeton University Press, Princeton, NJ, 63-105.

Mincer, J. and Polachek, S. (1974), "Family Investments in Human Capital: Earnings of Women," Journal of Political Economy, 82, No. 2, Part 2: Marriage, Family Human Capital, and Fertility, S76-S108

Mincer, J. and Polachek, S. (1978), "An Exchange: The Theory of Human Capital and the Earnings of Women: Women's Earnings Reexamined," Journal of Human Resources, 13, 118-134.

Moffitt, R. (1984), "Optimal Life-Cycle Profiles of Fertility and Labor Supply", Research in Population Economics 5, 29-50.

Moffitt, R. (2005), "The Effect of Transfer Programs on Labor Supply in the Presence of Preference Heterogeneity and Variable Takeup," Mimeo, Johns Hopkins University

Montgomery, M. R. and Casterline, J. B. (1996), "Social Learning, Social Influence, and New Models of Fertility," Population and Development Review, 22, Supplement: Fertility in the United States: New Patterns, New Theories, 151-175.

Montgomery, M. and Trussell, J. (1986), "Models of Marital Status and Childbearing", in: O. Ashenfelter and R. Layard, eds., Handbook of Labor Economics (North-Holland, Amsterdam), 205-271.

Nakamura, A. and Nakamura, M. (1992), "The Econometrics of Female Labor Supply and Children," Econometric Reviews, 11, 1-71.

Newman, J. (1983), "Economic Analysis of the Spacing of Births," American Economic Review, 73, 33-37.

Newman, J. (1988), "A Stochastic Dynamic Model of Fertility", Research in Population Economics, 6, 41-68.

Newman J.L., McCulloch, D. (1984), "A hazard rate approach to the timing of births, " Econometrica 52, 939-961.

Rodgers, J. L. and Rowe, D. C. (1988), "Influence of Siblings on Adolescent Sexual Behavior," Developmental Psychology, 24, 722-728.

Rosenzweig, M. R., and Wolpin, K. I. (1980), "Life-Cycle Labor Supply and Fertility: Causal Inference from Household Models," The Journal of Political Economy, 88, 328-348.

Rowe, D. C., Rodgers, J. L., Meseck-Bushey, S., and St. John, C., (1989), "Sexual Behavior and Nonsexual Deviance: A Sibling Study of Their Relationship," Developmental Psychology, 25: 61-69. 
Ruhm, C. (2004), "Parental Employment and Child Cognitive Development," Journal of Human Resources, vol. 39(1), 155-92.

Tasiran 1995. Fertility Dynamics Spacing and Timing of Births in Sweeden and the United States. Elsevier.

Shapiro, D. and Mott, F. L. (1994), "Long-Term Employment and Earnings of Women in Relation to Employment Behavior Surrounding the First Birth," Journal of Human Resources 29, 248-275.

Troske, K.R., Voicu, A., (2009a) "Joint estimation of sequential labor force participation and fertility decisions using Markov chain Monte Carlo techniques," Labour Economics, doi:10.1016/ j.labeco.2009.07.003.

Troske, K.R., Voicu, A., (2009b) "The Effect of Children on the Level of Labor Market Involvement of Married Women: What is the Role of Education?" IZA Discussion Paper No. 4074.

Waldfogel, J., Han, Wen-Jui and Brooks-Gunn, J. (2002), "The Effects of Early Maternal Employment on Child Cognitive Development," Demography, vol. 39(2), 369-92.

Walker, J. (1995), "The Effect of Public Policies on Recent Swedish Fertility Behavior", Journal of Population Economics, 8, 223-251.

Willis, R. (1973), "A New Approach to the Economic Theory of Fertility Behavior." Journal of Political Economy, 81, No. 2, Part 2: New Economic Approaches to Fertility, S14-S64.

Wolpin, K. (1984), "An Estimable Dynamic Stochastic Model of Fertility and Child Mortality", Journal of Political Economy, 92, 852-874. 
Figure 1. Timing and spacing of births

A. Timing of the first birth from marriage

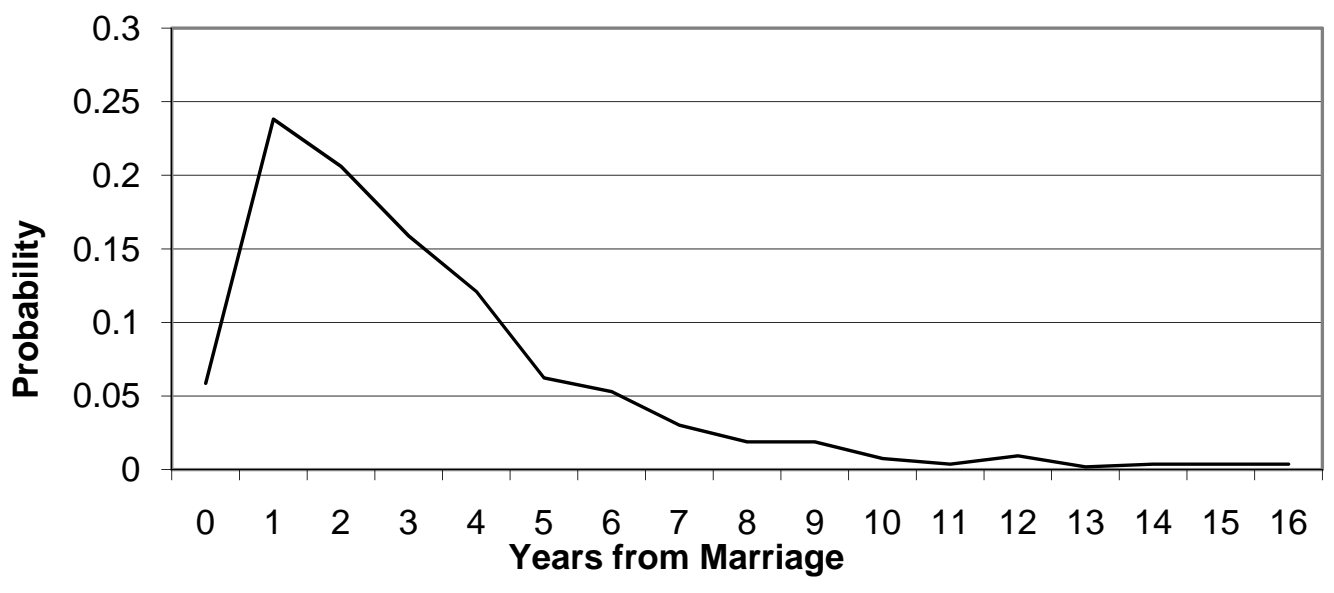

B. Spacing of two births

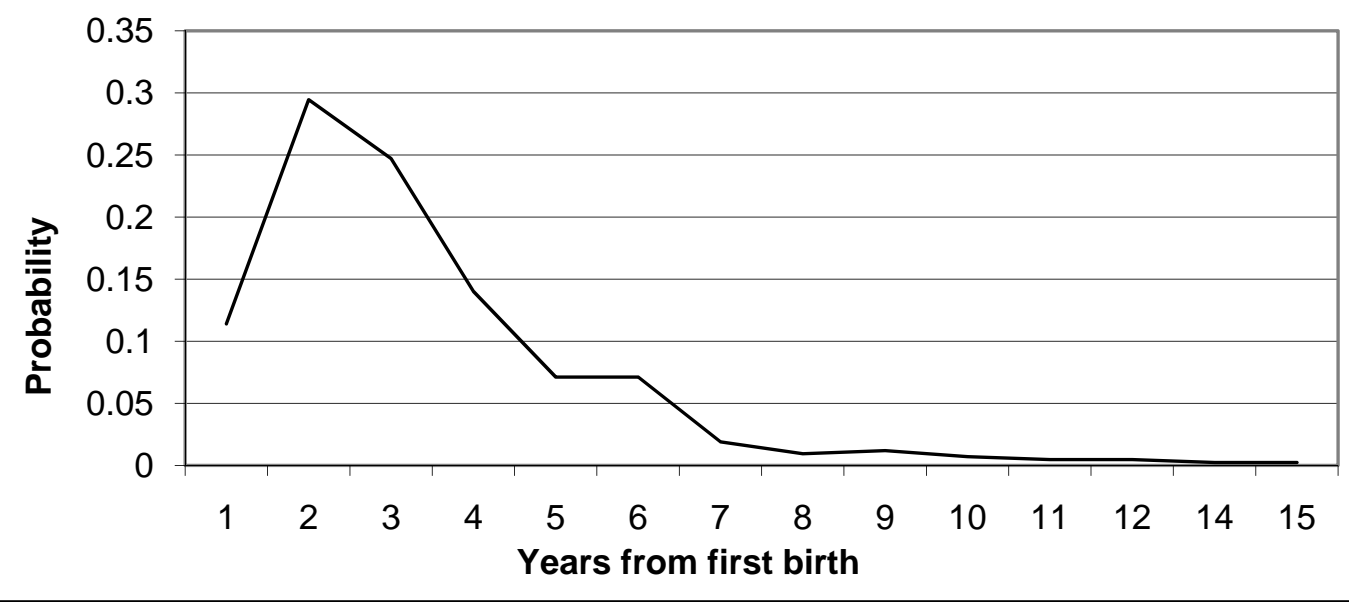

C. Spacing of three births

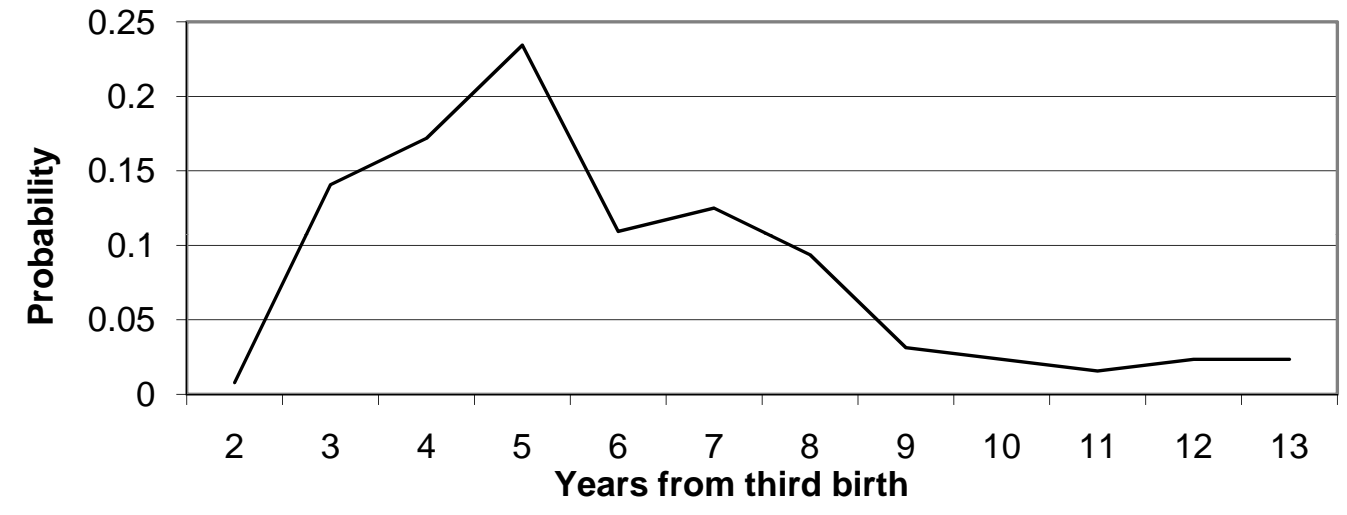


Figure 2. Timing and spacing of births, by the number of children

A. Timing of the first birth from marriage

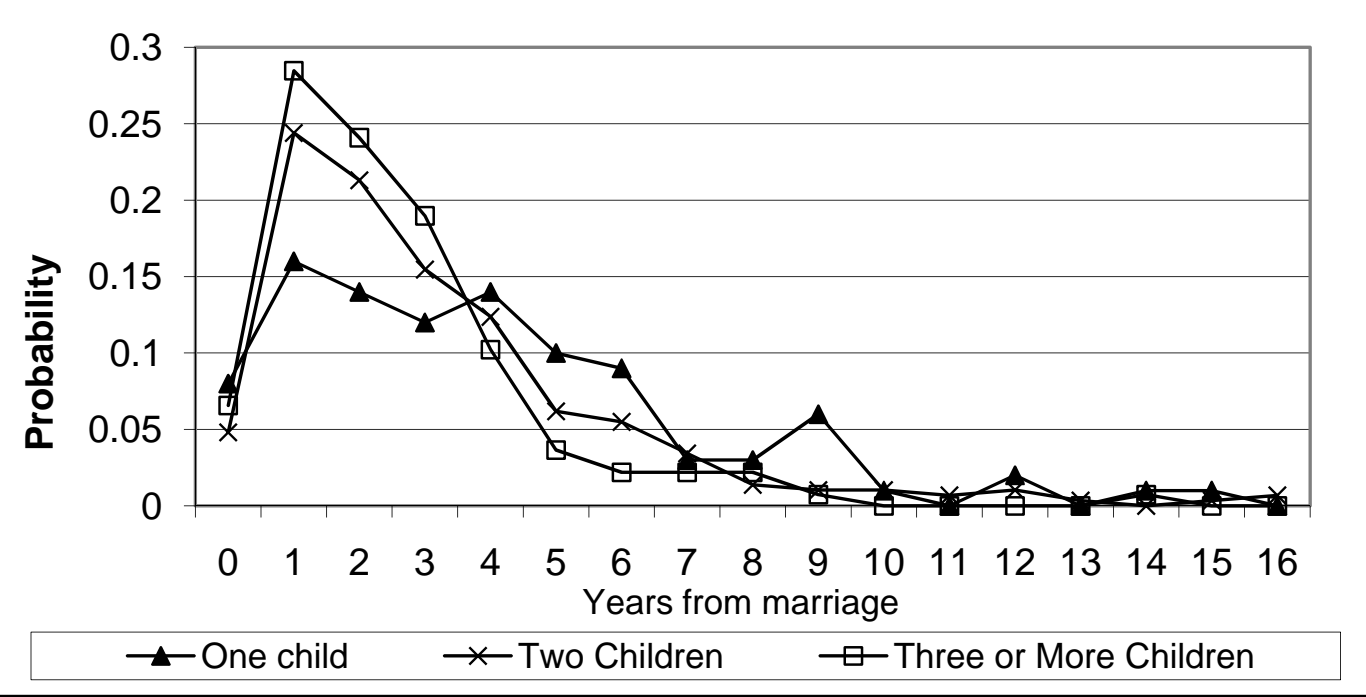

B. Spacing of the first two births

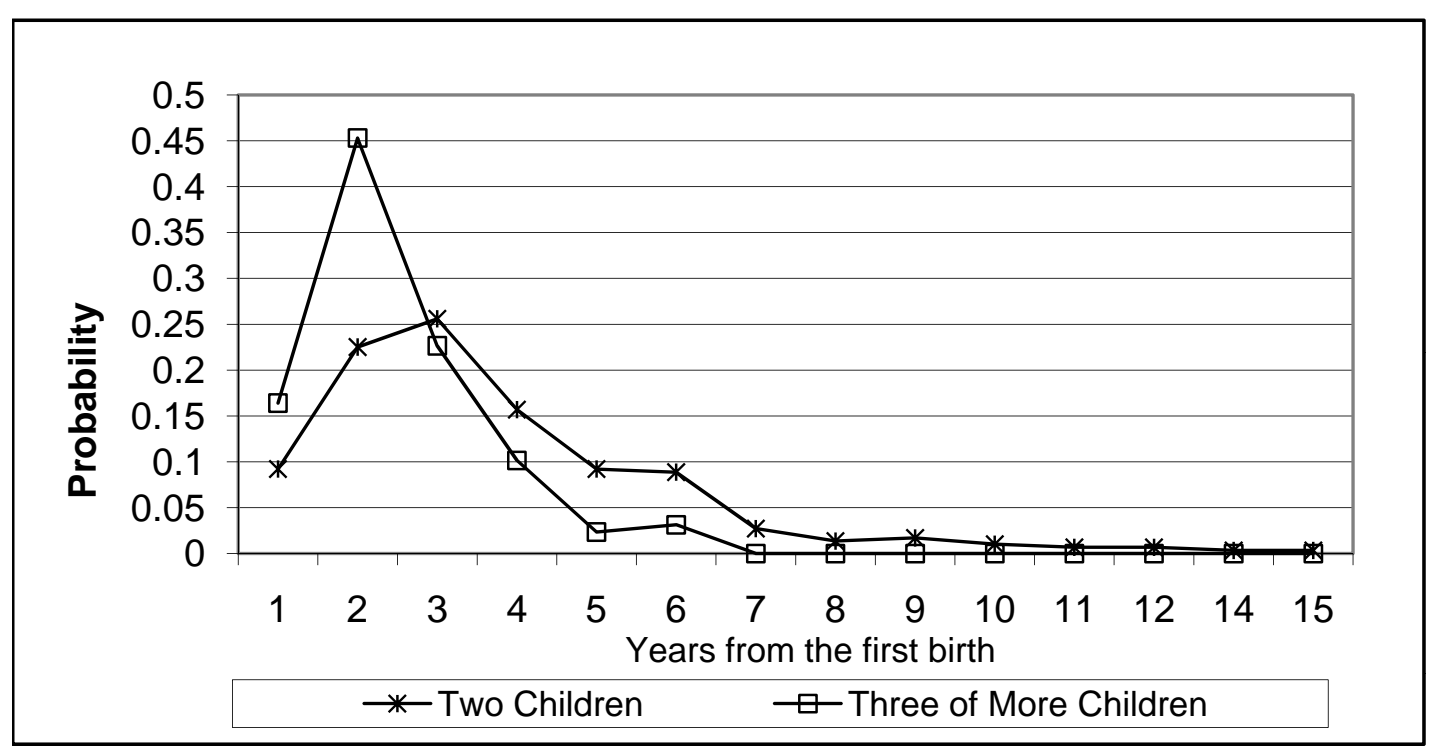


Figure 3. Number of children, timing of the first birth, and spacing of two births. White women with 12 years of education

\section{A. Number of children}

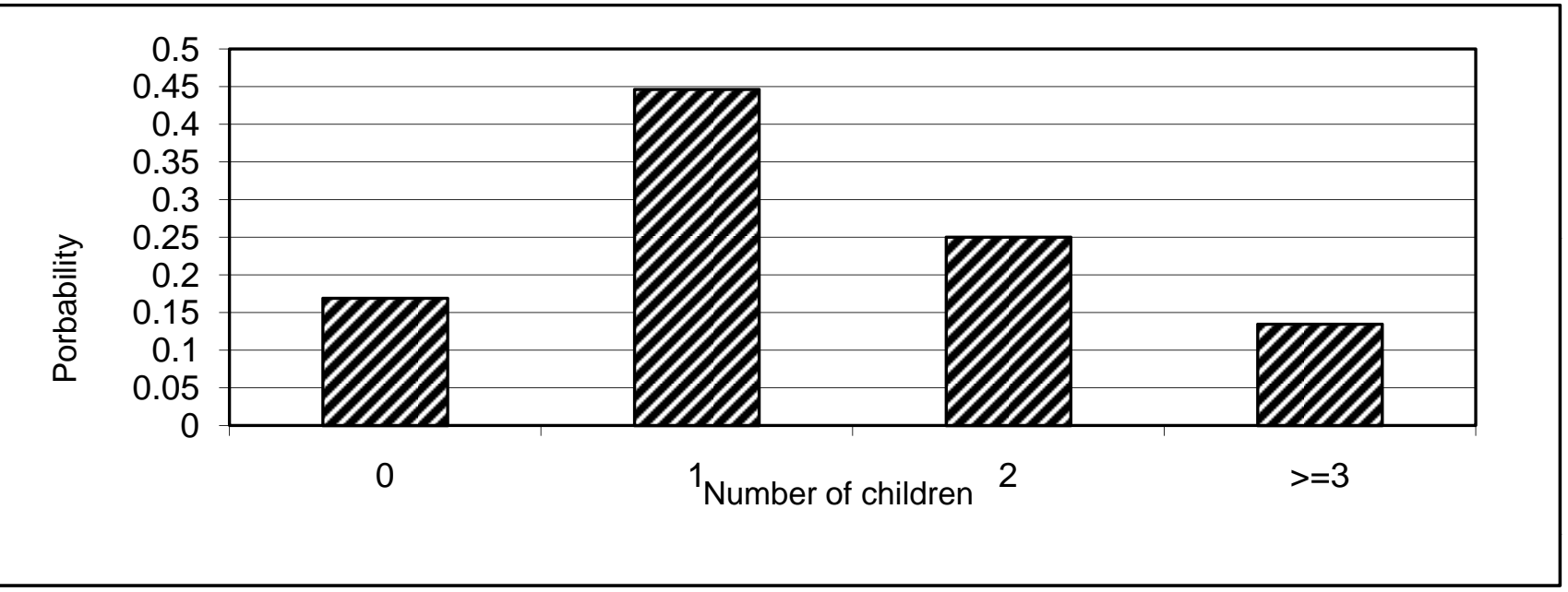

B. Timing of the first birth

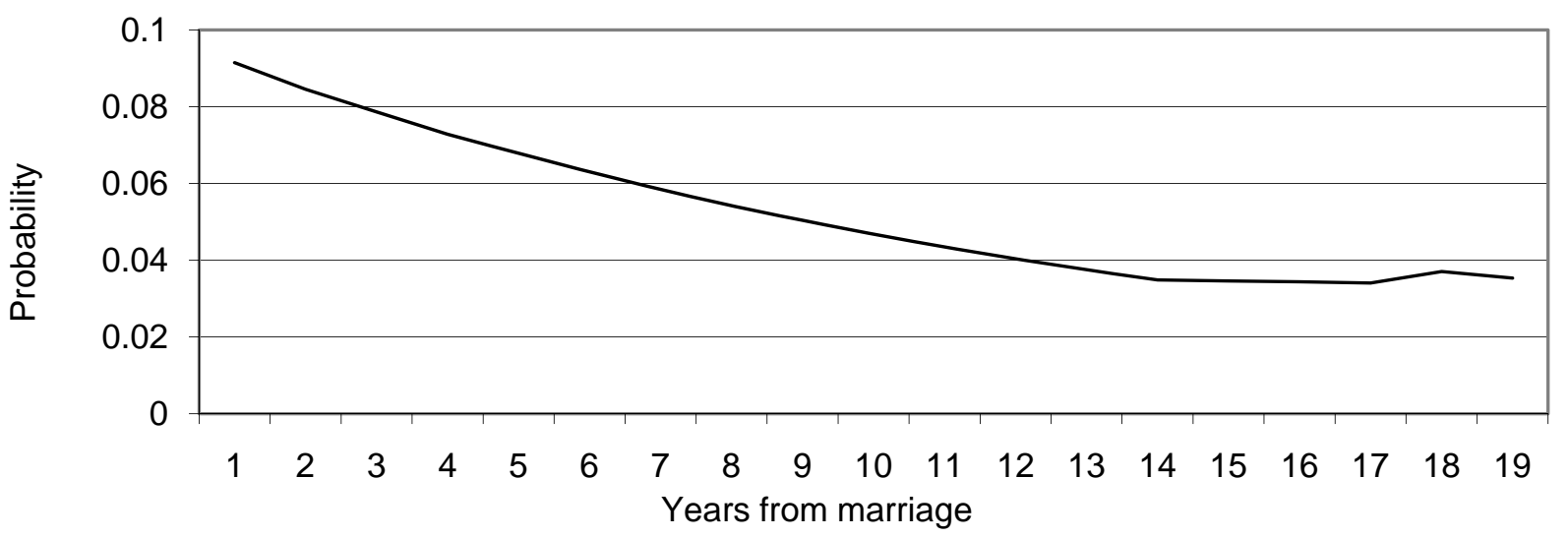

C. Spacing of two births

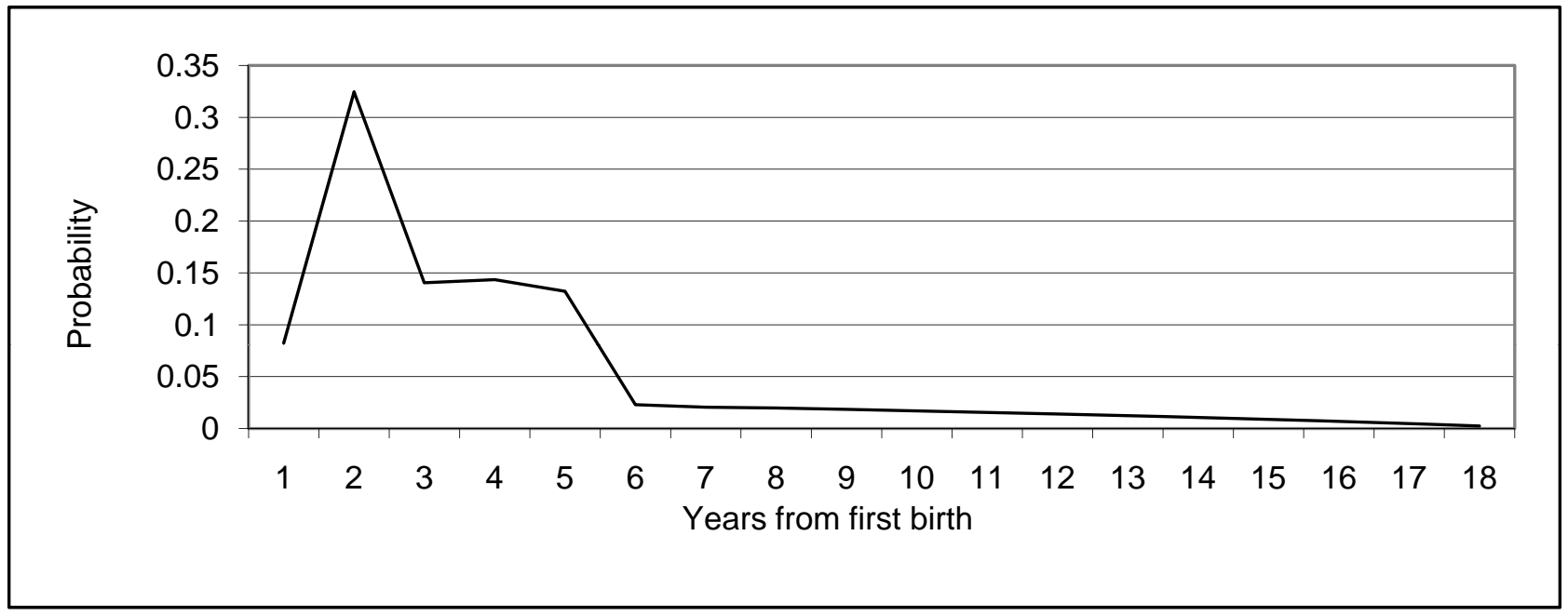


Figure 4. The Level of Labor Market Involvement in the Year before the First Birth, by the Timing of the First Birth Simulation Results

Participation

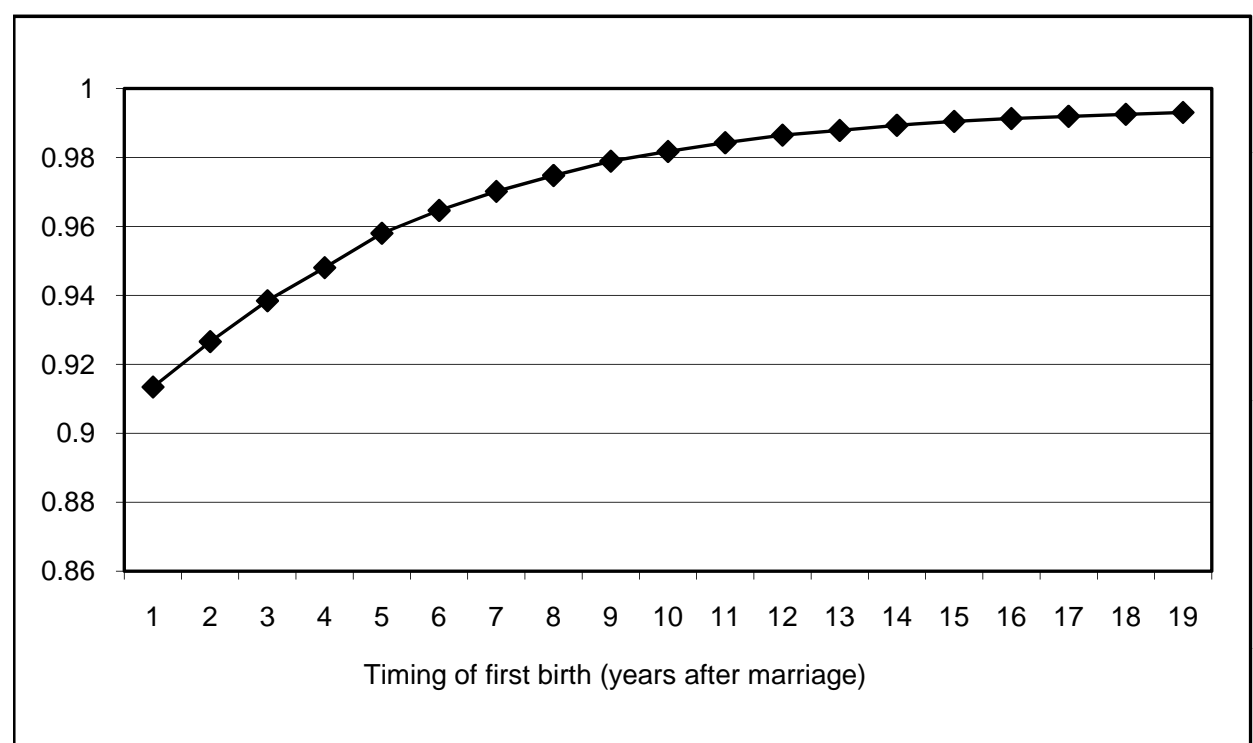

Full Time Part Year

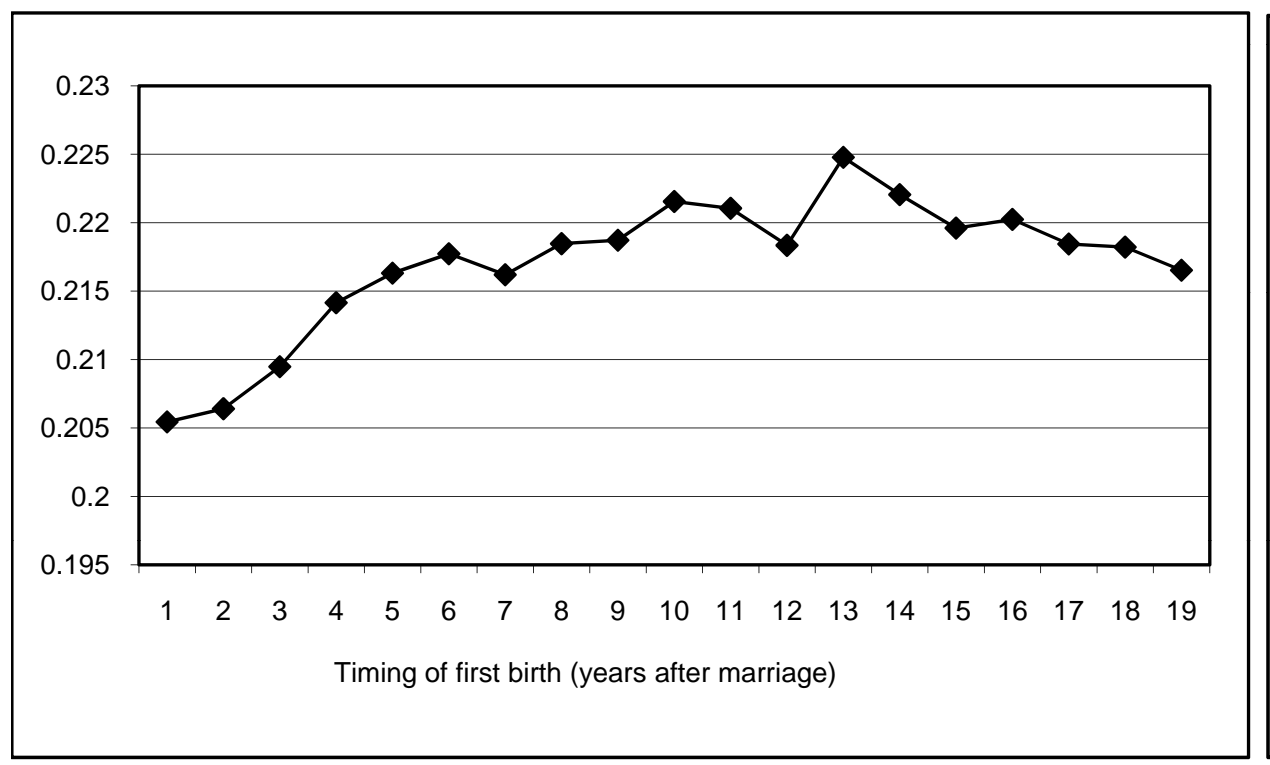

Full Time Part Year

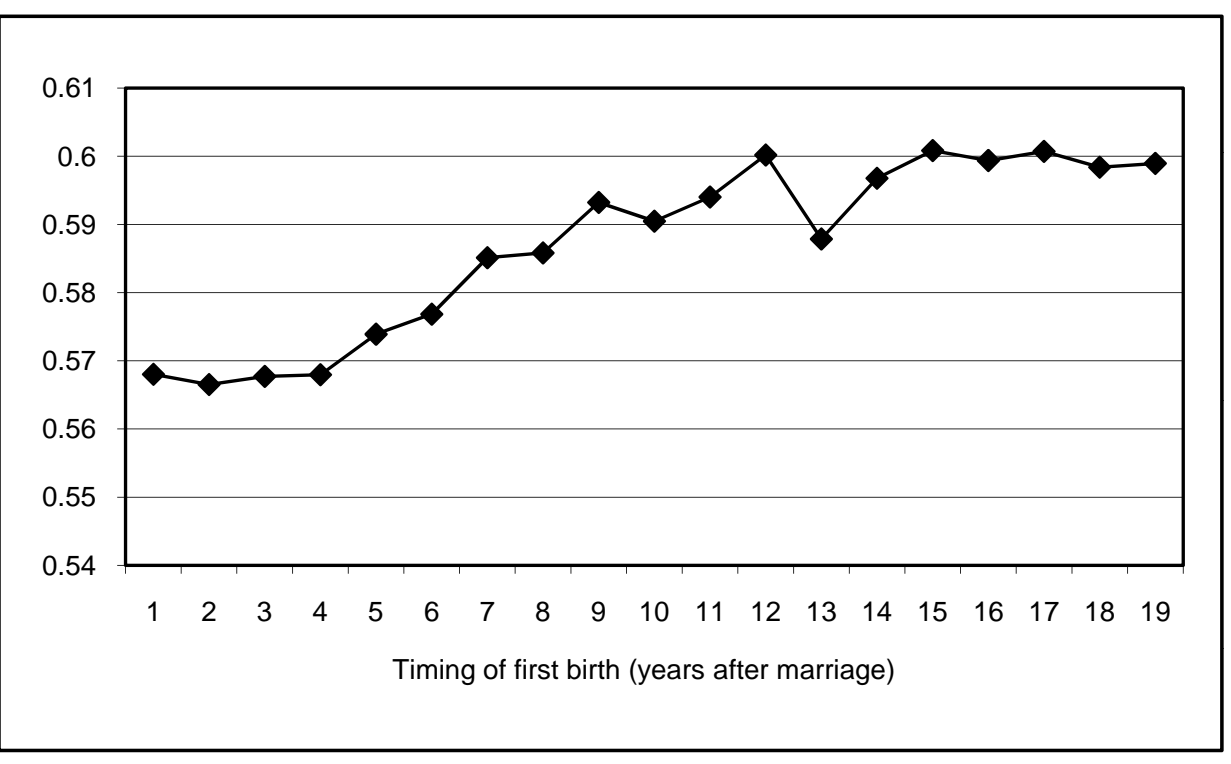

\section{Part Time}

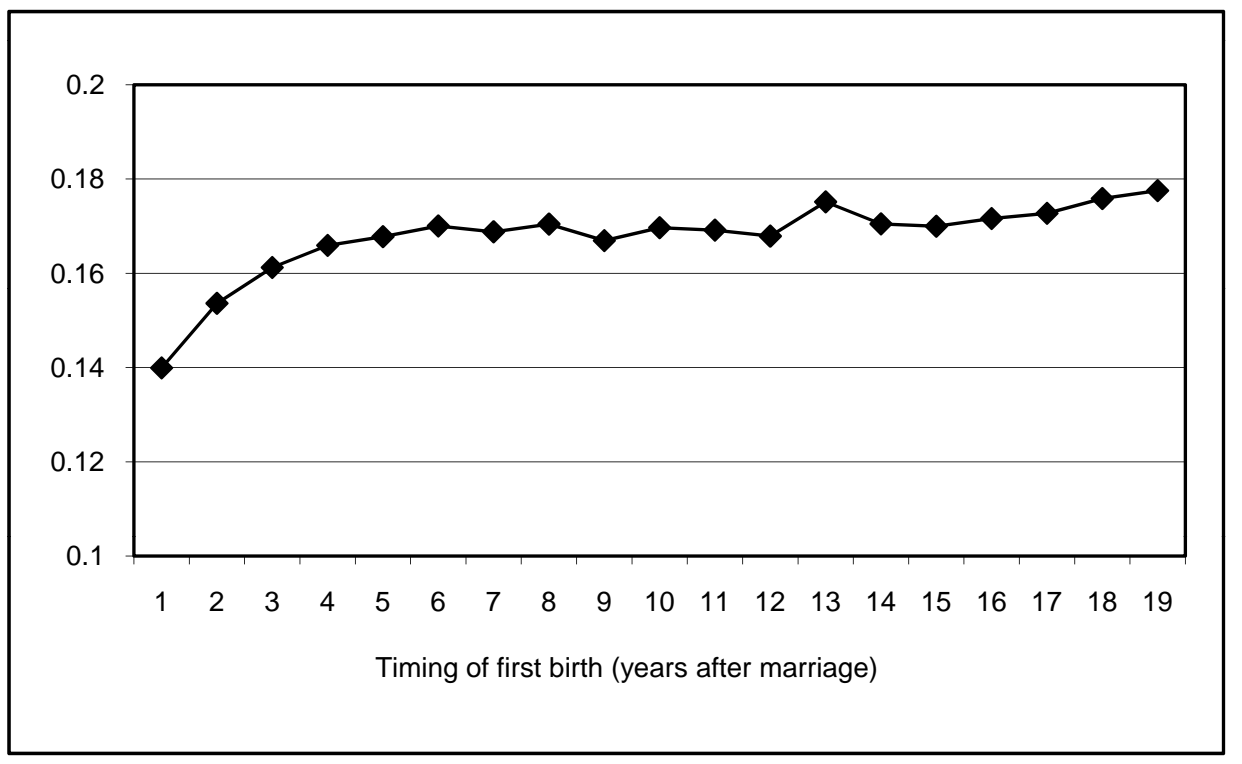


Figure 5. The Effect of the First Child on the Level of Labor Market Involvement. Education White Women with 12 years of Education

A. The effect of a child born in year 3

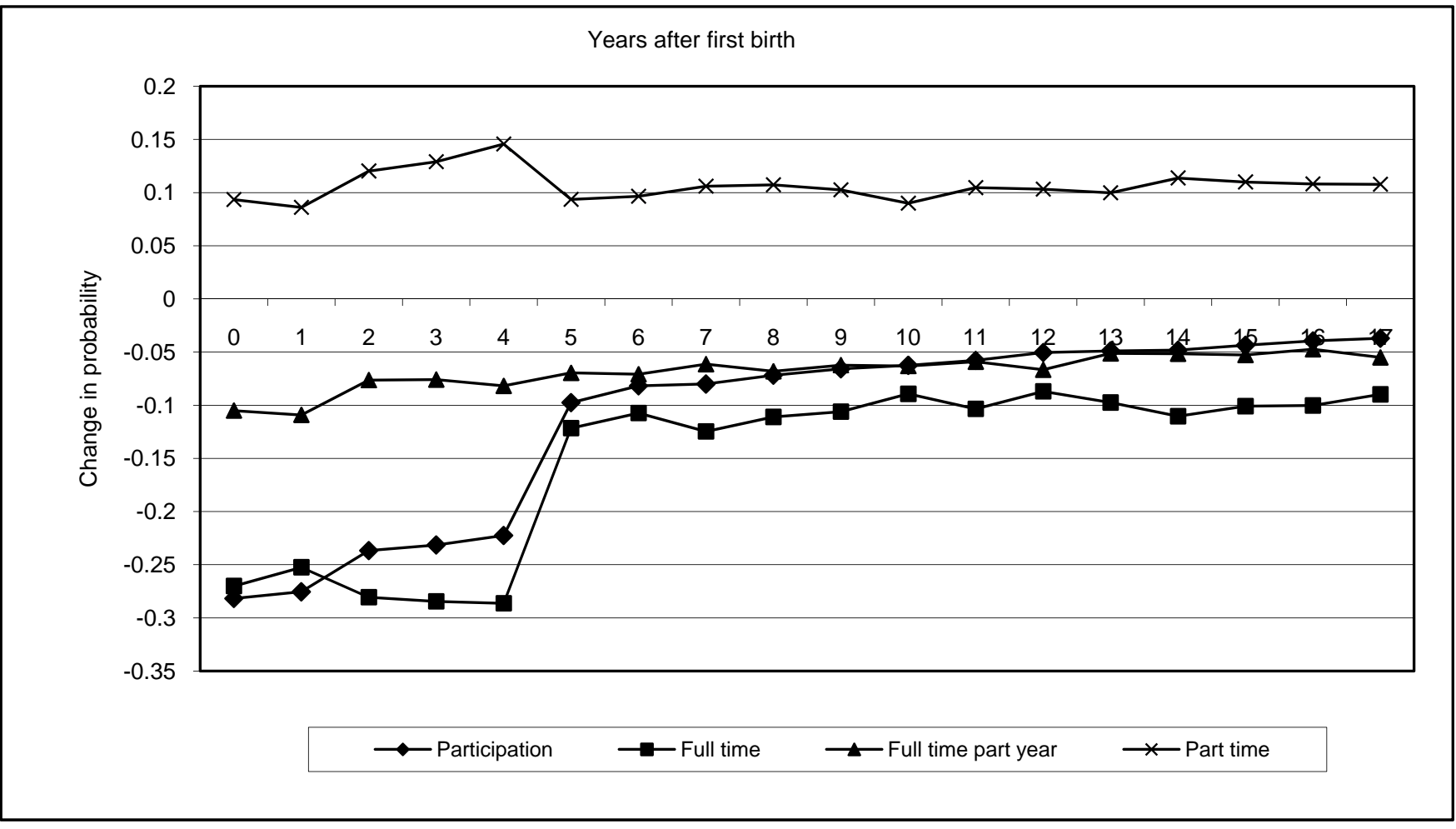

B. The effect of the child in the year of birth, by the timing of the first birth

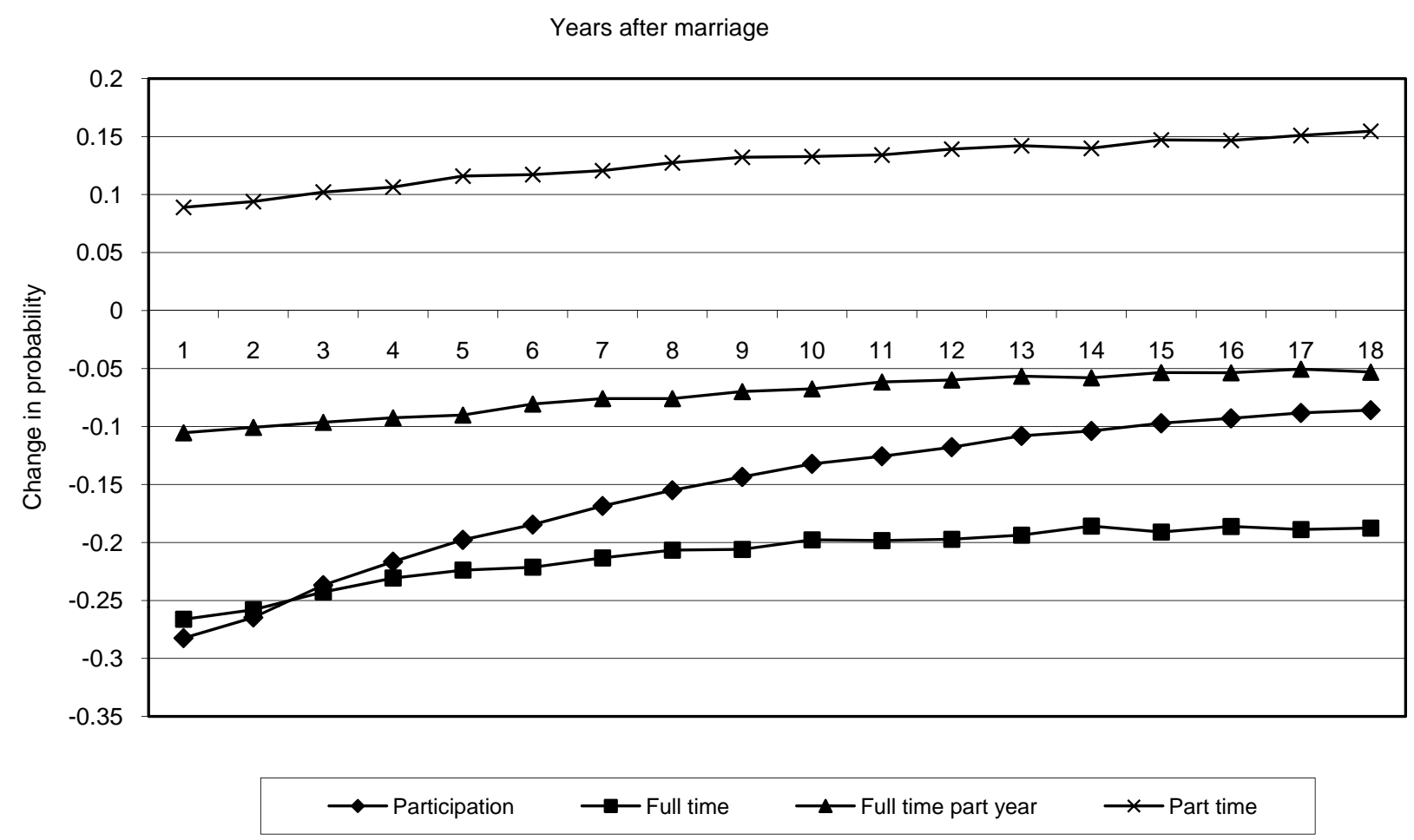


Figure 6. The Effect of the First Child on the Level of Labor Market Involvement by the Timing of the First Birth

\section{Participation}

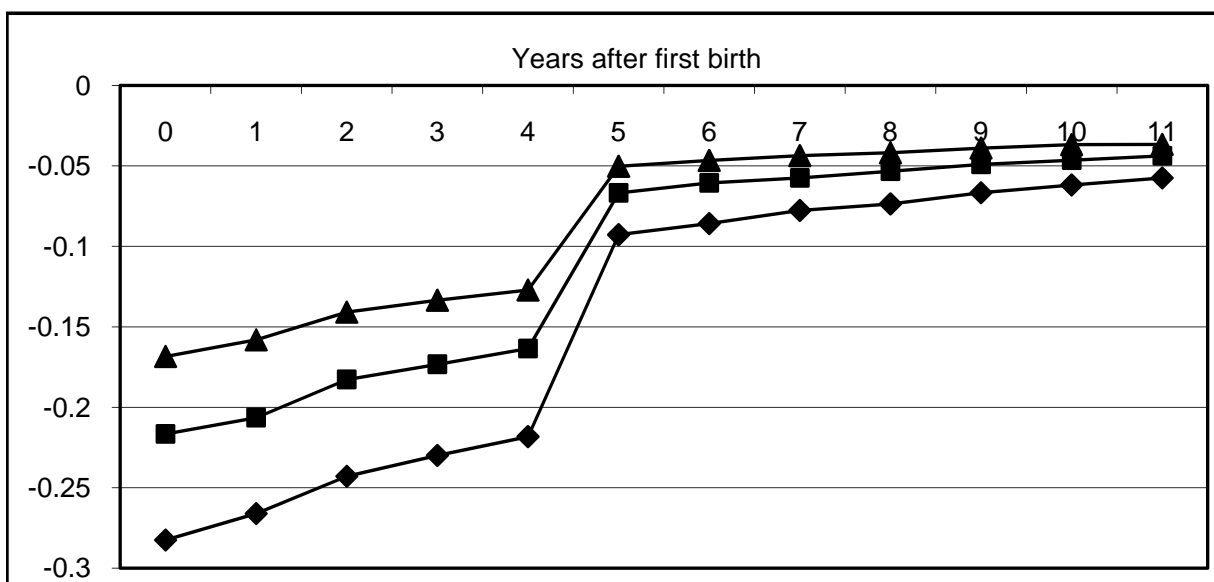

$\longrightarrow$ Marriage yr. +1

$\rightarrow-$ Marriage yr. +4

$\longrightarrow$ Marriage yr. +7
Full Time Part Year

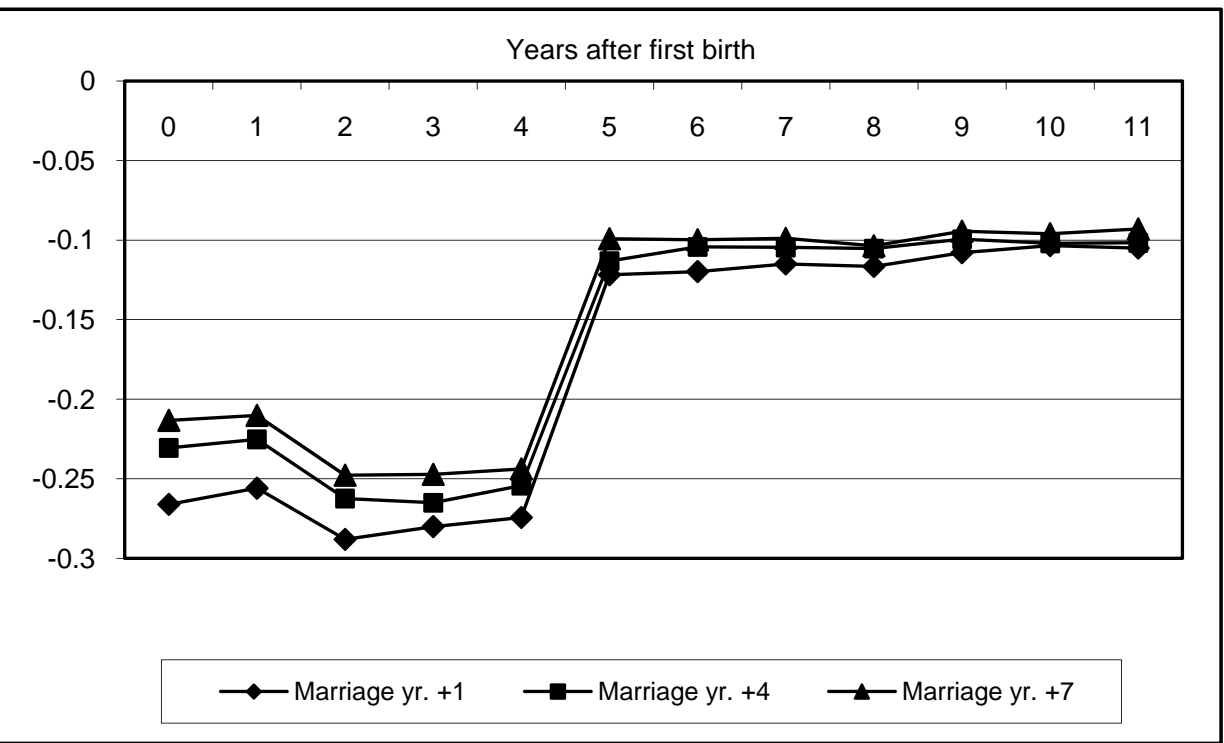

Part Time

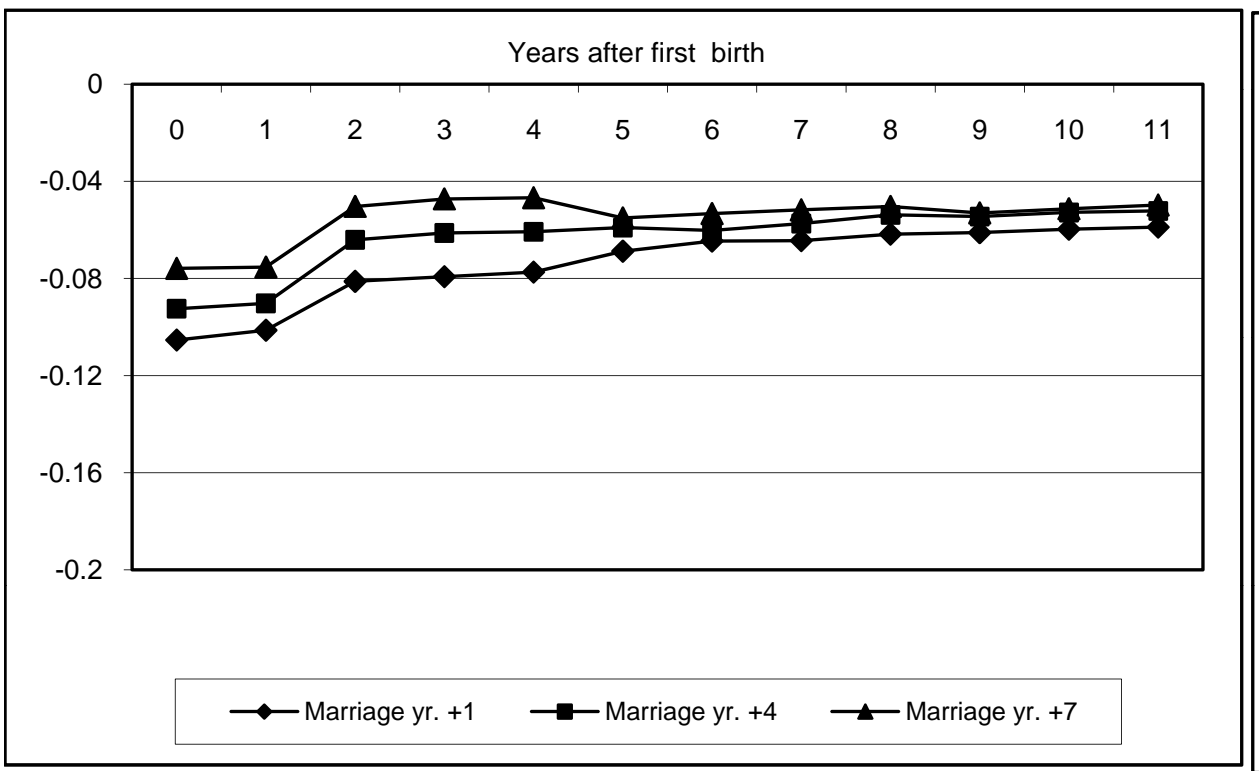

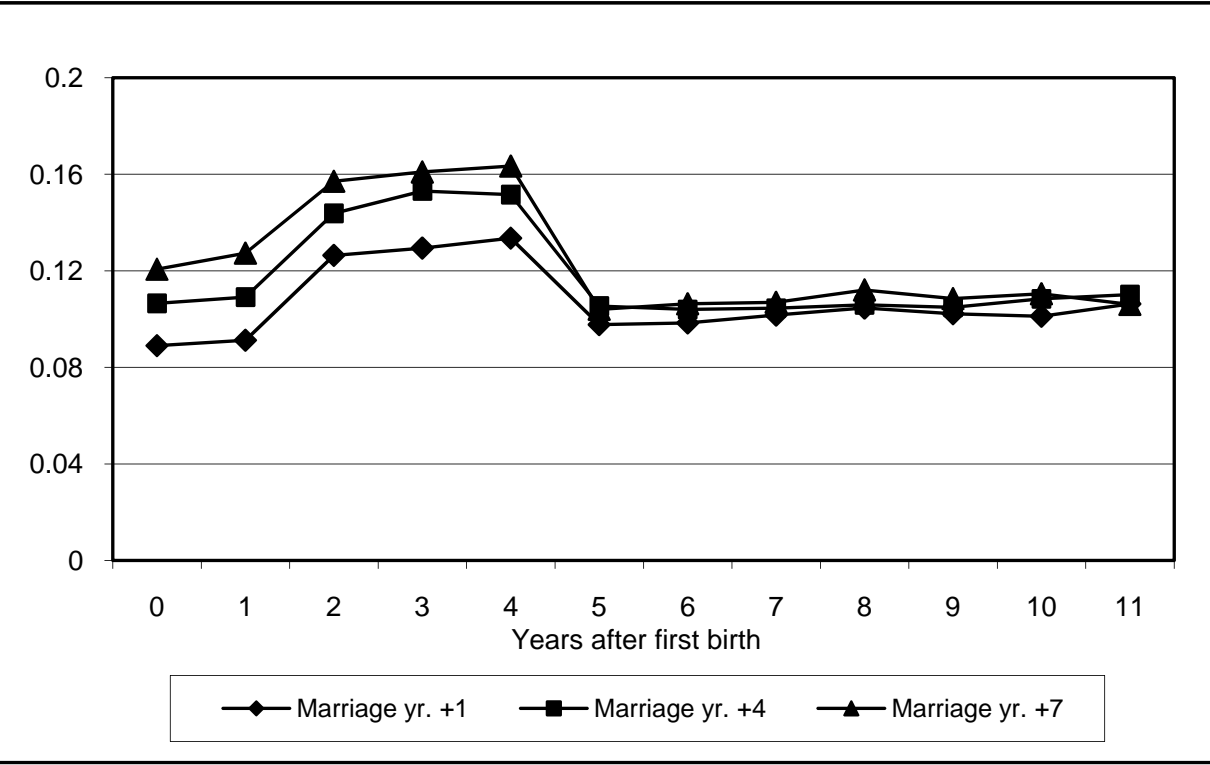


Figure 7. The Effect of Two Children on the Level of Labor Market Involvement

Participation

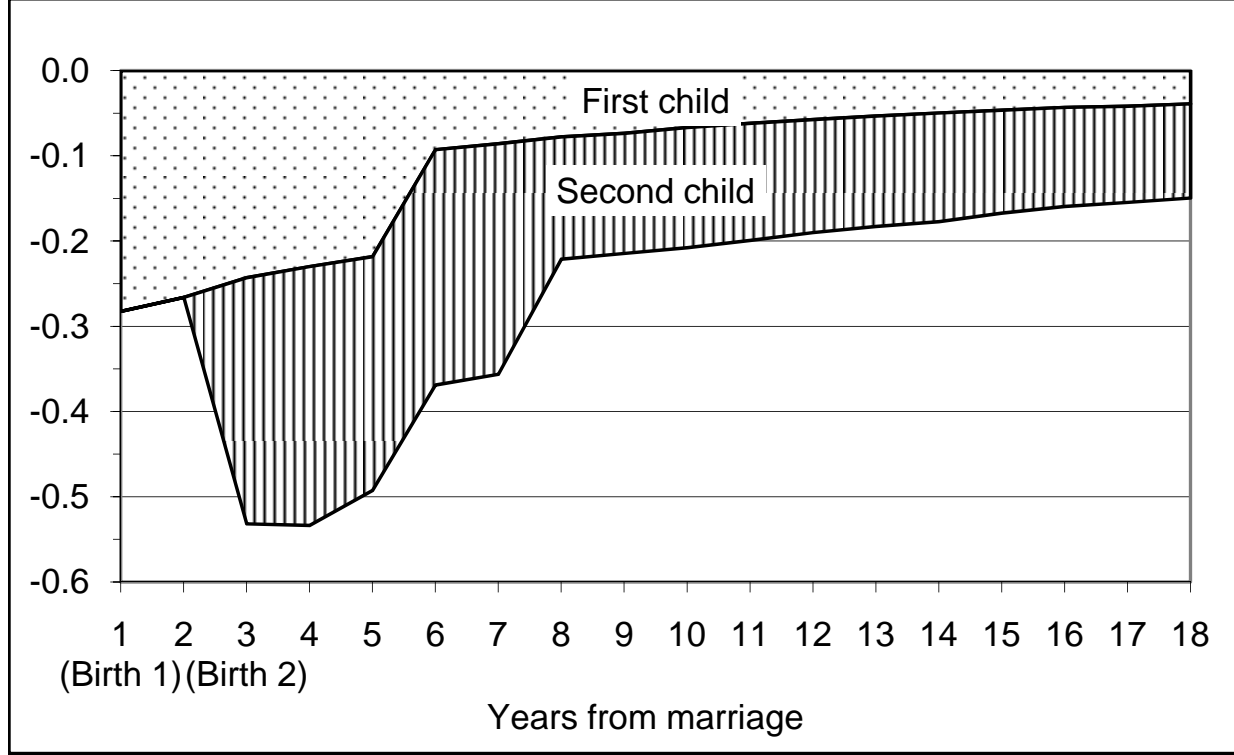

Full Time Part Year

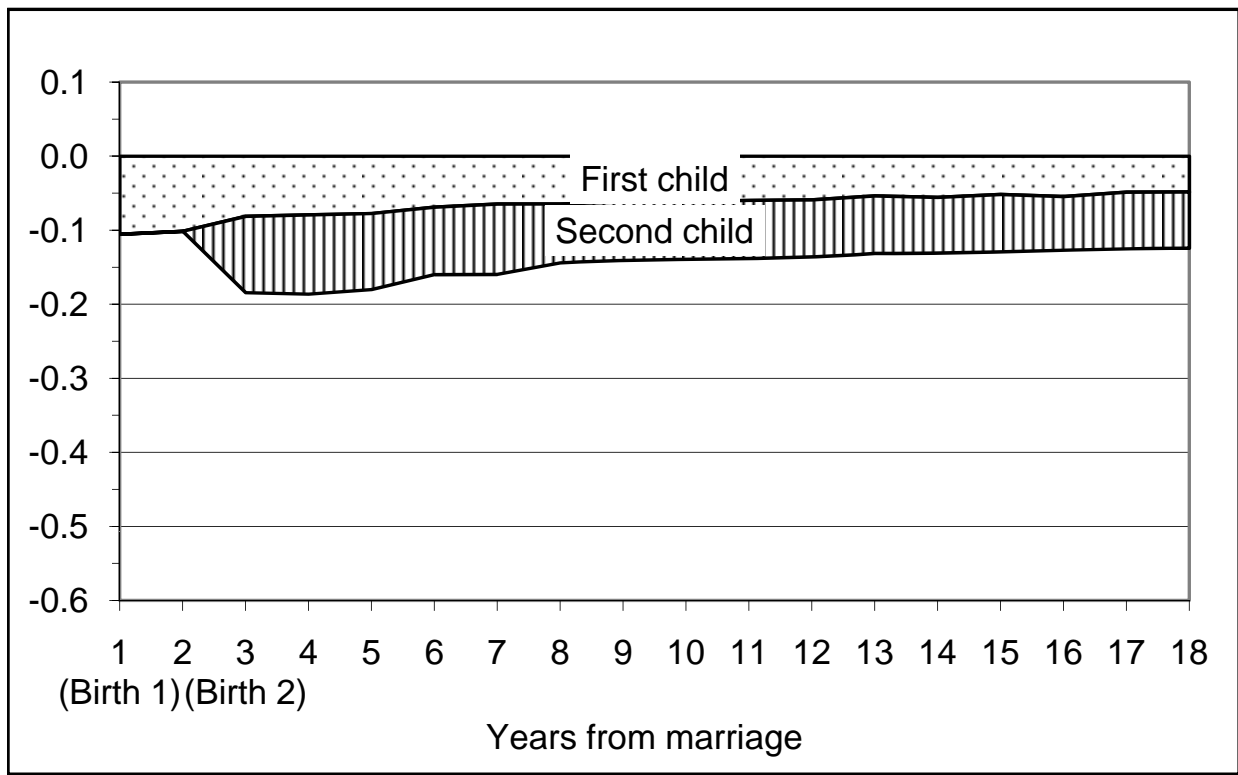

Full Time Part Year

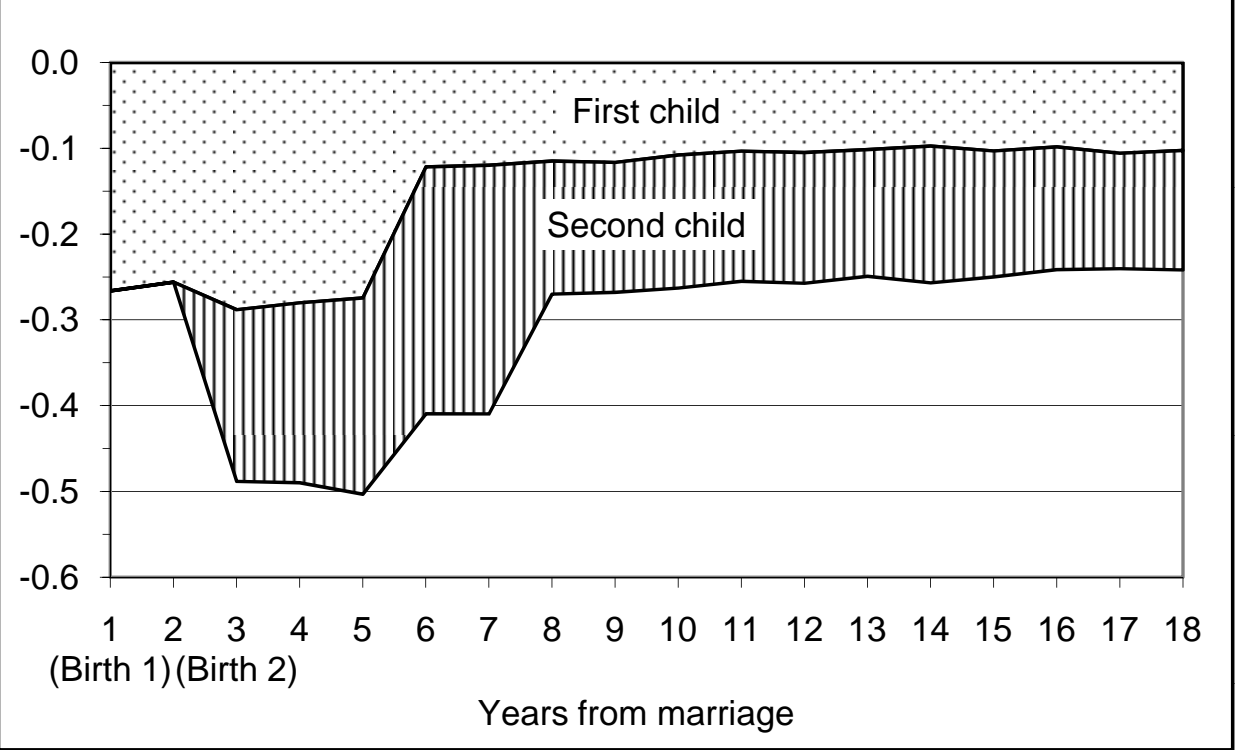

Part Time

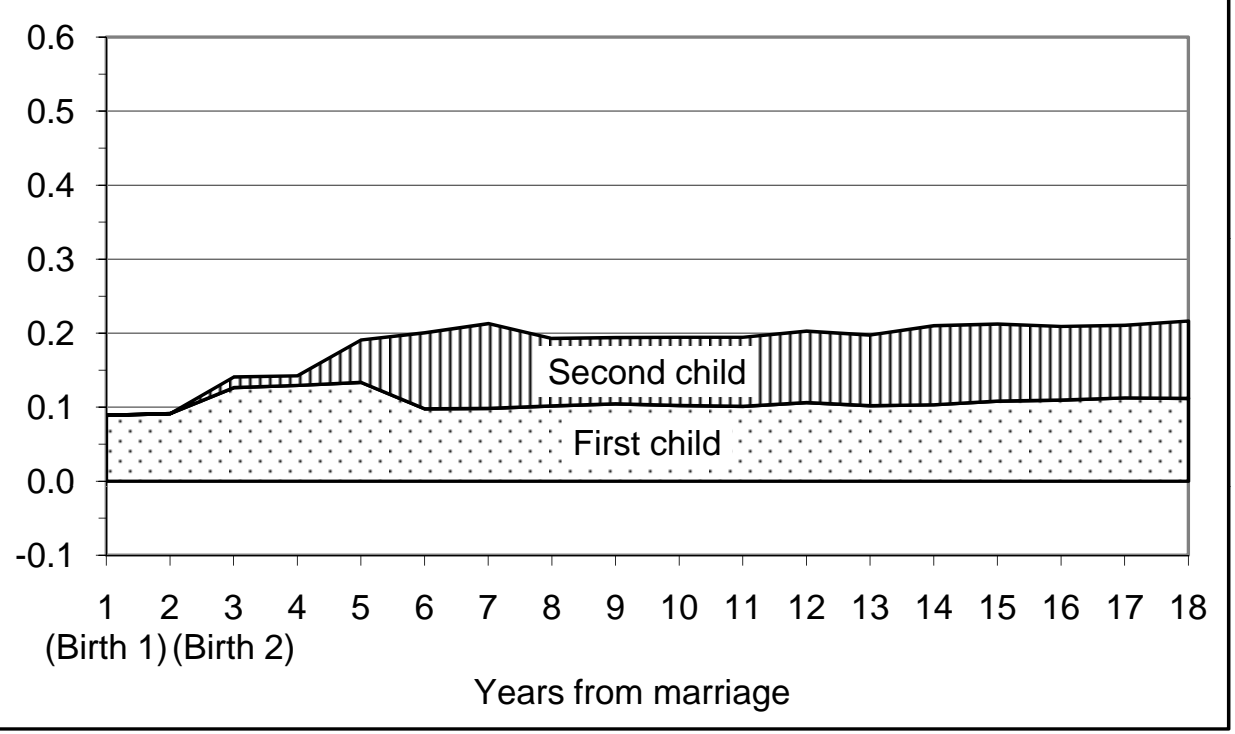


Figure 8. The effect of the second child in the year of birth, by the spacing of the two births

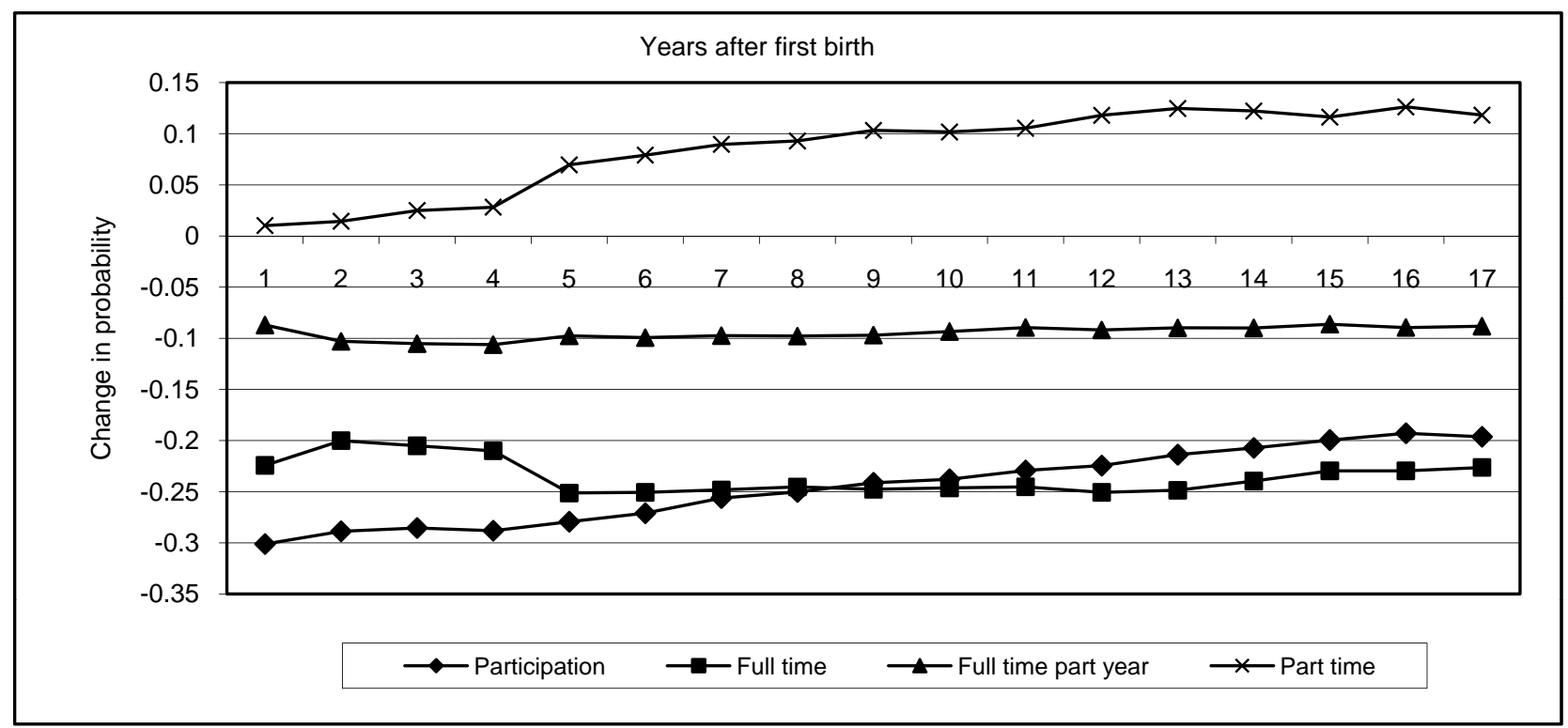


Figure 9. The Effect of the Second Child on the Level of Labor Market Involvement by the Spacing of the Two Births

Participation

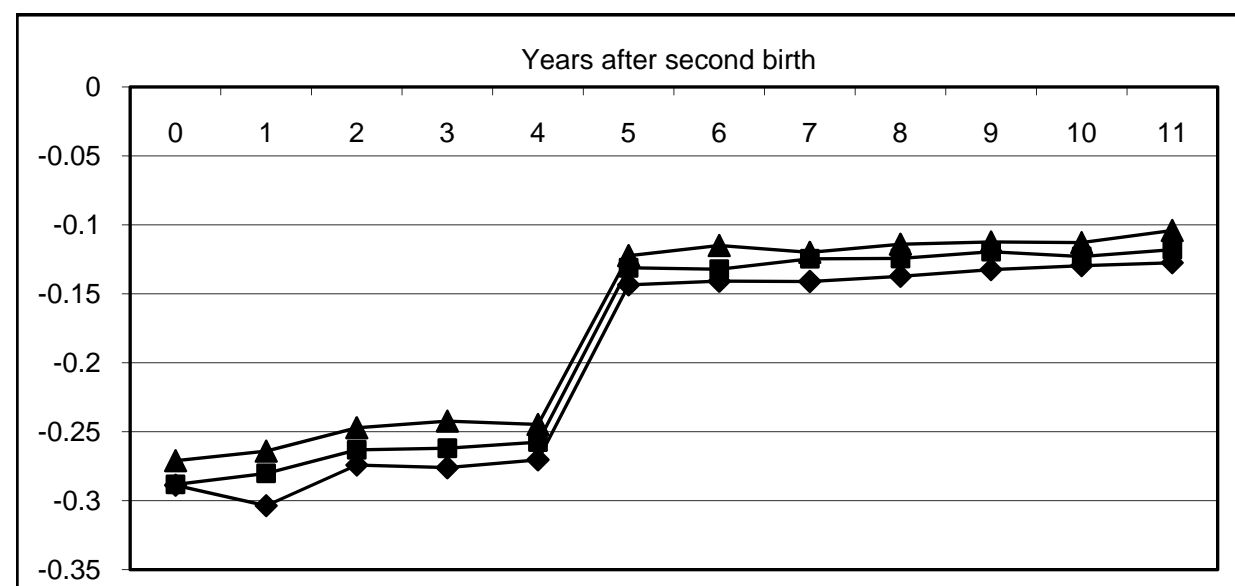

$\multimap$ Brth1 yr. +2

$\rightarrow-B r t h 1 \mathrm{yr} .+$

$\longrightarrow$ Brth1 yr. +

\section{Full Time Part Year}

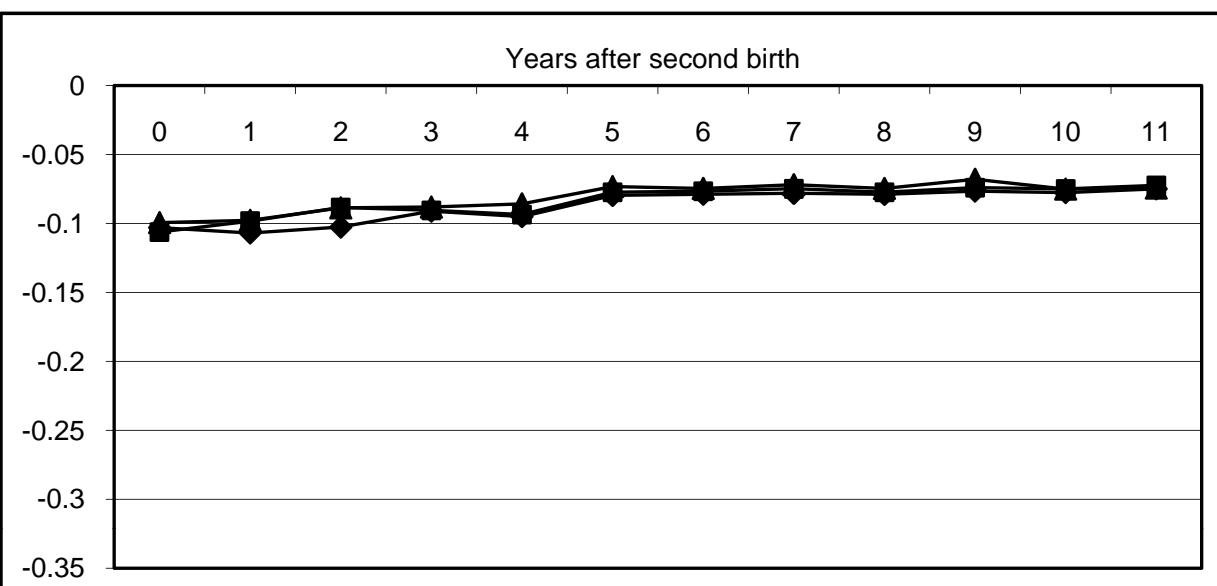

$\multimap B r t h 1$ yr. +2

$\longrightarrow$ Brth1 yr. + 4

$\multimap$ Brth1 yr. +6
Full Time Part Year

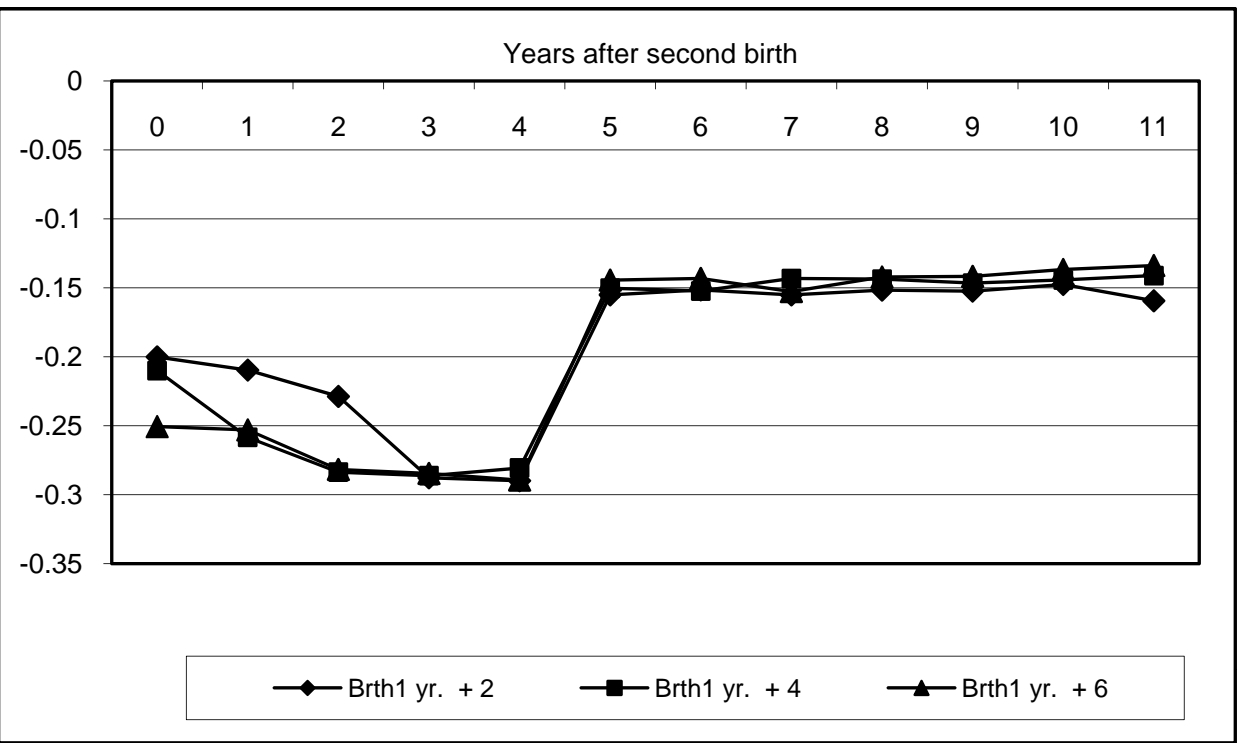

Part Time

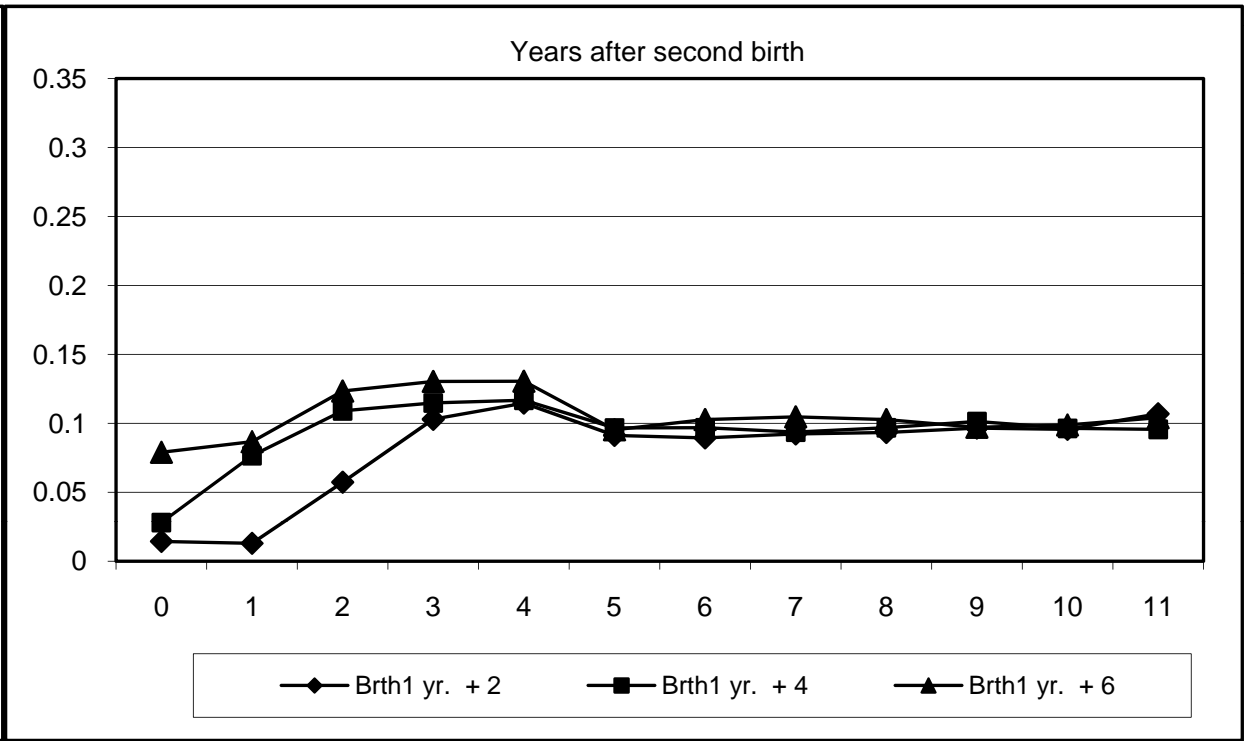


Figure 10. Number of children, timing of the first birth, and spacing of two births. White women, by education

\section{A. Number of children}

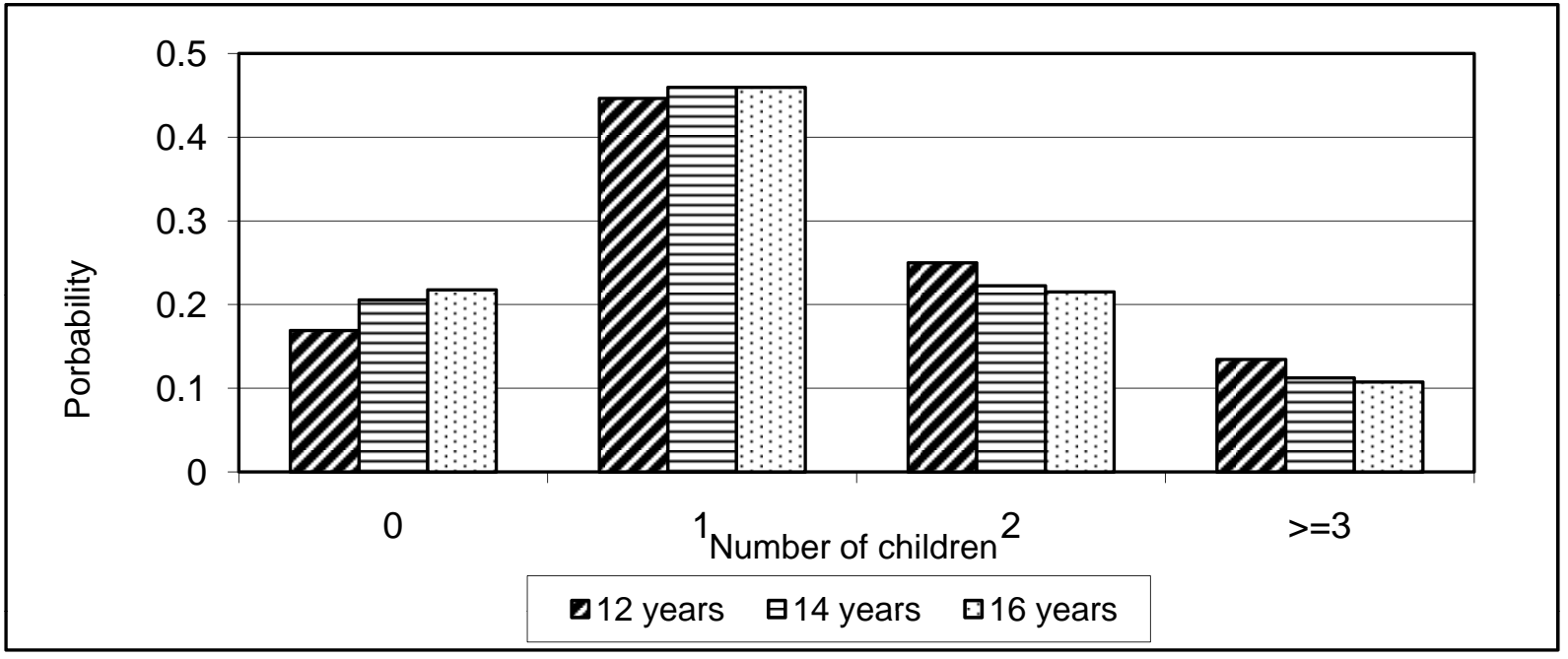

\section{B. Timing of the first birth}

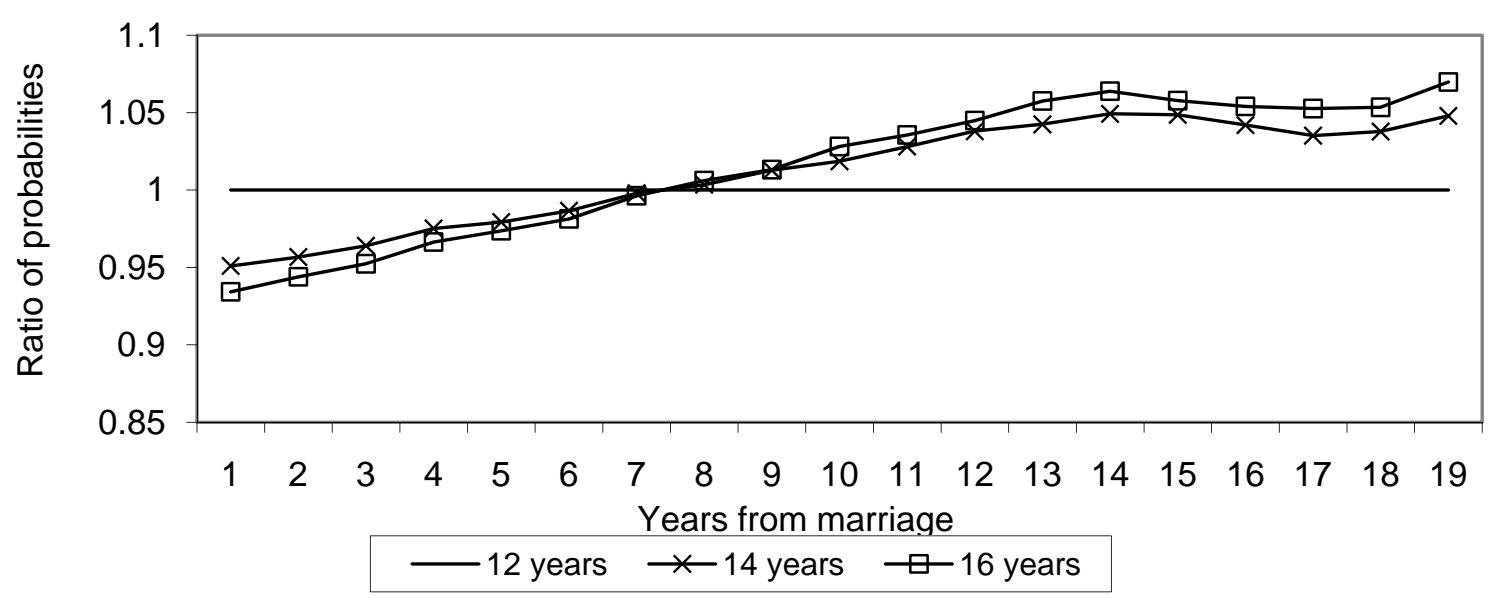

\section{Spacing of two births}

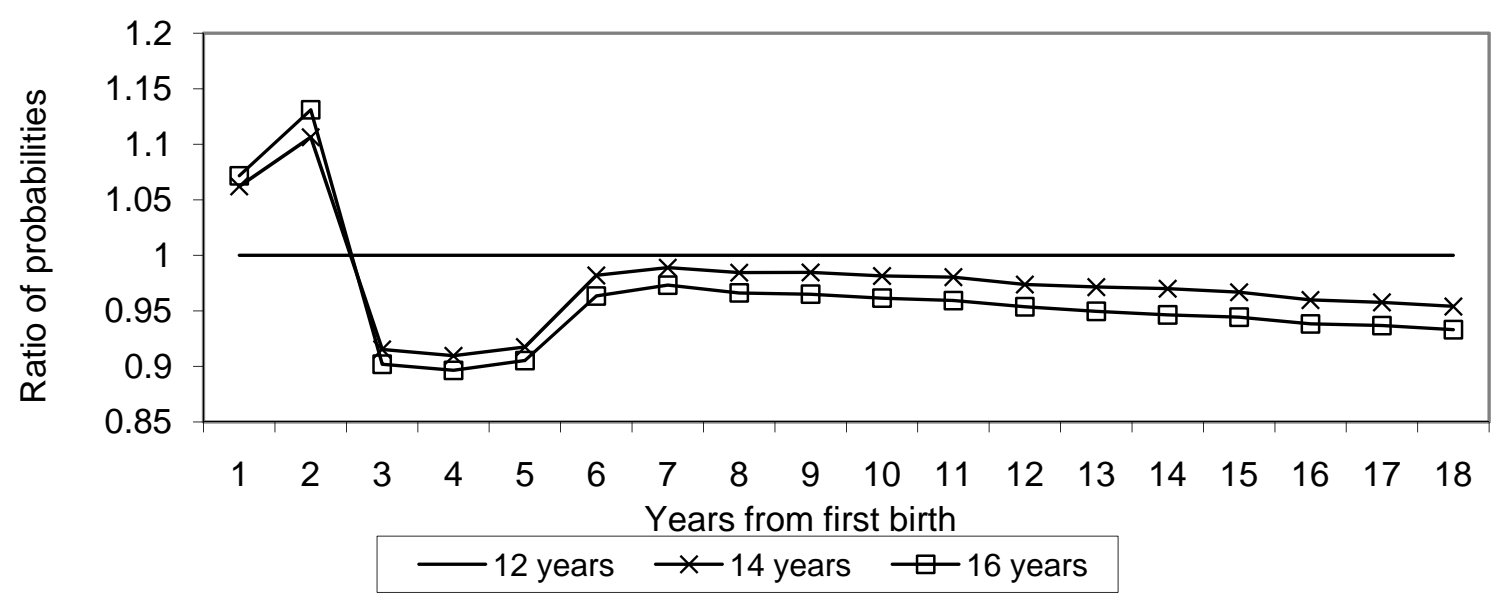


Figure 11. Number of children, timing of the first birth, and spacing of two births. Women with 12 years of education, by race

\section{A. Number of children}

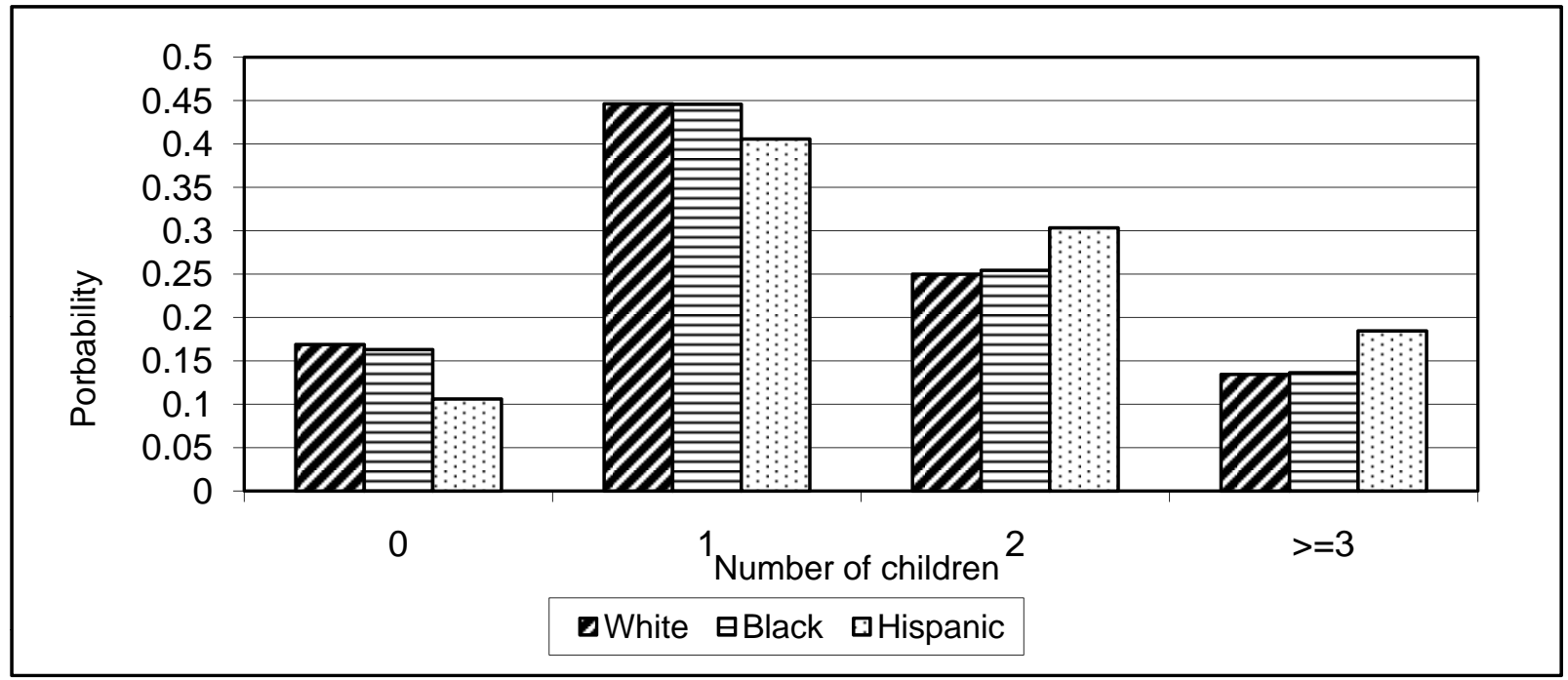

B. Timing of the first birth

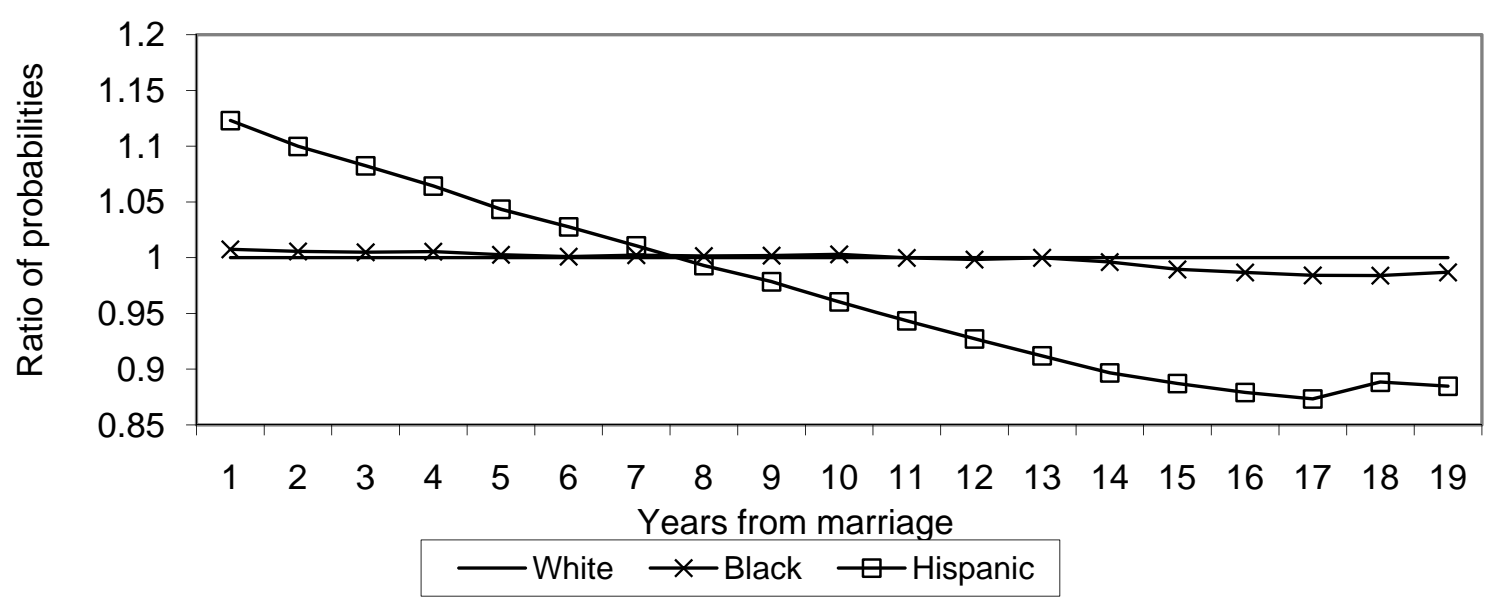

C. Spacing of two births

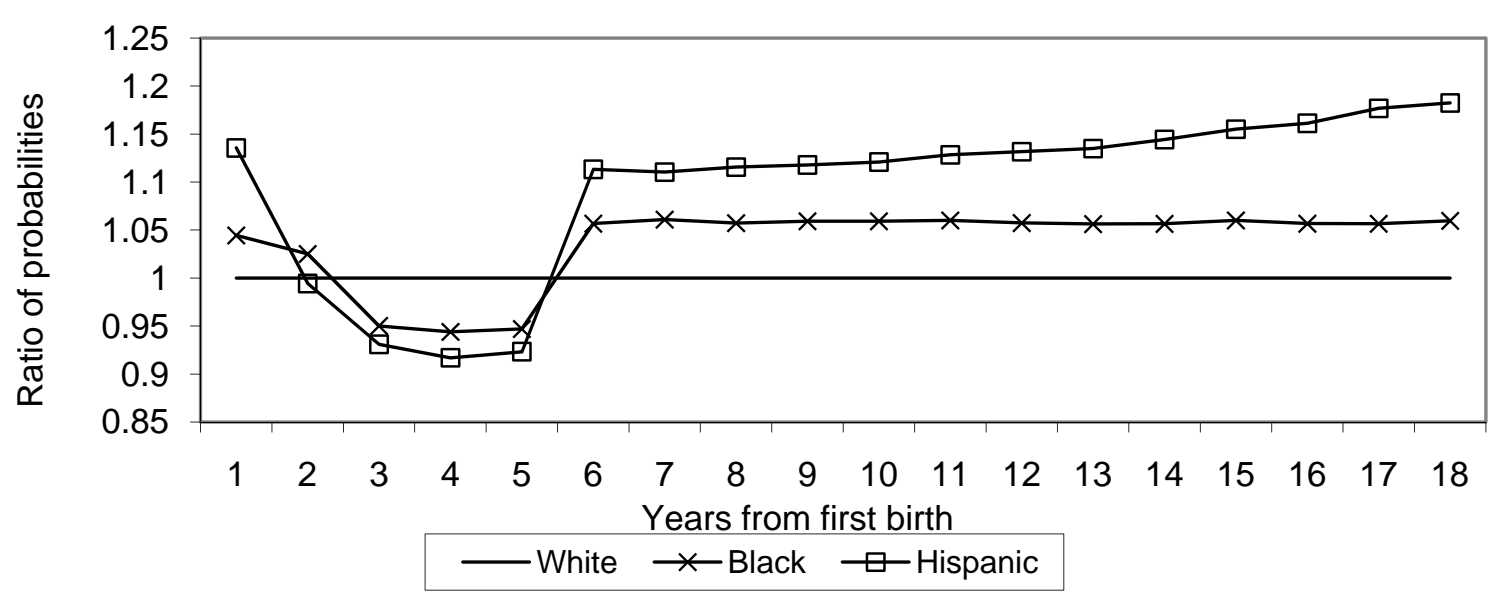


Figure 12. Number of children, timing of the first birth, and spacing of two births. White women with 12 years of education, by individual heterogeneity

A. Number of children

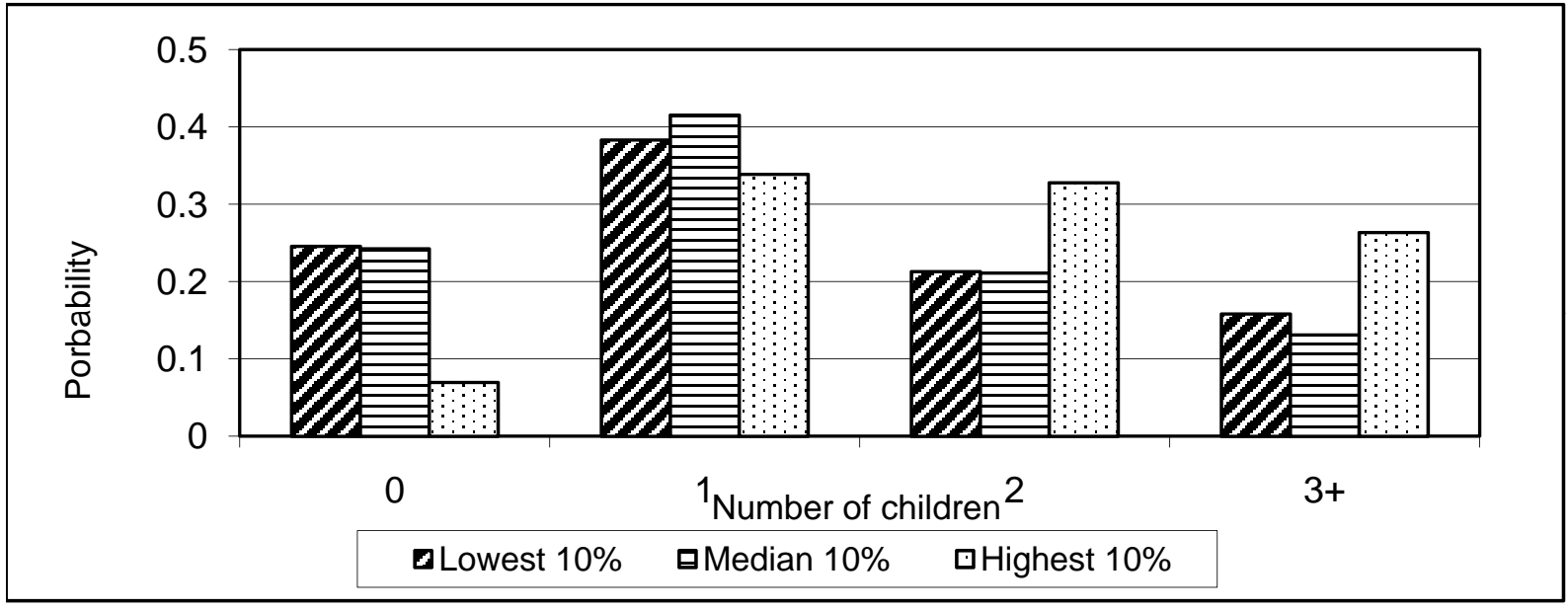

\section{B. Timing of the first birth}

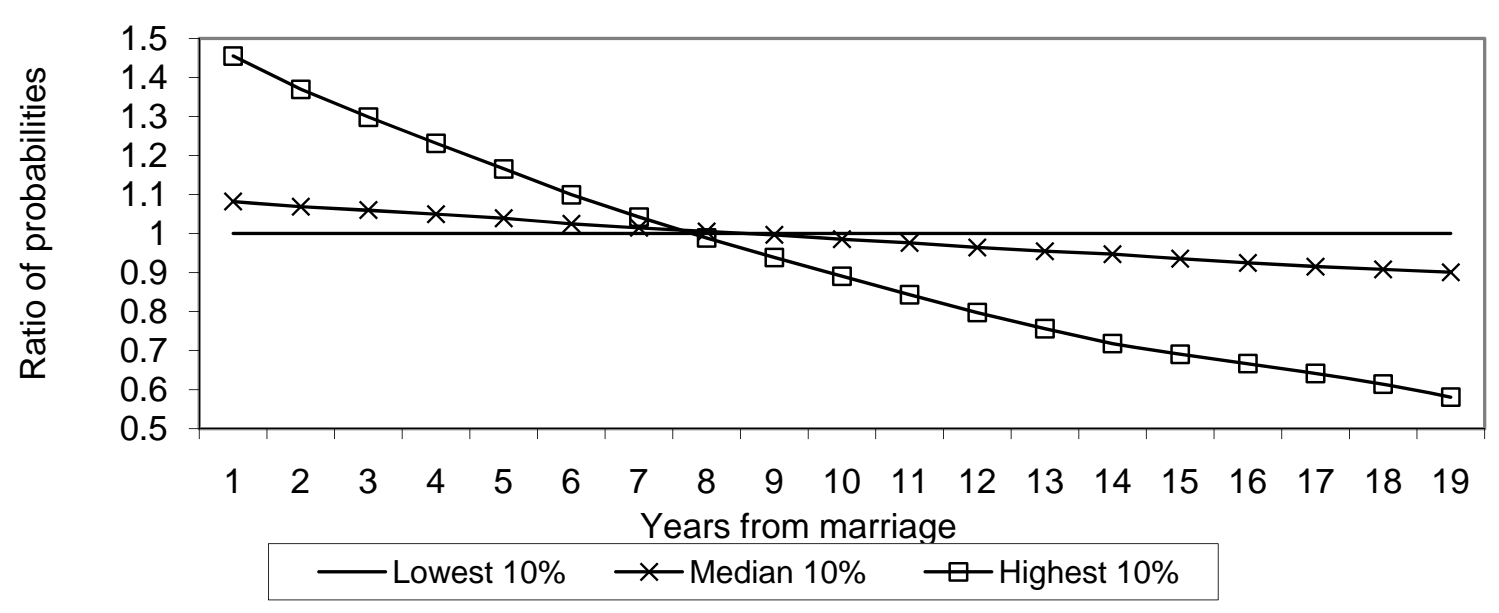

\section{Spacing of two births}

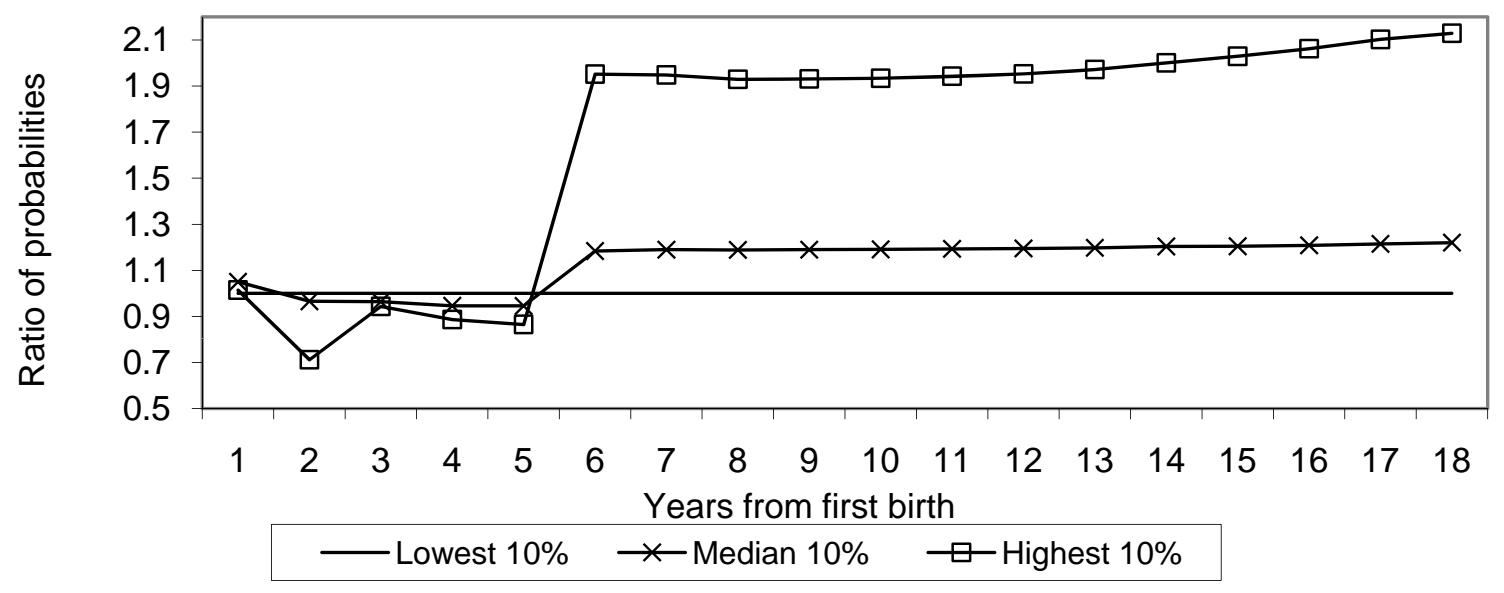


Table 1. Summary Statistics of the Variables in the Data Set

\section{A. Time-Varying Characteristics}

\begin{tabular}{|c|c|c|c|c|c|c|c|c|c|c|c|c|}
\hline \multirow[b]{2}{*}{$\begin{array}{l}\text { Year } \\
(1)\end{array}$} & \multirow[b]{2}{*}{$\begin{array}{c}\text { Number } \\
\text { at Risk } \\
(2)\end{array}$} & \multirow[b]{2}{*}{$\begin{array}{c}\text { Married } \\
\text { (3) } \\
\end{array}$} & \multirow[b]{2}{*}{$\begin{array}{l}\text { Avg. } \\
\text { Husband's } \\
\text { Income } \\
\text { (4) }\end{array}$} & \multirow[b]{2}{*}{$\begin{array}{l}\text { Avg. } \\
\text { Other } \\
\text { Income } \\
\text { (5) }\end{array}$} & \multirow[b]{2}{*}{$\begin{array}{c}\text { Birth } \\
\text { Rate } \\
(6)\end{array}$} & \multicolumn{3}{|c|}{$\begin{array}{c}\text { Number of Children per Woman } \\
\text { at Risk, by Age }\end{array}$} & \multicolumn{4}{|c|}{ Labor Market Status } \\
\hline & & & & & & $\begin{array}{c}\text { Age } \\
0 \text { to } 1 \\
(7) \\
\end{array}$ & $\begin{array}{c}\text { Age } \\
2 \text { to } 4 \\
(8) \\
\end{array}$ & $\begin{array}{l}\text { Age } \\
5+ \\
(9) \\
\end{array}$ & $\begin{array}{l}\text { Full } \\
\text { Time } \\
(10)\end{array}$ & $\begin{array}{c}\text { Full Time } \\
\text { Part Year } \\
(11)\end{array}$ & $\begin{array}{l}\text { Part Time } \\
(12)\end{array}$ & $\begin{array}{c}\text { Not } \\
\text { Working } \\
(13)\end{array}$ \\
\hline 1979 & 116 & 0.00 & 0.0 & 72.4 & 0.00 & 0.00 & 0.00 & 0.00 & 0.67 & 0.18 & 0.11 & 0.03 \\
\hline 1980 & 185 & 0.22 & 1507.9 & 123.7 & 0.00 & 0.00 & 0.00 & 0.00 & 0.62 & 0.18 & 0.14 & 0.06 \\
\hline 1981 & 263 & 0.28 & 2488.6 & 119.8 & 0.02 & 0.02 & 0.00 & 0.00 & 0.57 & 0.15 & 0.19 & 0.08 \\
\hline 1982 & 340 & 0.34 & 2725.6 & 94.5 & 0.04 & 0.06 & 0.00 & 0.00 & 0.58 & 0.15 & 0.18 & 0.09 \\
\hline 1983 & 402 & 0.42 & 3924.8 & 221.7 & 0.05 & 0.08 & 0.01 & 0.00 & 0.58 & 0.16 & 0.15 & 0.10 \\
\hline 1984 & 455 & 0.49 & 5266.3 & 313.1 & 0.07 & 0.11 & 0.05 & 0.00 & 0.58 & 0.18 & 0.15 & 0.09 \\
\hline 1985 & 511 & 0.55 & 6157.3 & 526.6 & 0.09 & 0.15 & 0.08 & 0.00 & 0.59 & 0.15 & 0.18 & 0.08 \\
\hline 1986 & 561 & 0.57 & 8106.4 & 646.7 & 0.09 & 0.17 & 0.12 & 0.01 & 0.62 & 0.12 & 0.17 & 0.10 \\
\hline 1987 & 606 & 0.62 & 8749.0 & 704.5 & 0.09 & 0.17 & 0.16 & 0.03 & 0.61 & 0.14 & 0.17 & 0.08 \\
\hline 1988 & 624 & 0.67 & 10373.9 & 907.7 & 0.11 & 0.20 & 0.21 & 0.06 & 0.60 & 0.11 & 0.19 & 0.09 \\
\hline 1989 & 631 & 0.73 & 11684.7 & 963.5 & 0.12 & 0.23 & 0.24 & 0.12 & 0.59 & 0.12 & 0.17 & 0.12 \\
\hline 1990 & 636 & 0.77 & 13015.5 & 711.6 & 0.13 & 0.25 & 0.27 & 0.19 & 0.59 & 0.10 & 0.18 & 0.12 \\
\hline 1991 & 638 & 0.80 & 14435.0 & 668.0 & 0.13 & 0.26 & 0.32 & 0.26 & 0.55 & 0.11 & 0.20 & 0.14 \\
\hline 1992 & 639 & 0.84 & 15547.3 & 698.6 & 0.13 & 0.27 & 0.35 & 0.35 & 0.55 & 0.09 & 0.23 & 0.14 \\
\hline 1993 & 642 & 0.86 & 15981.3 & 1123.9 & 0.13 & 0.27 & 0.38 & 0.45 & 0.52 & 0.09 & 0.22 & 0.16 \\
\hline 1994 & 643 & 0.89 & 18432.9 & 2213.6 & 0.13 & 0.26 & 0.39 & 0.57 & 0.52 & 0.08 & 0.22 & 0.19 \\
\hline 1995 & 644 & 0.91 & 18083.1 & 2066.9 & 0.12 & 0.25 & 0.40 & 0.70 & 0.53 & 0.07 & 0.21 & 0.19 \\
\hline 1996 & 644 & 0.93 & 20263.3 & 2104.9 & 0.10 & 0.22 & 0.39 & 0.83 & 0.49 & 0.09 & 0.23 & 0.19 \\
\hline 1997 & 645 & 0.94 & 19878.5 & 1481.3 & 0.09 & 0.19 & 0.38 & 0.96 & 0.50 & 0.07 & 0.23 & 0.20 \\
\hline 1998 & 645 & 0.95 & 21807.5 & 2149.2 & 0.09 & 0.18 & 0.34 & 1.09 & 0.52 & 0.05 & 0.23 & 0.20 \\
\hline 1999 & 645 & 0.96 & 19960.9 & 2291.8 & 0.06 & 0.15 & 0.31 & 1.22 & 0.52 & 0.05 & 0.23 & 0.21 \\
\hline 2000 & 645 & 0.97 & 23862.0 & 2768.1 & 0.06 & 0.12 & 0.27 & 1.34 & 0.51 & 0.04 & 0.24 & 0.20 \\
\hline 2001 & 645 & 0.98 & 22397.7 & 1829.4 & 0.03 & 0.08 & 0.24 & 1.44 & 0.53 & 0.04 & 0.24 & 0.19 \\
\hline 2002 & 645 & 0.99 & 24945.3 & 2838.3 & 0.03 & 0.06 & 0.20 & 1.53 & 0.52 & 0.06 & 0.24 & 0.18 \\
\hline 2003 & 645 & 1.00 & 23925.9 & 2315.4 & 0.02 & 0.05 & 0.14 & 1.61 & 0.51 & 0.06 & 0.22 & 0.21 \\
\hline
\end{tabular}

\section{B. Time-Invariant Personal Characteristics and Family Backgound Variables}

\begin{tabular}{|c|c|c|c|c|c|c|c|}
\hline Education & $\%$ & Race & $\%$ & Mother's LM status & $\%$ & Parents' education & $\%$ \\
\hline$<=12$ yrs & 36.4 & White & 69.9 & Full-time & 31.2 & None college & 74.6 \\
\hline 13-15yrs & 26.7 & Black & 13.8 & Other & 68.8 & One college & 16.0 \\
\hline$>=16 \mathrm{yrs}$ & 36.9 & Hispanic & 16.3 & & & Both college & 9.5 \\
\hline
\end{tabular}


Table 2. The dynamics of the level of labor market involvement in the period surrounding the first birth, by the number of children

\begin{tabular}{cccc}
\hline \hline & \multicolumn{2}{l}{ Level of labor market involvement } \\
\cline { 2 - 4 } Timing of first birth & Before first & After first birth \\
& birth & First child 0-1 years old \\
& Prob. & Prob. & Change \\
$(1)$ & $(2)$ & $(3)$ \\
\hline
\end{tabular}

\section{One child}

Participation

Full time

0.963

0.845

$-0.118$

Full time part year

0.781

0.505

$-0.276$

Part time

0.097

0.195

0.098

0.085

0.145

0.060

Two children

Participation

0.964

0.849

$-0.115$

Full time

0.732

0.387

$-0.345$

Full time part year

0.095

0.205

0.110

Part time

0.137

0.256

0.120

Three or more children

Participation

0.963

0.786

$-0.177$

Full time

0.691

0.250

$-0.441$

Full time part year

0.131

0.262

0.130

Part time

0.140

0.274

0.134 
Table 3. The timing and spacing of births and the dynamics of the level of labor market involvement in the period surrounding the births

A. The dynamics of the level of labor market involvement in the period surrounding first birth, women with two children, by the timing of the first birth

\begin{tabular}{lccc}
\hline \hline & \multicolumn{3}{c}{ Level of labor market involvement } \\
\cline { 2 - 4 } & Before first & \multicolumn{2}{c}{ After first birth } \\
Tirth & First child 0-1 years old & Change \\
& Prob. & Prob. & $(3)$ \\
& $(1)$ & $(2)$ & \\
& & & -0.142 \\
0-2 years from marriage & & 0.807 & -0.314 \\
Participation & 0.949 & 0.332 & 0.106 \\
Full time & 0.646 & 0.239 & 0.066 \\
Full time part year & 0.133 & 0.236 &
\end{tabular}

3-7 years from marriage

$\begin{array}{llll}\text { Participation } & 0.976 & 0.892 & -0.084 \\ \text { Full time } & 0.774 & 0.416 & -0.358 \\ \text { Full time part year } & 0.093 & 0.177 & 0.084 \\ \text { Part time } & 0.108 & 0.299 & 0.190\end{array}$

B. The dynamics of the level of labor market involvement in the period surrounding second birth, women with two children, by the spacing of the second birth

\begin{tabular}{cccc}
\hline \hline & \multicolumn{2}{c}{ Level of labor market involvement } \\
\cline { 2 - 4 } Spacing of second birth & Before first & After first birth \\
& birth & First child 0-1 years old \\
& Prob. & Prob. & Change \\
& $(1)$ & $(2)$ & $(3)$ \\
\hline
\end{tabular}

\section{1-3 years from first birth}

Participation

$\begin{array}{lll}0.833 & 0.745 & -0.088 \\ 0.363 & 0.282 & -0.081 \\ 0.157 & 0.117 & -0.040 \\ 0.313 & 0.347 & 0.033\end{array}$

4-6 years from first birth

$\begin{array}{lccc}\text { Participation } & 0.880 & 0.797 & -0.083 \\ \text { Full time } & 0.505 & 0.427 & -0.078 \\ \text { Full time part year } & 0.109 & 0.104 & -0.005 \\ \text { Part time } & 0.266 & 0.266 & 0.000\end{array}$


Table 4. The effect of timing and spacing of births on the dynamics of the level of labor market involvement white women, by education

\begin{tabular}{|c|c|c|c|c|c|c|c|c|c|}
\hline \multicolumn{10}{|c|}{ A. The level of labor market involvement before the first birth } \\
\hline & \multicolumn{3}{|c|}{$\begin{array}{l}\text { First birth in year } 3 \\
(\text { marriage year }+1)\end{array}$} & \multicolumn{3}{|c|}{$\begin{array}{l}\text { First birth in year } 9 \\
(\text { marriage year }+7)\end{array}$} & \multicolumn{3}{|c|}{$\begin{array}{c}\text { Change } \\
\text { from year } 3 \text { to year } 9\end{array}$} \\
\hline & $\begin{array}{l}12 \\
(1)\end{array}$ & $\begin{array}{l}14 \\
(2)\end{array}$ & $\begin{array}{l}16 \\
(3)\end{array}$ & $\begin{array}{l}12 \\
(4)\end{array}$ & $\begin{array}{l}14 \\
(5)\end{array}$ & $\begin{array}{l}16 \\
(6)\end{array}$ & $\begin{array}{l}12 \\
(7)\end{array}$ & $\begin{array}{l}14 \\
(8)\end{array}$ & $\begin{array}{l}16 \\
(9)\end{array}$ \\
\hline Participation & 0.913 & 0.966 & 0.977 & 0.970 & 0.990 & 0.994 & 0.057 & 0.025 & 0.017 \\
\hline Full time & 0.568 & 0.715 & 0.744 & 0.585 & 0.703 & 0.736 & 0.017 & -0.012 & -0.009 \\
\hline Full time part year & 0.205 & 0.163 & 0.158 & 0.216 & 0.173 & 0.161 & 0.011 & 0.010 & 0.003 \\
\hline Part time & 0.140 & 0.088 & 0.074 & 0.169 & 0.115 & 0.097 & 0.029 & 0.027 & 0.023 \\
\hline
\end{tabular}

\section{B. The change in the level of labor market involvement in the year of the first birth}

\begin{tabular}{|c|c|c|c|c|c|c|c|c|c|}
\hline & \multicolumn{3}{|c|}{$\begin{array}{l}\text { First birth in year } 3 \\
(\text { marriage year }+1)\end{array}$} & \multicolumn{3}{|c|}{$\begin{array}{l}\text { First birth in year } 9 \\
(\text { marriage year }+7)\end{array}$} & \multicolumn{3}{|c|}{$\begin{array}{c}\text { Change } \\
\text { from year } 3 \text { to year } 9\end{array}$} \\
\hline & $\begin{array}{l}12 \\
(1)\end{array}$ & $\begin{array}{l}14 \\
(2)\end{array}$ & $\begin{array}{l}16 \\
(3)\end{array}$ & $\begin{array}{l}12 \\
(4)\end{array}$ & $\begin{array}{l}14 \\
(5)\end{array}$ & $\begin{array}{l}16 \\
(6)\end{array}$ & $\begin{array}{l}12 \\
(7)\end{array}$ & $\begin{array}{l}14 \\
(8)\end{array}$ & $\begin{array}{l}16 \\
(9)\end{array}$ \\
\hline Participation & -0.283 & -0.255 & -0.247 & -0.177 & -0.133 & -0.120 & 0.106 & 0.122 & 0.128 \\
\hline Full time & -0.266 & -0.305 & -0.328 & -0.207 & -0.226 & -0.247 & 0.059 & 0.080 & 0.081 \\
\hline Full time part year & -0.105 & -0.075 & -0.066 & -0.077 & -0.052 & -0.036 & 0.029 & 0.023 & 0.030 \\
\hline Part time & 0.089 & 0.125 & 0.147 & 0.107 & 0.145 & 0.164 & 0.018 & 0.020 & 0.017 \\
\hline
\end{tabular}

\begin{tabular}{|c|c|c|c|c|c|c|c|c|c|}
\hline \multicolumn{10}{|c|}{ C. The change in the level of labor market involvement in the year of the second birth } \\
\hline & \multicolumn{3}{|c|}{$\begin{array}{l}\text { Second birth in year } 5 \\
\text { (first birth }+2 \text { ) }\end{array}$} & \multicolumn{3}{|c|}{$\begin{array}{c}\text { Second birth in year } 9 \\
(\text { first birth }+6)\end{array}$} & \multicolumn{3}{|c|}{$\begin{array}{c}\text { Change } \\
\text { from year } 5 \text { to year } 9\end{array}$} \\
\hline & $\begin{array}{l}12 \\
(1)\end{array}$ & $\begin{array}{l}14 \\
(2)\end{array}$ & $\begin{array}{l}16 \\
(3) \\
\end{array}$ & $\begin{array}{l}12 \\
(4)\end{array}$ & $\begin{array}{l}14 \\
(5)\end{array}$ & $\begin{array}{l}16 \\
(6)\end{array}$ & $\begin{array}{l}12 \\
(7)\end{array}$ & $\begin{array}{l}14 \\
(8)\end{array}$ & $\begin{array}{l}16 \\
(9)\end{array}$ \\
\hline Participation & -0.289 & -0.324 & -0.343 & -0.271 & -0.283 & -0.289 & 0.018 & 0.041 & 0.054 \\
\hline Full time & -0.200 & -0.278 & -0.316 & -0.251 & -0.328 & -0.354 & -0.051 & -0.049 & -0.038 \\
\hline Full time part year & -0.103 & -0.097 & -0.099 & -0.099 & -0.089 & -0.095 & 0.004 & 0.008 & 0.004 \\
\hline Part time & 0.014 & 0.052 & 0.072 & 0.079 & 0.134 & 0.160 & 0.065 & 0.082 & 0.088 \\
\hline
\end{tabular}


Table 5. The effect of timing and spacing of births on the dynamics of the level of labor market involvement women with 12 years of education, by race

\begin{tabular}{|c|c|c|c|c|c|c|c|c|c|}
\hline \multicolumn{10}{|c|}{ A. The level of labor market involvement before the first birth } \\
\hline & \multicolumn{3}{|c|}{$\begin{array}{l}\text { First birth in year } 3 \\
\text { (marriage year }+1)\end{array}$} & \multicolumn{3}{|c|}{$\begin{array}{l}\text { First birth in year } 9 \\
(\text { marriage year }+7)\end{array}$} & \multicolumn{3}{|c|}{$\begin{array}{c}\text { Change } \\
\text { from year } 3 \text { to year } 9\end{array}$} \\
\hline & $\begin{array}{l}\text { White } \\
\text { (1) }\end{array}$ & $\begin{array}{c}\text { Black } \\
(2)\end{array}$ & $\begin{array}{l}\text { Hispanic } \\
\text { (3) }\end{array}$ & $\begin{array}{l}\text { White } \\
(4)\end{array}$ & $\begin{array}{c}\text { Black } \\
(5)\end{array}$ & $\begin{array}{l}\text { Hispanic } \\
\text { (6) }\end{array}$ & $\begin{array}{l}\text { White } \\
(7)\end{array}$ & $\begin{array}{c}\text { Black } \\
\text { (8) }\end{array}$ & $\begin{array}{l}\text { Hispanic } \\
\text { (9) }\end{array}$ \\
\hline Participation & 0.913 & 0.914 & 0.905 & 0.970 & 0.971 & 0.968 & 0.057 & 0.056 & 0.063 \\
\hline Full time & 0.568 & 0.506 & 0.473 & 0.585 & 0.531 & 0.497 & 0.017 & 0.025 & 0.024 \\
\hline Full time part year & 0.205 & 0.266 & 0.283 & 0.216 & 0.270 & 0.293 & 0.011 & 0.004 & 0.010 \\
\hline Part time & 0.140 & 0.142 & 0.150 & 0.169 & 0.170 & 0.178 & 0.029 & 0.028 & 0.028 \\
\hline
\end{tabular}

\section{B. The change in the level of labor market involvement in the year of the first birth}

\begin{tabular}{|c|c|c|c|c|c|c|c|c|c|}
\hline & \multicolumn{3}{|c|}{$\begin{array}{l}\text { First birth in year } 3 \\
(\text { marriage year }+1)\end{array}$} & \multicolumn{3}{|c|}{$\begin{array}{l}\text { First birth in year } 9 \\
(\text { marriage year }+7)\end{array}$} & \multicolumn{3}{|c|}{$\begin{array}{c}\text { Change } \\
\text { from year } 3 \text { to year } 9\end{array}$} \\
\hline & $\begin{array}{l}\text { White } \\
(1)\end{array}$ & $\begin{array}{c}\text { Black } \\
(2)\end{array}$ & $\begin{array}{c}\text { Hispanic } \\
\text { (3) }\end{array}$ & $\begin{array}{c}\text { White } \\
(4)\end{array}$ & $\begin{array}{c}\text { Black } \\
(5)\end{array}$ & $\begin{array}{c}\text { Hispanic } \\
(6)\end{array}$ & $\begin{array}{l}\text { White } \\
(7)\end{array}$ & $\begin{array}{c}\text { Black } \\
(8)\end{array}$ & $\begin{array}{c}\text { Hispanic } \\
(9)\end{array}$ \\
\hline Participation & -0.283 & -0.201 & -0.192 & -0.177 & -0.116 & -0.119 & 0.106 & 0.085 & 0.072 \\
\hline Full time & -0.266 & -0.168 & -0.156 & -0.207 & -0.127 & -0.125 & 0.059 & 0.041 & 0.031 \\
\hline Full time part year & -0.105 & -0.088 & -0.077 & -0.077 & -0.053 & -0.049 & 0.029 & 0.034 & 0.028 \\
\hline Part time & 0.089 & 0.055 & 0.042 & 0.107 & 0.065 & 0.056 & 0.018 & 0.010 & 0.013 \\
\hline
\end{tabular}

\begin{tabular}{|c|c|c|c|c|c|c|c|c|c|}
\hline \multicolumn{10}{|c|}{ C. The change in the level of labor market involvement in the year of the second birth } \\
\hline & \multicolumn{3}{|c|}{$\begin{array}{c}\text { Second birth in year } 5 \\
\text { (first birth }+2)\end{array}$} & \multicolumn{3}{|c|}{$\begin{array}{c}\text { Second birth in year } 9 \\
(\text { first birth }+6)\end{array}$} & \multicolumn{3}{|c|}{$\begin{array}{c}\text { Change } \\
\text { from year } 5 \text { to year } 9\end{array}$} \\
\hline & $\begin{array}{l}\text { White } \\
(1)\end{array}$ & $\begin{array}{c}\text { Black } \\
(2)\end{array}$ & $\begin{array}{l}\text { Hispanic } \\
(3)\end{array}$ & $\begin{array}{c}\text { White } \\
(4)\end{array}$ & $\begin{array}{c}\text { Black } \\
(5)\end{array}$ & $\begin{array}{l}\text { Hispanic } \\
(6)\end{array}$ & $\begin{array}{l}\text { White } \\
(7)\end{array}$ & $\begin{array}{c}\text { Black } \\
(8)\end{array}$ & $\begin{array}{c}\text { Hispanic } \\
(9)\end{array}$ \\
\hline Participation & -0.289 & -0.248 & -0.241 & -0.271 & -0.163 & -0.177 & 0.018 & 0.084 & 0.064 \\
\hline Full time & -0.200 & -0.183 & -0.167 & -0.251 & -0.168 & -0.155 & -0.051 & 0.014 & 0.012 \\
\hline Full time part year & -0.103 & -0.093 & -0.092 & -0.099 & -0.064 & -0.066 & 0.004 & 0.028 & 0.026 \\
\hline Part time & 0.014 & 0.028 & 0.018 & 0.079 & 0.069 & 0.044 & 0.065 & 0.041 & 0.026 \\
\hline
\end{tabular}


Table 6. The effect of timing and spacing of births on the dynamics of the level of labor market involvement white women with 12 years of education, by individual heterogeneity

\begin{tabular}{|c|c|c|c|c|c|c|c|c|c|}
\hline \multicolumn{10}{|c|}{ A. The level of labor market involvement before the first birth } \\
\hline & \multicolumn{3}{|c|}{$\begin{array}{r}\text { First birth in year } 3 \\
(\text { marriage year }+1) \\
\end{array}$} & \multicolumn{3}{|c|}{$\begin{array}{c}\text { First birth in year } 9 \\
(\text { marriage year }+7) \\
\end{array}$} & \multicolumn{3}{|c|}{$\begin{array}{c}\text { Change } \\
\text { from year } 3 \text { to year } 9\end{array}$} \\
\hline & $\begin{array}{l}\text { Low } 10 \% \\
(1)\end{array}$ & $\begin{array}{c}\text { Median } 10 \% \\
\text { (2) }\end{array}$ & $\begin{array}{l}\text { High } 10 \% \\
\text { (3) }\end{array}$ & $\begin{array}{l}\text { Low } 10 \% \\
(4)\end{array}$ & Median $10 \%$ & $\begin{array}{l}\text { High } 10 \% \\
(6)\end{array}$ & $\begin{array}{l}\text { Low } 10 \% \\
(7)\end{array}$ & $\begin{array}{l}\text { Median } 10 \% \\
(8)\end{array}$ & $\begin{array}{l}\text { High } 10 \% \\
\text { (9) }\end{array}$ \\
\hline Participation & 0.884 & 0.748 & 0.750 & 0.939 & 0.820 & 0.834 & 0.055 & 0.072 & 0.084 \\
\hline Full time & 0.501 & 0.462 & 0.397 & 0.524 & 0.490 & 0.432 & 0.023 & 0.028 & 0.034 \\
\hline Full time part year & 0.144 & 0.145 & 0.226 & 0.157 & 0.161 & 0.248 & 0.013 & 0.016 & 0.023 \\
\hline Part time & 0.239 & 0.142 & 0.127 & 0.258 & 0.169 & 0.154 & 0.019 & 0.027 & 0.027 \\
\hline
\end{tabular}

\section{B. The change in the level of labor market involvement in the year of the first birth}

\begin{tabular}{|c|c|c|c|c|c|c|c|c|c|}
\hline & \multicolumn{3}{|c|}{$\begin{array}{l}\text { First birth in year } 3 \\
(\text { marriage year }+1)\end{array}$} & \multicolumn{3}{|c|}{$\begin{array}{r}\text { First birth in year } 9 \\
(\text { marriage year }+7) \\
\end{array}$} & \multicolumn{3}{|c|}{$\begin{array}{c}\text { Change } \\
\text { from year } 3 \text { to year } 9 \\
\end{array}$} \\
\hline & $\begin{array}{l}\text { Low } 10 \% \\
(1) \\
\end{array}$ & $\begin{array}{c}\text { Median } 10 \% \\
(2) \\
\end{array}$ & $\begin{array}{l}\text { High } 10 \% \\
(3)\end{array}$ & $\begin{array}{l}\text { Low } 10 \% \\
(4) \\
\end{array}$ & $\begin{array}{c}\text { Median } 10 \% \\
(5) \\
\end{array}$ & $\begin{array}{l}\text { High } 10 \% \\
(6)\end{array}$ & $\begin{array}{l}\text { Low } 10 \% \\
(7) \\
\end{array}$ & $\begin{array}{c}\text { Median } 10 \% \\
(8) \\
\end{array}$ & $\begin{array}{l}\text { High } 10 \% \\
(9)\end{array}$ \\
\hline Participation & -0.519 & -0.240 & 0.063 & -0.438 & -0.199 & 0.048 & 0.080 & 0.041 & -0.016 \\
\hline Full time & -0.393 & -0.207 & 0.049 & -0.374 & -0.193 & 0.042 & 0.018 & 0.014 & -0.007 \\
\hline Full time part year & -0.123 & -0.072 & -0.019 & -0.118 & -0.070 & -0.028 & 0.005 & 0.002 & -0.009 \\
\hline Part time & -0.003 & 0.038 & 0.033 & 0.054 & 0.064 & 0.034 & 0.057 & 0.026 & 0.001 \\
\hline
\end{tabular}

\begin{tabular}{|c|c|c|c|c|c|c|c|c|c|}
\hline \multicolumn{10}{|c|}{ C. The change in the level of labor market involvement in the year of the second birth } \\
\hline & \multicolumn{3}{|c|}{$\begin{array}{c}\text { Second birth in year } 5 \\
\text { (first birth }+2)\end{array}$} & \multicolumn{3}{|c|}{$\begin{array}{c}\text { Second birth in year } 9 \\
(\text { first birth }+6)\end{array}$} & \multicolumn{3}{|c|}{$\begin{array}{c}\text { Change } \\
\text { from year } 5 \text { to year } 9\end{array}$} \\
\hline & $\begin{array}{l}\text { Low } 10 \% \\
(1)\end{array}$ & $\begin{array}{c}\text { Median } 10 \% \\
(2)\end{array}$ & $\begin{array}{l}\text { High } 10 \% \\
\text { (3) }\end{array}$ & $\begin{array}{l}\text { Low } 10 \% \\
(4)\end{array}$ & $\begin{array}{c}\text { Median } 10 \% \\
(5)\end{array}$ & $\begin{array}{l}\text { High } 10 \% \\
(6)\end{array}$ & $\begin{array}{c}\text { Low } 10 \% \\
(7)\end{array}$ & $\begin{array}{c}\text { Median } 10 \% \\
(8)\end{array}$ & $\begin{array}{l}\text { High } 10 \% \\
(9)\end{array}$ \\
\hline Participation & -0.283 & -0.168 & 0.033 & -0.400 & -0.200 & 0.030 & -0.117 & -0.032 & -0.003 \\
\hline Full time & -0.079 & -0.139 & 0.027 & -0.196 & -0.194 & 0.031 & -0.117 & -0.055 & 0.004 \\
\hline Full time part year & -0.036 & -0.051 & -0.039 & -0.070 & -0.063 & -0.039 & -0.033 & -0.012 & 0.000 \\
\hline Part time & -0.167 & 0.022 & 0.045 & -0.134 & 0.057 & 0.038 & 0.033 & 0.035 & -0.008 \\
\hline
\end{tabular}


Appendix Table 1. The relationship between fertility and the number of siblings with children. Estimation results of OLS regression with the number of children born between 1979 and 2003

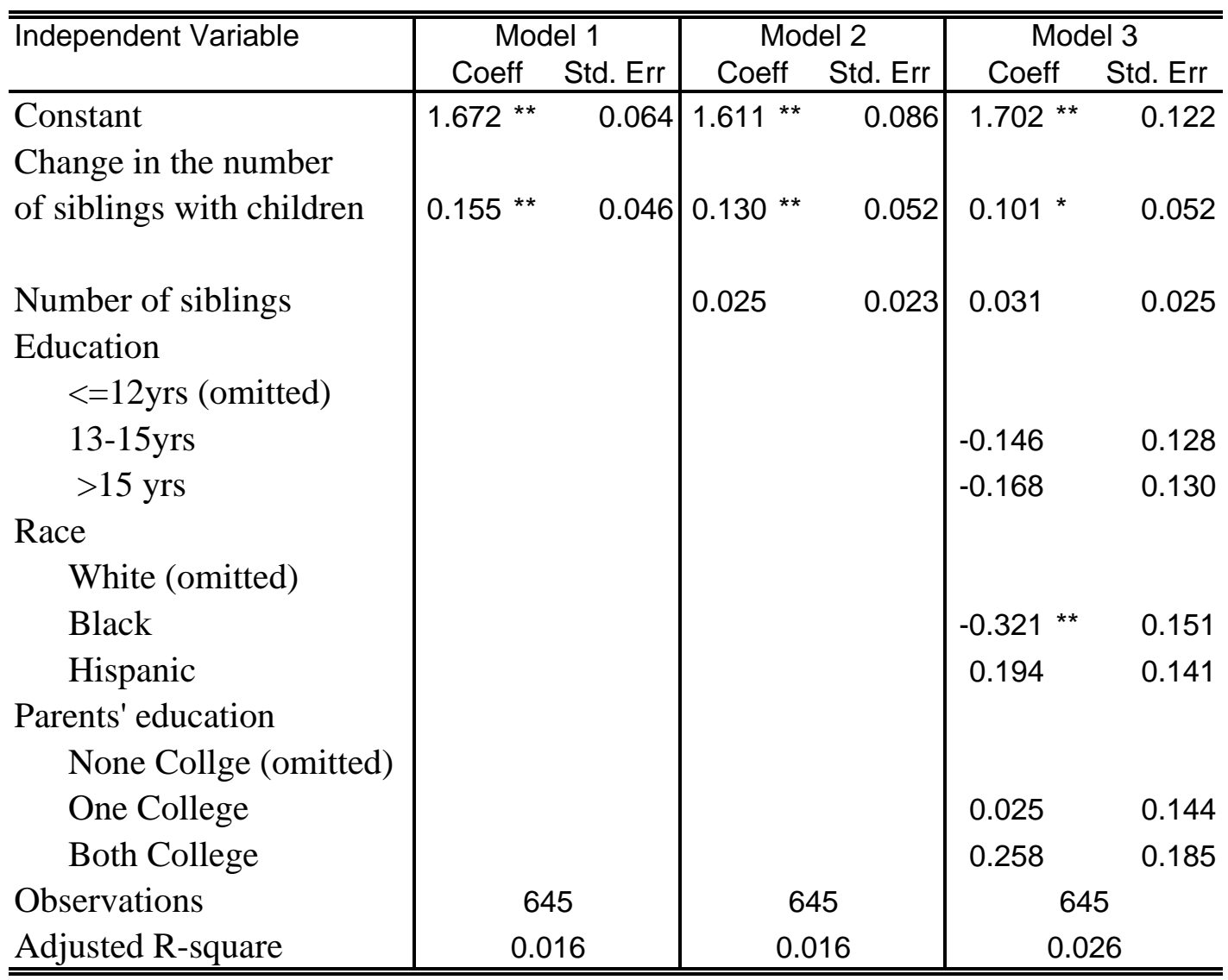

Note: ** significant at $95 \%$ level of confidence; * significant at $90 \%$ level of confidence 
Appendix Table 2. Estimation Results. Posterior Means and Standard Deviations for the Coefficients.

\begin{tabular}{|c|c|c|c|c|c|c|c|c|}
\hline \multirow[t]{2}{*}{ Equation } & \multicolumn{2}{|c|}{ Full Time - Nonwork } & \multicolumn{2}{|c|}{ Full Time Part Year - Nonwork } & \multicolumn{2}{|c|}{ Part Time - Nonwork } & \multicolumn{2}{|c|}{ Fertility } \\
\hline & Mean & PSTD & Mean & PSTD & Mean & PSTD & Mean & PSTD \\
\hline Variable & $(1)$ & $(2)$ & $(3)$ & $(4)$ & $(5)$ & $(6)$ & $(7)$ & $(8)$ \\
\hline Constant & 0.100 & 0.266 & -0.831 & 0.196 & -1.475 & 0.248 & -1.398 & 0.071 \\
\hline Children age $0-1$ & -1.429 & 0.199 & -0.975 & 0.184 & -0.128 & 0.168 & 0.285 & 0.051 \\
\hline Children age $2-4$ & -1.058 & 0.201 & -0.868 & 0.173 & -0.050 & 0.137 & -0.068 & 0.050 \\
\hline Children age $5+$ & -0.530 & 0.155 & -0.429 & 0.101 & 0.218 & 0.093 & -0.781 & 0.069 \\
\hline Married & -1.142 & 0.153 & -0.722 & 0.129 & -0.797 & 0.167 & & \\
\hline Spouse's wage & -0.025 & 0.012 & -0.018 & 0.010 & -0.010 & 0.012 & & \\
\hline Other income & -0.017 & 0.014 & -0.039 & 0.012 & -0.017 & 0.013 & 0.029 & 0.006 \\
\hline Region & & & & & & & & \\
\hline North East & 0.288 & 0.216 & 0.036 & 0.147 & 0.139 & 0.194 & -0.043 & 0.063 \\
\hline North Central & 0.491 & 0.211 & 0.336 & 0.139 & 0.346 & 0.185 & 0.088 & 0.064 \\
\hline South & 0.287 & 0.200 & -0.038 & 0.132 & -0.036 & 0.176 & -0.072 & 0.062 \\
\hline Urban & 0.218 & 0.111 & 0.117 & 0.088 & 0.093 & 0.107 & 0.004 & 0.047 \\
\hline Wage & 0.702 & 0.017 & 0.702 & 0.017 & 0.702 & 0.017 & & \\
\hline Wage*Children age $0-1$ & -0.015 & 0.030 & -0.015 & 0.030 & -0.015 & 0.030 & & \\
\hline Wage*Children age $2-4$ & -0.046 & 0.022 & -0.046 & 0.022 & -0.046 & 0.022 & & \\
\hline Wage*Children age $5+$ & -0.097 & 0.010 & -0.097 & 0.010 & -0.097 & 0.010 & & \\
\hline Sibling with kids & & & & & & & 0.028 & 0.012 \\
\hline$\rho$ & 0.701 & 0.018 & 0.017 & 0.045 & 0.724 & 0.028 & -0.278 & 0.026 \\
\hline
\end{tabular}

